\title{
On configuration and control of the thermal plant for fuel cell micro-cogeneration
}

\author{
by \\ Stephen McMurtry, B.Sc. \\ A thesis submitted to the \\ Faculty of Graduate and Postdoctoral Affairs \\ in partial fulfillment of the requirements for the degree of \\ Master of Applied Science in Sustainable Energy Engineering and Policy \\ Ottawa-Carleton Institute for Mechanical and Aerospace Engineering \\ Department of Mechanical and Aerospace Engineering \\ Carleton University \\ Ottawa, Ontario \\ January, 2013 \\ (C)Copyright \\ Stephen McMurtry, 2013
}


Library and Archives

Canada

Published Heritage

Branch

395 Wellington Street

Ottawa ON K1A ON4

Canada
Bibliothèque et

Archives Canada

Direction du

Patrimoine de l'édition

395 , rue Wellington

Ottawa ON K1A ON4

Canada
Your file Votre référence

ISBN: 978-0-494-94257-4

Our file Notre référence

ISBN: 978-0-494-94257-4
NOTICE:

The author has granted a nonexclusive license allowing Library and Archives Canada to reproduce, publish, archive, preserve, conserve, communicate to the public by telecommunication or on the Internet, loan, distrbute and sell theses worldwide, for commercial or noncommercial purposes, in microform, paper, electronic and/or any other formats.

The author retains copyright ownership and moral rights in this thesis. Neither the thesis nor substantial extracts from it may be printed or otherwise reproduced without the author's permission.
AVIS:

L'auteur a accordé une licence non exclusive permettant à la Bibliothèque et Archives Canada de reproduire, publier, archiver, sauvegarder, conserver, transmettre au public par télécommunication ou par l'Internet, prêter, distribuer et vendre des thèses partout dans le monde, à des fins commerciales ou autres, sur support microforme, papier, électronique et/ou autres formats.

L'auteur conserve la propriété du droit d'auteur et des droits moraux qui protege cette thèse. $\mathrm{Ni}$ la thèse ni des extraits substantiels de celle-ci ne doivent être imprimés ou autrement reproduits sans son autorisation.
In compliance with the Canadian Privacy Act some supporting forms may have been removed from this thesis.

While these forms may be included in the document page count, their removal does not represent any loss of content from the thesis.
Conformément à la loi canadienne sur la protection de la vie privée, quelques formulaires secondaires ont été enlevés de cette thèse.

Bien que ces formulaires aient inclus dans la pagination, il n'y aura aucun contenu manquant. 
The undersigned hereby recommends to the

Faculty of Graduate and Postdoctoral Affairs acceptance of the thesis

\title{
On configuration and control of the thermal plant for fuel cell micro-cogeneration
}

\author{
submitted by Stephen McMurtry, B.Sc. \\ in partial fulfillment of the requirements for the degree of \\ Master of Applied Science in Sustainable Energy Engineering and Policy
}


Professor Ian Beausoleil-Morrison, Thesis Supervisor, Department of Mechanical and Aerospace Engineering

Alex Ferguson, Natural Resources Canada

Professor Edgar Matida,

Department of Mechanical and Aerospace Engineering

Professor Abhijit Sarkar,

Department of Civil and Environmental Engineering

Professor Metin Yaras, Chair,

Department of Mechanical and Aerospace Engineering

Ottawa-Carleton Institute for Mechanical and Aerospace Engineering

Department of Mechanical and Aerospace Engineering

Carleton University

January, 2013 


\section{Abstract}

Space and water heating in the residential sector is responsible for $12 \%$ of all greenhouse gas emissions in Canada. Micro-cogeneration has the potential to reduce these emissions by generating heat and electricity close to the place of consumption. However, high upfront costs and a lack of financial incentives have presented a barrier to the adoption of micro-cogeneration in Canada.

Proton exchange membrane fuel cells (PEMFCs) are a promising candidate for the residential sector due to their high electrical efficiency and ability to modulate electrical and thermal output. In order to meet a household's variable demand for heat, a system of plant components is required to store and deliver the thermal output. Plants using both one and two storage tanks have been examined in the past, however a direct performance comparison has not yet been made.

This thesis examines the performance of a $1.0 \mathrm{~kW}_{A C}$ PEMFC device coupled to both 1 and 2-tank plants. Building simulation software was used to capture interactions between the PEMFC device, thermal plants, and typical single-detached Canadian households. A hybrid controller was designed that determined PEMFC electrical output using a time-varying electricity price and information about the thermal load.

Optimizations were performed to minimize annual operating cost from the perspective of the homeowner. Hybrid control parameters and storage tank volumes were determined through optimization. It was found that the 1-tank plant resulted in lower annual costs relative to the 2 -tank plant. It was also found that the hybrid PEMFC controller outperformed other modes of operation, and should be biased towards tank temperature following. 
To my parents, for all of their love and support. 


\section{Acknowledgments}

I would first like to express my deepest gratitude to my supervisor, Dr. Ian BeausoleilMorrison. His patience and guidance was invaluable over the course of my studies at Carleton. His discipline and his approach to balancing work and life will continue to provide an example for me in the future.

I would also like to express my appreciation for my colleagues in the Sustainable Building Energy Systems Laboratory. Thank you for all of your support and for making my time in Ottawa so enjoyable. In particular, thanks to Sebastian Brideau, Evan Boucher, Courtney Edwards, Geoff Johnson, Briana Paige Kemery, Andrea Pietila, and last but not least, Adam Wills.

Thanks as well to Lukas Swan at Dalhousie University for providing the building models used in this work. Having these allowed me more time to dedicate to the rest of my research. Thanks to Leen Peeters at the University of Leuven for providing the example input files for coupling GenOpt and ESP-r. Thanks also to Alex Ferguson at Natural Resources Canada for his advice regarding cluster computing.

Lastly, to my family: I would not be where I am today without your constant support and encouragement, so thank you. Your cautionary stories about grad students who began employment before finishing their theses also helped. 


\section{Table of Contents}

Abstract $\quad$ iv

Acknowledgments $\quad$ vi

Table of Contents vii

List of Tables $\quad$ x

List of Figures $\quad$ xii

Nomenclature $\quad$ xv

1 Introduction and Literature Review 1

1.1 Introduction . . . . . . . . . . . . . . . . 1

1.2 Literature Review . . . . . . . . . . . . . . . . . . . 3

1.2.1 Micro-cogeneration . . . . . . . . . . . . . . 3

1.2.2 Fuel Cell Micro-cogeneration . . . . . . . . . . . . . . 5

1.2 .3 Modelling .................. 5

1.2.4 The Thermal Plant . . . . . . . . . . . . . . . 7

1.2.5 Control Strategies . . . . . . . . . . . . . . . 8

1.3 Research Objectives . . . . . . . . . . . . . . . . . 9

1.4 Thesis Outline . . . . . . . . . . . . . . . . 9

2 ESP-r Building Performance Simulation 11

2.1 Introduction . . . . . . . . . . . . . . . . 11

2.2 The Plant Domain . . . . . . . . . . . . . . 12

2.2.1 Energy and Mass Balance Approach . . . . . . . . . . . . 12

2.2.2 Solving the Plant Matrices . . . . . . . . . . . . . 14 
2.3 The Building Domain . . . . . . . . . . . . . . . . . 16

2.4 The Electrical Domain . . . . . . . . . . . . . . . . . . . . 19

3 Model Construction $\quad 21$

3.1 Introduction . . . . . . . . . . . . . . . . . . 21

3.2 Building Model . . . . . . . . . . . . . . . . 21

3.2 .1 Model Details . . . . . . . . . . . . . . . . . 22

3.2.2 Modifications to the building models . . . . . . . . . . 24

3.3 Weather Data . . . . . . . . . . . . . . 25

3.4 Occupant Model . . . . . . . . . . . . . . . 25

3.4 .1 Occupant Heat Gains . . . . . . . . . . . . . . . 26

3.4 .2 Non-HVAC Electrical Load Profile . . . . . . . . . . . 27

3.4.3 Stochastic DHW model . . . . . . . . . . . . . . 28

3.5 Plant Components . . . . . . . . . . . . . . . . 29

3.5.1 Annex 42 Fuel Cell Model and PEMFC Calibration . . . . . 29

3.5.2 Other HVAC Component Models . . . . . . . . . . . . . . . 31

3.5.3 Component Sizing . . . . . . . . . . . . . 33

3.6 Electrical Model . . . . . . . . . . . . . . . . . . . . . . . 34

4 Plant Configuration and Control $\quad 36$

4.1 Plant Configuration . . . . . . . . . . . . . . . 36

4.1.1 1-tank Configuration ............... 37

4.1.2 2-tank Configuration ............... 38

4.2 Control . . . . . . . . . . . . . . . . . . 40

4.2.1 PEMFC Control . . . . . . . . . . . . . . . 40

4.2.2 Control of Supporting Plant Components . . . . . . . . . . . . 43

4.2.3 Aquastatic DHW Control .............. 45

5 Optimization Methodology $\quad 46$

5.1 Introduction . . . . . . . . . . . . . . 46

5.1.1 Optimization Problem ............... 46

5.1 .2 GenOpt ...................... 47

5.2 Setting Up the Optimization . . . . . . . . . . . . . . 47

5.2 .1 Objective Function . . . . . . . . . . . . . 47

5.2.2 Independent Parameters . . . . . . . . . . . . 48 
5.3 Optimization Algorithms . . . . . . . . . . . . . . . . . 49

5.3.1 Particle Swarm Optimization _............ 49

5.3 .2 Generalized Pattern Search _............. 50

5.4 Results Processing . . . . . . . . . . . . . . . . 53

5.4 .1 Mathematical Processing . . . . . . . . . . . . . 53

5.4 .2 Electrical Generation Revenue . . . . . . . . . . . . . 54

5.5 Software Coupling $\ldots \ldots \ldots \ldots \ldots \ldots \ldots \ldots \ldots$

6 Results $\quad 58$

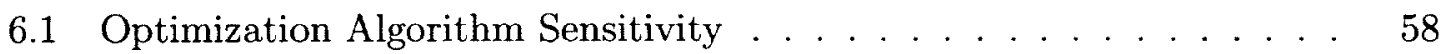

6.2 1-tank Plant Performance $\ldots \ldots \ldots \ldots \ldots$

6.3 2-tank Plant Performance . . . . . . . . . . . . . . 65

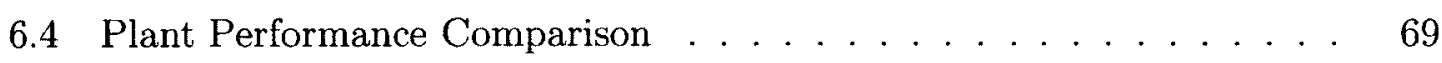

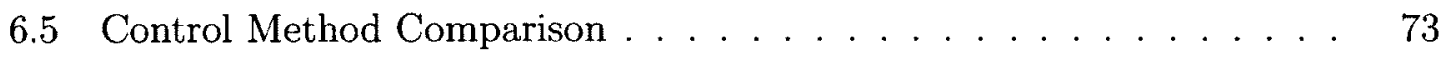

6.6 Concluding Remarks $\ldots \ldots \ldots \ldots \ldots \ldots$

$\begin{array}{lll}7 & \text { Conclusions and Recommendations } & \mathbf{7 8}\end{array}$

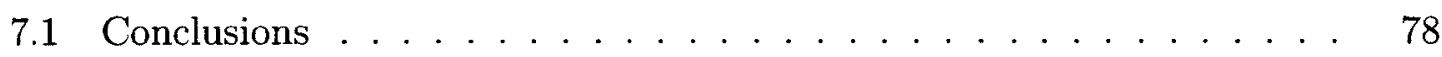

7.2 Recommendations for Future Work . . . . . . . . . . . . 84

$\begin{array}{ll}\text { List of References } & 86\end{array}$

$\begin{array}{ll}\text { Appendix A Plant Behaviour } & 91\end{array}$

Appendix B ESP-r Plant Controller $\quad 96$

Appendix C ESP-r Plant Network Configuration Files 106

C.1 1-tank Plant . . . . . . . . . . . . . . . . . . . . 106

C.2 2-tank Plant . . . . . . . . . . . . . . . . 112

Appendix D GenOpt Algorithm Configuration Files $\quad 119$

D.1 PSO Input File . . . . . . . . . . . . . . . . . . . . . . . 119

D.2 GPS Input File $\ldots \ldots \ldots \ldots \ldots \ldots \ldots \ldots \ldots$

Appendix E Additional Files $\quad \mathbf{1 2 2}$

E.1 GenOpt-ESP-r Coupling . . . . . . . . . . . . . . . . . . 122

E.2 GenOpt/ESP-r Input Files . . . . . . . . . . . . . . . . . 122 


\section{List of Tables}

3.1 Comparison of the three building models selected from Swan's database. 23

3.2 Comparison of occupancy cases. . . . . . . . . . . . . . 26

3.3 Typical metabolic heat generation for adults and children due to different levels of activity [1]. . . . . . . . . . . . . . 27

3.4 Occupancy schedule. Note: heat gain values are combined radiative and sensible amounts. . . . . . . . . . . . . . . . . 29

3.5 Component sizing by building model. Note: * indicates component is only present in the 2-tank plant (described in Chapter 4) . . . . . . . 34

4.1 Modes of control implemented for the PEMFC. . . . . . . . . . . . . 41

4.2 Control parameters for plant components actuated using a deadband control.

5.1 Box-constrained independent parameters varied during optimization (described in Chapter 4) . . . . . . . . . . . . . . . 48

5.2 Molar composition of natural gas in Ontario, for July to December, 2011 [2]. HHVs from Cengel, 2008 [3] . . . . . . . . . . . . .

5.3 Time-of-Use electricity rates for Ontario as of January, 2012. Summer rates apply May through October, winter rates apply November through April [4]. . . . . . . . . . . . . . . . . . . . .

6.1 Independent parameter values and annual operating cost for PSO-GPS optimizations using three different particle numbers. Results for 1-tank plant coupled with B2. . . . . . . . . . . . . . .

6.2 1-tank plant independent parameter values obtained through optimization for B1, B2, and B3. . . . . . . . . . . .

6.3 2-tank plant independent parameter values obtained through optimization for B1, B2, and B3. . . . . . . . . . . . . 66

6.4 Performance metric results of the building/occupant sensitivity study for both plant configurations. . . . . . . . . . . . . . . . 
6.5 Results of the control mode comparison for both plant configurations

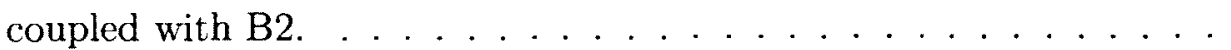




\section{List of Figures}

1.1 Canadain GHG emissions (\% by mass of $\mathrm{CO}_{2}$ equivalent) including electricity-related emissions [5]. . . . . . . . . . . . . 2

1.2 Simulated space and DHW heating loads on a typical spring day, using a 1 -minute time step. . . . . . . . . . . . . . 4

1.3 Proton exchange membrane fuel cell $[6] \ldots \ldots \ldots$

2.1 Mass and energy balance depiction for two plant network nodes, adapted from Hensen, $1991[7] . \ldots \ldots \ldots \ldots$

2.2 Heat transfer paths for internal construction and surface nodes within

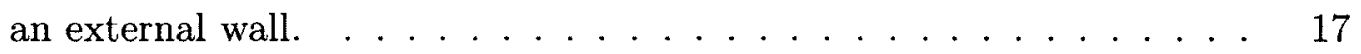

3.1 Wireframe representations of the single-detached building models selected from Swan's database [8]. . . . . . . . . . . . . . . 24

3.2 PEMFC total efficiency (LHV) map calculated using the Annex 42 fuel cell model with calibration data from Johnson et al., $2012[9] . \ldots 31$

4.1 1-tank thermal plant configuration. . . . . . . . . . . 38

4.2 2-tank thermal plant configuration. . . . . . . . . . . . . 39

4.3 Graphical representation of Equation 4.4. . . . . . . . . . . . 42

4.4 Deadband control logic for plant components. . . . . . . . . . 44

5.1 PSO procedure as implemented in GenOpt [10] . . . . . . . . . 51

5.2 GPS procedure as implemented in GenOpt [10] . . . . . . . . . . 52

5.3 GenOpt - ESP-r coupling. This procedure occurs once per optimization iteration. . . . . . . . . . . . . . . 57

6.1 Independent parameter values and annual operating cost plotted for the 8-particle PSO-GPS optimization. Results for 1-tank plant coupled with building/occupancy model B2. . . . . . . . . . .

6.2 Sensitivity of annual operating cost to tank volume. Results for both 1 and 2-tank plants coupled to building/occupancy model B2. . . . . 
6.3 PEMFC AC electrical output and average tank temperature for a weekday in Spring (day \#=150). Results for 1-tank plant coupled with

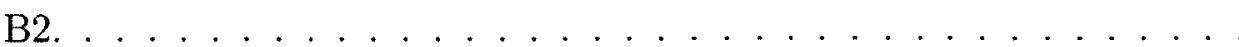

6.4 Daily heat dump and PEMFC AC electrical output (averaged daily) for one year. Results for 1-tank plant coupled with B2. . . . . . . .

6.5 PEMFC AC electrical output and average DHW tank temperature for a weekday in Spring (day \# = 150). Results for 2-tank plant coupled with B2. . . . . . . . . . . . . . . . . .

6.6 Daily heat dump and PEMFC AC electrical output (averaged daily) for one year. Results for 2-tank plant coupled with B2. . . . . . . . . 68

6.7 Annual heat dump for 1 and 2-tank plant configurations, for each of the three building/occupancy models. . . . . . . . . . . 72

6.8 Annual operating cost comparison between 1 and 2 tank configurations, for B1, B2, and B3. . . . . . . . . . . . . . .

6.9 Annual operating cost comparison between 1 and 2-tank plants, for each control mode. . . . . . . . . . . . . . . .

6.10 Annual heat dump comparison between 1 and 2-tank plants, for each control mode. . . . . . . . . . . . . . . . . . . . . .

A.1 Annual indoor zone temperatures for the 1-tank plant coupled with building/occupant model B2. Basement temperature varied sinusoidally throughout the year with changing ground temperature. . . .

A.2 Modelled heating and cooling loads (averaged hourly) for household B2 coupled with the 1-tank plant. Heating loads were met by an explicitly defined plant model (described in Chapters 3 and 4), while cooling loads were met using ideal heat extraction at the main floor air point.

A.3 Heat dump and average tank temperature for the 1-tank plant coupled with household B2 (averaged daily). The heat dump became active when the tank temperature reached $59^{\circ} \mathrm{C}$, as described in Subsection 4.2 .2 , pg. 43. . . . . . . . . . . . . . . .

A.4 Heat dump and average tank temperatures for the 2-tank plant coupled with household B2 (averaged daily). The heat dump became active when the tank temperature reached $51^{\circ} \mathrm{C}$, as described in Subsection 4.2 .2 , pg. 43 . 
A.5 Space heating performance on January 6 (of CWEC weather data), 12am - 6am. Results for the 1-tank plant coupled with household B2. Instances where the in-line heater and space heating pump operation (plots of $q_{s p c}$ and $m_{w}$ ) did not coincided demonstrate how thermal energy stored in the tank was used to meet space heating loads. . . . 


\section{Nomenclature}

$\begin{array}{ll}\text { Abbreviations } \\ \text { AC } & \text { alternating current } \\ \text { AIM-2 } & \text { Alberta air infiltration model } \\ \text { CCGT } & \text { combined-cycle gas turbine } \\ \text { CV } & \text { control volume } \\ \text { CWEC } & \text { Canadian weather for energy calculations } \\ \text { DC } & \text { direct current } \\ \text { DHW } & \text { domestic hot water } \\ \text { ECM } & \text { electronically commutated motor } \\ \text { FC } & \text { fuel cell } \\ \text { FCPM } & \text { fuel cell power module } \\ \text { GHG } & \text { greenhouse gas } \\ \text { GPS } & \text { generalized pattern search } \\ \text { HHV } & \text { higher heating value } \\ \text { HVAC } & \text { heating, ventilating and air-conditioning } \\ \text { ICE } & \text { internal combustion engine } \\ \text { LHV } & \end{array}$




$\begin{array}{ll}\text { PCU } & \text { power conditioning unit } \\ \text { PEMFC } & \text { proton exchange membrane fuel cell } \\ \text { PSO } & \text { particle swarm optimization } \\ \text { SE } & \text { Stirling engine } \\ \text { SOFC } & \text { solid oxide fuel cell } \\ \text { STP } & \text { standard temperature and pressure } \\ \text { TMC } & \text { transparent multi-layered construction } \\ \text { TOU } & \text { time-of-use }\end{array}$

\section{Symbols}

$\begin{array}{lll}\phi & \text { heat generation rate } & \mathrm{W} \\ \alpha & \text { hybrid control ratio } & - \\ \gamma & \text { mass diversion ratio } & - \\ \beta & \text { implicit-explicit weighting factor } & - \\ \eta & \text { electrical/thermal/total efficiency } & - \\ \theta & \text { phase angle } & \mathrm{radians} \\ A & \text { area } & \mathrm{m}{ }^{2} \\ \bar{c} & \text { average heat capacity } & \mathrm{J} / \mathrm{kgK} \\ c_{p} & \text { specific heat capacity } & \mathrm{J} / \mathrm{kgK} \\ \dot{c} & \text { fluid heat capacity rate } & \mathrm{W} / \mathrm{kgK} \\ C & \text { monetary cost } & \$(\mathrm{CAN}) \\ h_{c} & \text { convective heat transfer coefficient } & \mathrm{W} / \mathrm{m}^{2} \mathrm{~K} \\ h_{f} & \text { enthalpy of formation } & \mathrm{kJ} / \mathrm{kg}\end{array}$




\begin{tabular}{|c|c|c|}
\hline$h_{r}$ & radiative heat transfer coefficient & $\mathrm{W} / \mathrm{m}^{2} \mathrm{~K}$ \\
\hline$\widetilde{I}$ & current (complex) & A \\
\hline$k$ & thermal conductivity & $\mathrm{W} / \mathrm{mK}$ \\
\hline$m$ & mass & $\mathrm{kg}$ \\
\hline$\dot{m}$ & mass flow rate & $\mathrm{kg} / \mathrm{s}$ \\
\hline$q$ & heat energy & $\mathrm{J}$ \\
\hline$\dot{q}$ & heat flow & W \\
\hline$Q$ & electrical power (imaginary) & W \\
\hline$P$ & electrical power (real) & $\mathrm{W}$ \\
\hline$R_{\text {elec }}$ & electricity price & $\$ / \mathrm{kWh}$ \\
\hline$R_{\text {fuel }}$ & natural gas price & $\$ / \mathrm{kWh}$ \\
\hline$T$ & temperature & ${ }^{\circ} \mathrm{C}$ or $\mathrm{K}$ \\
\hline$\Delta T$ & temperature difference & ${ }^{\circ} \mathrm{C}$ or $\mathrm{K}$ \\
\hline$t$ & time & $\mathrm{s}$ \\
\hline$\Delta t$ & time interval & s \\
\hline$U$ & overall heat transfer coefficient & $\mathrm{W} / \mathrm{m}^{2} \mathrm{~K}$ \\
\hline$V$ & volume & $\mathrm{m}^{3}$ \\
\hline$\dot{V}$ & volumetric flow rate & $\mathrm{m}^{3} / \mathrm{s}$ \\
\hline$\widetilde{V}$ & voltage (complex) & V \\
\hline$\widetilde{Z}$ & impedance (complex) & $\Omega$ \\
\hline$S$ & control signal & - \\
\hline$\widetilde{X}$ & electrical power (complex) & W \\
\hline
\end{tabular}


G independent variable

set of independent variables

electricity consumption

$\mathrm{kWh}$

gross $\mathrm{AC}$ electrical generation
$\mathrm{kWh}$

xviii 


\section{Chapter 1}

\section{Introduction and Literature Review}

\subsection{Introduction}

There is now widespread consensus in the scientific community that the global climate is warming, and that most of this warming is due to increasing concentrations of anthropogenic greenhouse gases (GHGs) in the atmosphere [11]. Continued warming could threaten the stability of the natural life-support systems that humans depend on. Despite the relatively small population of Canada, Canadians contribute in no small part to this problem. According to the most recent global emissions data, Canada is the seventh worst polluter in the world in terms of total carbon emissions [12]. The average Canadian is responsible for 16.33 tonnes of $\mathrm{CO}_{2}$ each year - more than three times the global average [13]. There is an urgent need to implement technologies that will help reduce GHG emissions. If they are to have a substantial impact, these technologies should be deployed in sectors that are responsible for a large fraction of total emissions.

In Canada, the residential sector is responsible for $67.9 \mathrm{Mt}$ of $\mathrm{CO}_{2}$ equivalent GHG emissions $\left(\mathrm{CO}_{2} \mathrm{e}\right)$, which is $15 \%$ of total emissions [5]. Heat demand in houses is responsible for a large portion of this, with emissions released as a result of indoor space heating and domestic hot water (DHW) production totaling $54.4 \mathrm{Mt} \mathrm{CO}_{2} \mathrm{e}$, or $12 \%$ of Canada's total 2009 emissions. This break-down is shown in Figure 1.1. Single-detached homes make up the largest part of the building stock, with $7,106,000$ units, or $57 \%$ of the total as of 2002 [5]. This means that technologies designed for this building type could have a large effect on the emissions for the whole Canadian residential sector. 


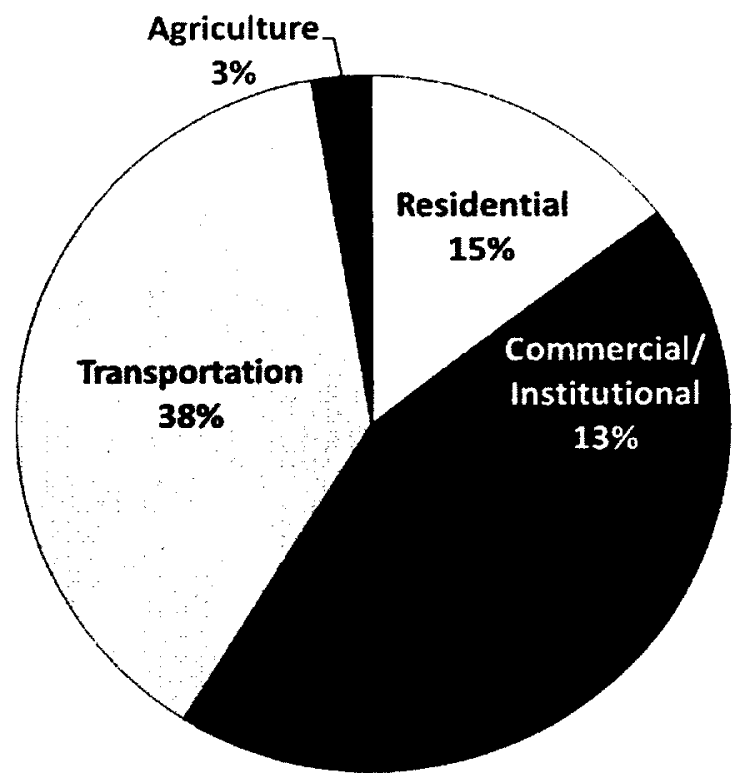

(a) Canada by sector

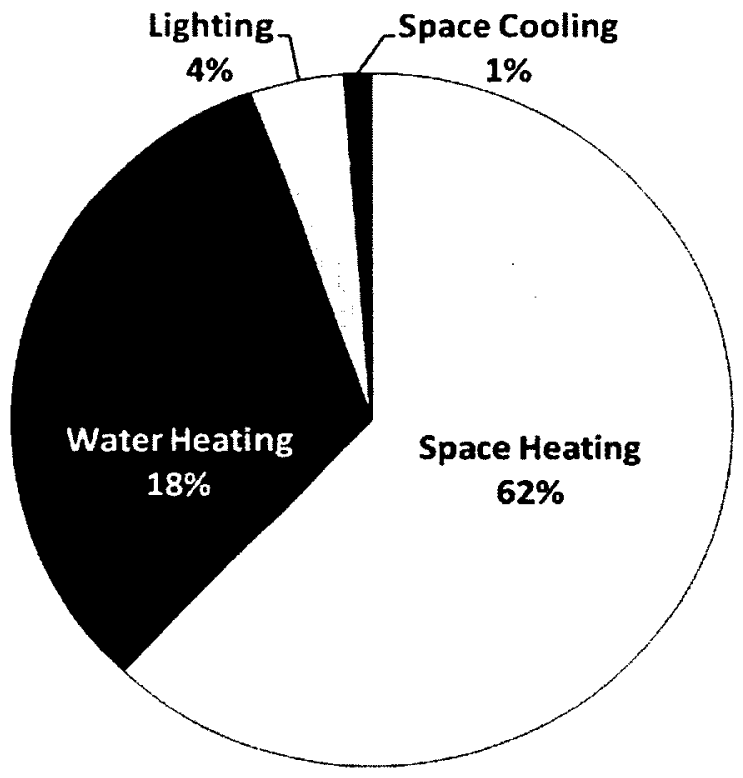

(b) Residential sector by end-use

Figure 1.1: Canadain GHG emissions (\% by mass of $\mathrm{CO}_{2}$ equivalent) including electricity-related emissions [5].

Typically in Canada, electricity is generated at central plants and delivered to consumers by transmission lines. Central generation has the advantage of the high electrical conversion efficiency that comes with large power plants - modern combined cycle gas turbine (CCGT) plants are $55 \%$ efficient (referenced to the source fuel's lower heating value, or LHV) [14], [15]. However, central generation also has disadvantages: $9.6 \%$ of the electricity produced in Canada is lost due to resistive losses in transmission lines [13], and low-grade heat produced at central plants is rejected to nearby lakes or the atmosphere.

One technology that has the potential to address some of these limitations is micro-cogeneration. The following section presents a review of the literature on this topic. 


\subsection{Literature Review}

\subsubsection{Micro-cogeneration}

Micro-cogeneration is the concurrent generation of heat and electrical power from a single fuel source at a small scale, with an electrical output less than $15 \mathrm{~kW}$. The term micro-cogeneration encompasses a number of different technologies, the most prominent being internal combustion engine (ICE), Stirling engine (SE), and fuel cell (FC) devices. These devices typically have electrical conversion efficiencies of $5-40 \%$, measured as alternating current (AC) output as a percentage of the source fuel's lower heating value (LHV) [16], [17]. Many of these devices have been installed in residential houses in Japan and the UK, where favourable policies exist to encourage their adoption [18], [19]. When implemented in a residential house, the heat generated can be used for space heating and DHW production, increasing the device's total efficiency. Electrical transmission losses are reduced due to the close proximity of the generator and consumer. When operated at times of peak electricity use, microcogeneration lessens the load that central power plants must meet. This can reduce electrical grid congestion and the need to operate the GHG-intensive plants that come online during peak times.

Micro-CHP Accelerator, a field trial performed between 2005 and 2008, studied the performance of $87 \mathrm{SE}$ and ICE devices in residential houses in the UK. This study found that the devices resulted in average carbon savings of $9 \%$ for houses with heat demand over $54 \mathrm{GJ} /$ year [20], less than half that of the average Canadian house [5]. This indicates that the potential for micro-cogeneration in Canada may be high. Simulation based studies have also been conducted to assess the performance of micro-cogeneration. Alanne et al. found that an SE device could result in a $3-5 \%$ reduction in primary energy consumption and $\mathrm{CO}_{2}$ emissions in a Finnish setting [21]. In a Swiss study that considered ICE, SE and FC units, Dorer \& Weber found that the best systems resulted in a $14 \%$ decrease in primary energy consumption and a $22 \%$ reduction in $\mathrm{CO}_{2}$ emissions, relative to a gas boiler [22]. These results are sensitive to the emissions and primary energy consumption associated with grid electricity. In

general, micro-cogeneration will compare more favourably to more carbon-intensive grid electricity. Financial viability is also highly variable, and depends on the relative prices of fuel and grid electricity.

The electrical conversion efficiency of micro-cogeneration devices is low compared 


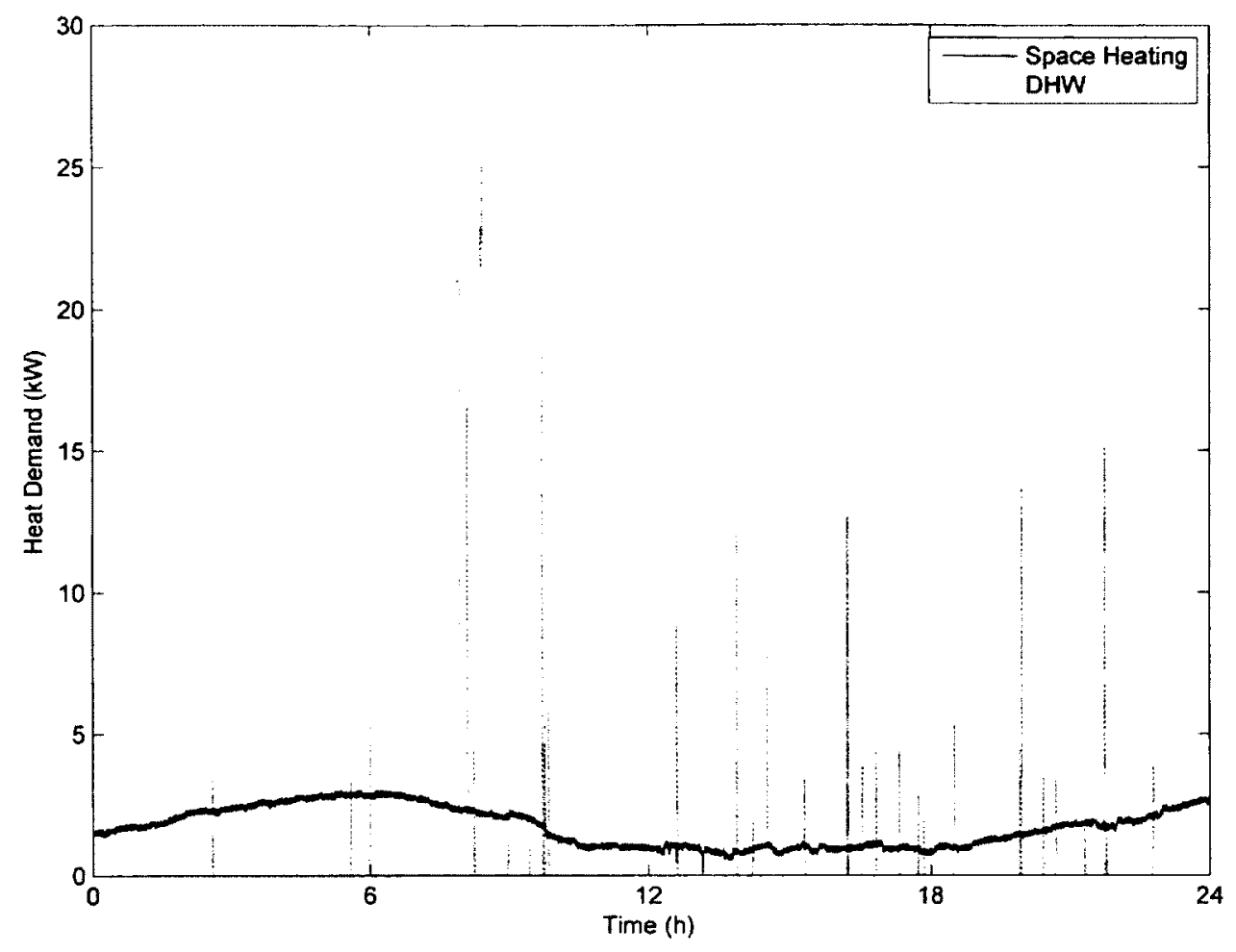

Figure 1.2: Simulated space and DHW heating loads on a typical spring day, using a 1-minute time step.

to modern central generation plants; therefore generated heat must be managed effectively to meet building demands with little waste. Heat demand in residential houses is highly variable. It depends on occupant behaviour, climate conditions, and building thermal characteristics. Figure 1.2 shows heat demand due to DHW use and space heating on a spring day. The space heating load was generated using a typical singlefamily building model (described in Section 3.2), and DHW loads were calculated using a generated profile [23]. To meet this demand, some form of thermal storage is required to buffer between the supply of heat and demand. The volume of storage, and configuration of components that manage the thermal energy is important. Also, the control of this system is non-trivial and impacts performance. The remainder of this section describes micro-cogeneration devices, their associated thermal plant, and their control in more detail. 


\subsubsection{Fuel Cell Micro-cogeneration}

This section describes fuel cell micro-cogeneration devices. For an overview of ICE and $\mathrm{SE}$ cogeneration, as well as further details on $\mathrm{FC}$ devices, the interested reader is referred to Knight \& Ugursal, 2005 [24]. FC devices are promising candidates for implementation in residential buildings because of their high electrical efficiency. Large FCs $(200 \mathrm{~kW}-2 \mathrm{MW})$ are capable of $40-60 \%$ efficiency [25], and smaller FCs $(\approx 1.5 \mathrm{~kW})$ are predicted to reach efficiencies of $45 \%$ (LHV) [26]. Usually, FCs directly convert the internal energy stored in a fuel's molecular bonds to electrical energy. FCs use hydrogen as fuel, which can be supplied directly or can be produced by reforming a light hydrocarbon fuel such as natural gas. This can be done in an external reformer in low-temperature FCs, or internally in high-temperature FCs.

Proton-exchange membrane fuel cells (PEMFCs) are low-temperature FCs that operate below $100^{\circ} \mathrm{C}$. They use a polymer electrolyte material and platinum as a catalyst. These are promising candidates for residential application because of their high power density and ability to modulate electrical production. They consist of: (i) a fuel cell power module (FCPM) where the electrochemical reaction takes place, (ii) a water-water heat exchanger that transfers heat from the FCPM, (iii) a power conditioning unit (PCU) that converts the $\mathrm{DC}$ output of the FCPM to $\mathrm{AC}$, and (iv) an external reformer.

Figure 1.3 shows the reaction that takes place within a PEMFC power module. The power module consists of an electrolyte material sandwiched between an anode and cathode. Hydrogen enters at the anode, where a catalyst causes it to split into positive and negative ions (electrons). The electrolyte material allows only positive ions to flow to the cathode. The electrons are forced to travel through an external circuit providing the device's electrical output (DC). At the cathode, positive ions react with electrons and oxygen molecules to produce water. Heat is also produced by this reaction. To increase voltage, a number of these cells are stacked together within a single FCPM.

\subsubsection{Modelling}

In order to assess the performance of FC devices and other micro-cogeneration units in residential houses, computer simulation has been used. This has the advantage of being relatively incxpensive (compared to field trials), and is useful for identifying 


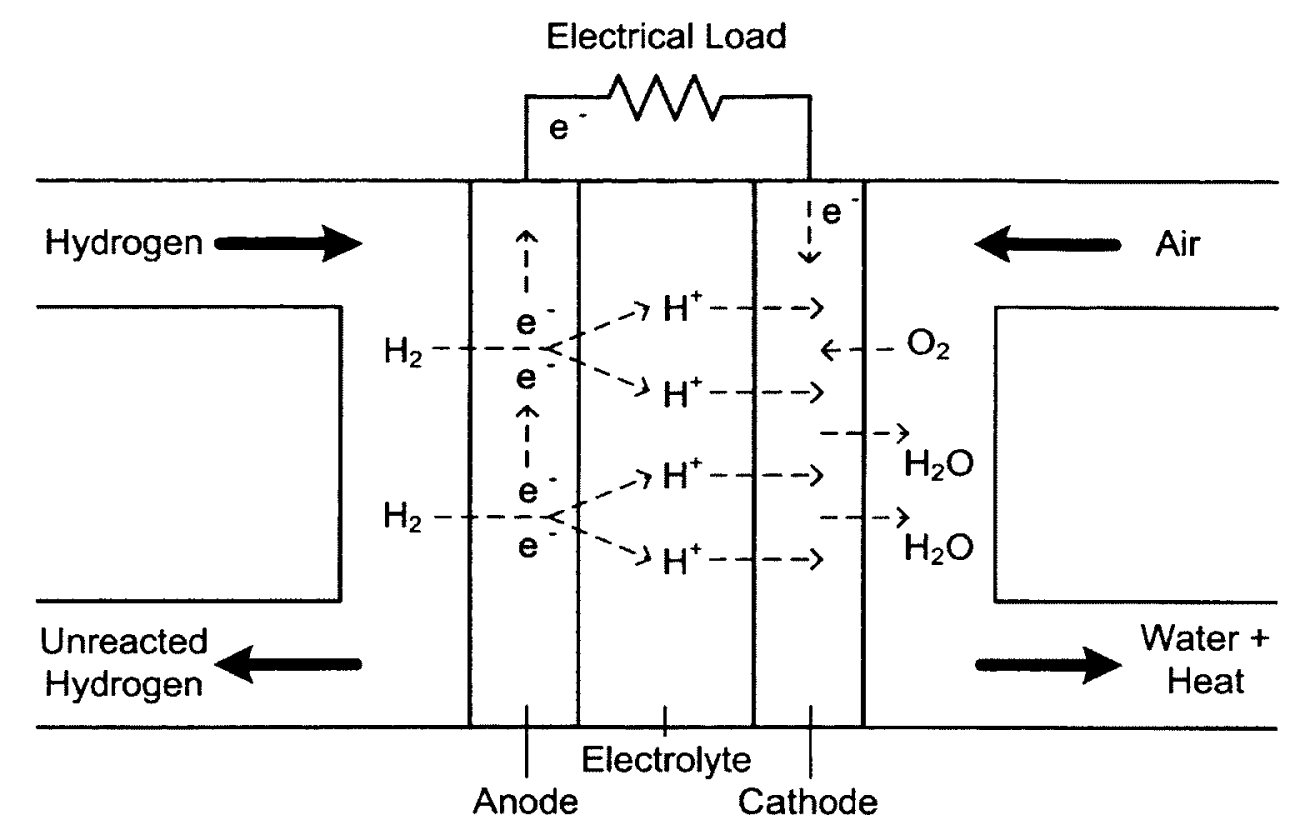

Figure 1.3: Proton exchange membrane fuel cell [6].

settings where micro-cogeneration devices will perform well. The TRNSYS simulation platform has been used for some work because of its strong HVAC modelling capabilities [27].

Often the cogeneration unit is modelled separately from the coupled building and heating loads, such as in Haeseldonckx et al., 2007 [28] and Alanne et al., 2006 [29]. Space heating/DHW loads were represented using hourly profiles obtained through measurement in the first study, and simulation in the second. The cogeneration unit and HVAC system were modelled in isolation, with thermal output scaled to match the load profile. A limitation of this approach is that it ignores the interdependencies between the building and its heating system. In reality, if a heating system cannot meet a space heating load at a certain time, the building will cool and future heating loads will increase. This is not well represented with heating load profiles.

To capture this behaviour, building performance simulation programs such as ESP-r have also been used to model micro-cogeneration. This software allows the concurrent simulation of a building's thermal performance along with its heating system. A number of models have been developed that are meant to integrate well into this type of simulation environment. SE and FC model frameworks have been developed as part of the International Energy Agency (IEA) research project Annex 
42 [30]. These models are based on a control volume approach and are flexible enough to represent the behaviour of many types of devices. These models have been calibrated using experimental data to represent $2.8 \mathrm{~kW}_{A C} \mathrm{SOFC}$ and $1.0 \mathrm{~kW}$ AC PEMFC devices. This work and its experimental validation is presented in Beausoleil-Morrison \& Lombardi, 2009 [31], Beausoleil-Morrison, 2010 [17], and Johnson et al., 2012 [9]. For further details about the modelling of FC devices, the interested reader is directed to Beausoleil-Morrison, 2010 [16].

\subsubsection{The Thermal Plant}

For the purposes of this research, the thermal plant is defined as the system of components that stores, adds to, and delivers the heat generated by a micro-cogeneration device to meet thermal loads within a building. The plant must: (i) dispatch thermal output to meet space-heating and DHW loads, (ii) integrate auxiliary heaters to meet loads exceeding the cogeneration device's capacity, (iii) integrate thermal storage appropriate for the plant's heat production and building loads, and (iv) accommodate the chosen control strategy.

Thermal storage is important because is helps to minimize the expulsion, or dump, of heat when household heat demand is less than production. Typically storage is implemented as a water tank. The size of this tank has an effect on system performance

- too large and the heat loss to the room will be high, too small and there will not be enough buffering. The past research examined has most often focussed on plants that include either one or two storage tanks. Including two tanks may be advantageous because this allows water to be supplied to DHW and space heating loads at two different temperatures. Stored DHW must meet strict temperature requirements to prevent the growth of legionella bacteria, while space heating water can be kept at a cooler temperature.

Examples of 1-tank plants can be found in Haeseldonckx et al., 2007 [28], Alanne et al., 2019 [21], Beausoleil-Morrison \& Ribberink, 2008 [32], and Gähler et al., 2008 [33]. Haeseldonckx et al. and Alanne et al. both varied tank volumes, and found that system performance increased with tank volume, but that there were diminishing returns as tank volume increased. Examples of 2-tank systems can be found in Dorer \& Weber, 2009 [22] and Alanne et al, 2006 [29]. Neither of these studies looked at the performance effects of changing tank volumes. To date, no studies have directly compared 1 and 2-tank plants, and there is still no definitive answer on how large the 
storage volume(s) should be.

\subsubsection{Control Strategies}

An effective plant control sets the thermal and electrical output of a microcogeneration device as well as the state of other plant components to maximize performance according to a chosen metric. The controller can set a rate of electrical production for modulating cogeneration devices, or can simply perform on/off switching for non-modulating devices. Control signals can be determined by sensing physical properties such as temperatures or electrical consumption, and external factors such as electricity prices. When a cogeneration device is controlled in response to thermal properties, this is termed "thermal following". When it is controlled by sensing electrical properties this is termed "electrical following". When both thermal and electrical information is used, this is termed a hybrid control. A hybrid approach may require prioritizing either electrical or thermal following depending on the time of day or some other condition.

Examples of thermal load following can be found in Dorer et al., 2005 [34], Haeseldonckx et al., 2007 [28], and Dorer \& Weber, 2009 [22]. In these studies the cogeneration device was actuated in response to the amount of stored energy, which was determined by sensing storage tank temperature. Haeseldonckx et al. studied a non-modulating ICE device that was switched on when the amount of stored energy in the tank fell below $80 \%$ of the fully charged state, and turned off when the tank became fully charged. Dorer et al. and Dorer \& Weber examined modulating SOFC and PEMFC cogeneration devices were controlled using a proportional-integral control, again sensing storage tank temperature. The storage tank set-point temperature varied with the 24 hour average outdoor temperature, according to outdoor temperature vs. space heating demand curves.

Examples of hybrid control can be found in Alanne et al., 2010 [21] and Gähler et al., 2008 [33]. Alanne et al. modelled a non-modulating SE device that was switched on when thermal or electrical demand exceeded a threshold value. Different thermal and electrical thresholds were examined. Gähler et al. used a hybrid controller to modulate a SE device model. This controller sensed the temperature of the storage tank, indoor air, outdoor air, heating supply water, and also received electricity consumption and tariff information. Operating cost and primary energy consumption were both used as performance metrics in a linear optimization. This optimization 
relied on linear approximations of the behaviour of the SE, water tank, auxiliary burner, and other component models.

No studies to date have optimized a hybrid control without linearizing the building and plant models. There have also been few studies done that directly compare thermal load following strategies to hybrid ones.

\section{$1.3 \quad$ Research Objectives}

Micro-cogeneration has the potential to reduce GHG emissions in Canada. The performance of a micro-cogeneration device in a residential household is dependant on a number of factors. The thermal storage volume, plant configuration, and control strategy employed are all important. In order to adequately represent these interdependencies, whole-building simulation will be used to model a PEMFC device and plant. To determine the sensitivity of the results obtained to the household the system is implemented in, simulations will be performed in three different single-family detached Canadian households. This thesis will attempt to meet the following research objectives:

- compare the performance of 1 and 2-tank PEMFC micro-cogeneration plants

- determine the volume(s) appropriate for thermal storage

- implement and optimize a hybrid control strategy

- examine the sensitivity of results obtained to changes in building and occupancy characteristics

\subsection{Thesis Outline}

In order to accomplish the research objectives presented above, this thesis is organized as follows:

Chapter 2: ESP-r describes the physical models and numerical methods used in the building performance simulation tool ESP-r

Chapter 3: Model Construction describes the building models, occupancy cases, and plant component models 
Chapter 4: Plant Configuration and Control describes the configuration and control of the thermal plants

Chapter 5: Optimization Methodology describes the optimization problem, algorithms chosen, and GenOpt-ESP-r software coupling

Chapter 6: Results presents the results of the optimizations, household sensitivity study, and control mode comparison

Chapter 7: Conclusions and Recommendations concludes the work and presents recommendations for future research 


\section{Chapter 2}

\section{ESP-r Building Performance Simulation}

\subsection{Introduction}

To achieve the goals described in Section 1.3, an accurate model of the relevant aspects of the system under study must be constructed. This model should include the heat and mass transfer that occurs within the PEMFC and other system components.

To evaluate the performance of the PEMFC in single-family homes in Canada, the model must include building and occupant loads typical of these settings. One approach would be to obtain thermal load profiles and place these on a stand-alone plant model. This approach would require less computation time since heat transfer between the building and the outdoors would not be calculated during simulation. However, this approach does not account for changes in building load with changes in plant behaviour. These interactions become important when heating loads are not met by the HVAC system, since this will affect heating loads in the future [16]. In order to capture these interactions, ESP-r was chosen to perform the simulations for this work.

ESP-r is a building simulation software tool that is capable of modelling the thermal behaviour of buildings concurrently with that of their subsystems. Its source code has been under development since the 1970s, is made available under an opensource license, and is thoroughly validated [35]. ESP-r has facilities to model HVAC systems, air flow within buildings, and electrical systems. Its open-source nature makes it possible to implement customized controllers and components that operate in all of the simulation domains. ESP-r is native to UNIX-based operating systems, but can be run in Windows using the Cygwin environment.

This chapter describes the methods used in ESP-r to model the domains relevant 
to this thesis. The following sections are adaptations of the cited works. Section 2.2 describes the modelling of HVAC systems, Section 2.3 summarizes the treatment of the building domain, and Section 2.4 describes the electrical network model.

\subsection{The Plant Domain}

This section describes the ESP-r plant solver. In the remainder of this thesis, HVAC components will be referred to as plant components. This is meant to be a general term for the components that generate, store, and transport mass and thermal energy in order to supply building demand for DHW, and space heating/cooling. Systems of connected components will be referred to as the thermal plant. The plant solver is capable of modelling both single-phase mass flow (water or dry air) and two-phase mass flow (moist air) within a plant network. For a more detailed description of the plant solver, the interested reader is referred to Henson, 1991 [7].

ESP-r supports two types of representations of the thermal plant - an ideal and an explicit representation. In both cases, a rate of heat addition or extraction is injected into one or more control volumes (CVs) within the building model. For the ideal case, it is only this output of heat that is modelled, and not how it is produced. This can be sufficient when only the building's behaviour is of interest. The explicit approach is more detailed - each plant component has an internal model coupled with one or more CVs, the number of these being commensurate with the level of detail required in the representation. Mass flow rates and temperature for each $\mathrm{CV}$ is calculated at each time-step. One or more plant components can be coupled to the building domain to add or extract heat and/or moist air. This thesis uses both ideal and explicit approaches, for reasons described in Chapter 3.

ESP-r is distributed with a library of plant component models, which includes a PEMFC model. The PEMFC model and others used in this thesis are described in Section 3.5. Energy and mass balance equations are solved for each node simultaneously by the plant solver using the methodology presented below.

\subsubsection{Energy and Mass Balance Approach}

Figure 2.1 shows an example of two connected nodes, $i$ and $i-1$, within a plant network. Their CVs are shown with dotted lines, heat-transfer paths are represented by dashed lines, and two-phase moist air connections are shown with solid lines. $\dot{m}_{m a, i}$ 


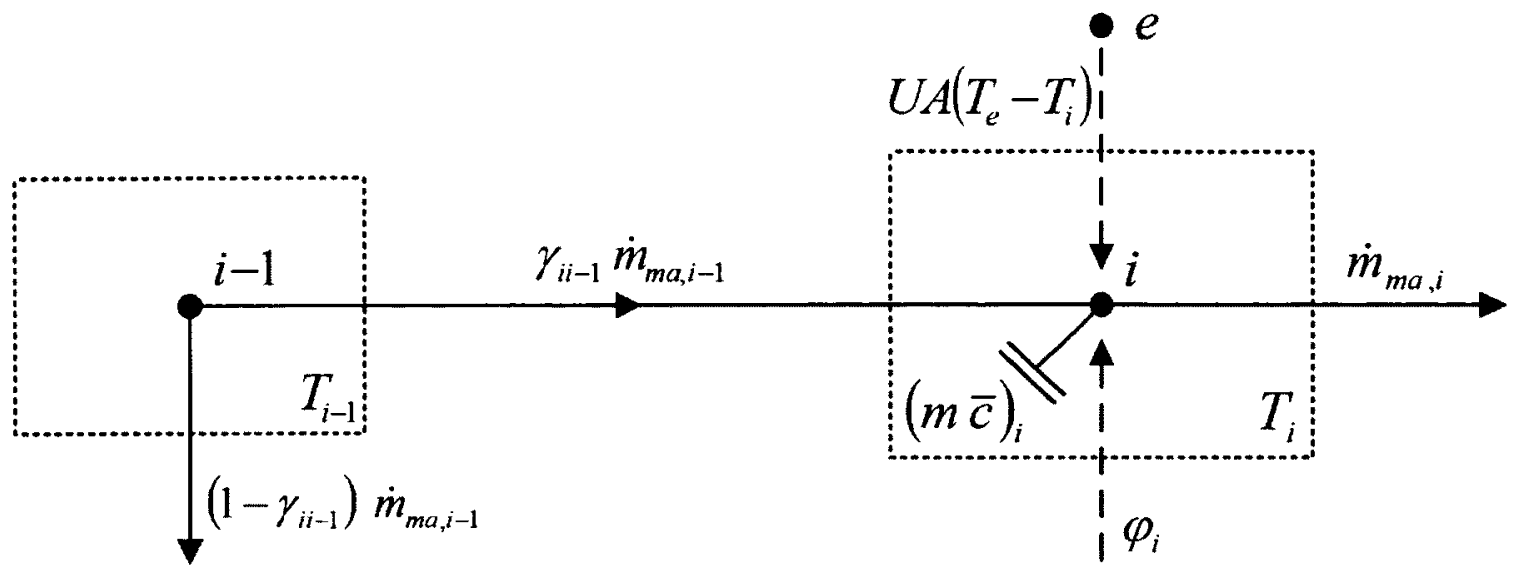

Figure 2.1: Mass and energy balance depiction for two plant network nodes, adapted from Hensen, 1991 [7].

and $\dot{m}_{m a, i-1}$ are the mass flow rates of moist air $[\mathrm{kg} / \mathrm{s}]$ from nodes $i$ and $i-1$, respectively. Node $i$ includes mass (shown as a capacitance), skin loss to the environment $(e)$, and heat generation $\left(\phi_{i}\right)$. While this example uses two-phase connections, the formulation is similar for single-phase flow of dry air or liquid water. Equating the rate of mass transfer into and out of node $i$ yeilds the following mass balance equation:

$$
\gamma_{i i-1} \dot{m}_{m a, i-1}-\dot{m}_{m a, i}=0
$$

Where $\gamma_{i i-1}$ is the ratio of mass entering node $i-1$ that is diverted to node $i$. The energy balance equation on this $\mathrm{CV}$ must take the form:

$$
\left\{\begin{array}{c}
\text { heat storage } \\
\text { in } C V
\end{array}\right\}=\left\{\begin{array}{c}
\text { net advection } \\
\text { into } C V
\end{array}\right\}+\left\{\begin{array}{c}
\text { net convection } \\
\text { into } C V
\end{array}\right\}+\left\{\begin{array}{c}
\text { heat generation } \\
\text { in } C V
\end{array}\right\}
$$

For node $i$, this equation becomes:

$$
\bar{c}_{i} m_{i} \frac{\partial T_{i}}{\partial t}=\gamma_{i i-1} \dot{m}_{m a, i-1} c_{p, m a}\left(T_{i-1}-T_{i}\right)+U A\left(T_{e}-T_{i}\right)+\phi_{i}
$$

where $c_{p, m a}$ is the heat capacity of moist air $\left[\mathrm{J} / \mathrm{kgK}\right.$ ], and $T_{i}$ and $T_{i-1}$ are the temperatures $[\mathrm{K}]$ of nodes $i$ and $i-1$, respectively. Storage of heat in $i$ a product of the rate of change of temperature $T_{i}[\mathrm{~K}]$, mass $m_{i}[\mathrm{~kg}]$, and mass-weighted average heat 
capacity $\left(\bar{c}_{i}\right)[\mathrm{J} / \mathrm{kgK}]$. If $i$ represents a component with $n$ parts of mass $m_{k}$ and heat capacity $c_{p, k}$, this is given by $\bar{c}=\sum_{k=1}^{n}\left(c_{p, k} m_{k}\right) / \sum_{k=1}^{n} m_{k}$. The following subsection describes how many equations of this type can be solved simultaneously in matrix form.

\subsubsection{Solving the Plant Matrices}

The remainder of this section presents the solution when $\gamma_{i i-1}=1$. In other words, each component has a downstream connection to only one other component. ${ }^{1}$ Equation 2.2 can be re-written using the finite difference method. This can be written both with unknown future time-step temperatures $T$ in the fully implicit form:

$$
\frac{\bar{c}_{i} m_{i}\left(T_{i}-T_{i}^{*}\right)}{\Delta t}=\dot{m}_{m a, i-1}^{*} c_{p, m a}\left(T_{i-1}-T_{i}\right)+U A\left(T_{e}-T_{i}\right)+\phi_{i}
$$

and known present time-step temperatures $T^{*}$ in the fully explicit form:

$$
\frac{\bar{c}_{i} m_{i}\left(T_{i}-T_{i}^{*}\right)}{\Delta t}=\dot{m}_{m a, i-1}^{*} c_{p, m a}\left(T_{i-1}^{*}-T_{i}^{*}\right)+U A\left(T_{e}^{*}-T_{i}^{*}\right)+\phi_{i}^{*}
$$

The solution to the explicit equation is conditionally stable, whereas the implicit equation is unconditionally stable but inaccurate when $\Delta t$ is large. To obtain a compromise between the explicit and implicit forms, a weighting factor $\beta$ can be used to combine Equations 2.3 and 2.4:

$$
\begin{aligned}
& {\left[\beta\left(\dot{m}_{w, i-1} c_{p, m a}+U A\right)+\frac{\bar{c}_{i} m_{i}}{\Delta t}\right] T_{i}-\beta \dot{m}_{m a, j} c_{p, m a} T_{i-1}} \\
& =\quad\left[(1-\beta)\left(-\dot{m}_{m a, i-1}^{*} c_{p, m a}-U A\right)+\frac{\bar{c}_{i} m_{i}}{\Delta t}\right] T_{i}^{*}+(1-\beta) \dot{m}_{m a, i-1}^{*} c_{p, m a} T_{i-1}^{*} \\
& \quad+U A\left[\left(1-\beta T_{e}^{*}+\beta T_{e}\right]+(1-\beta) \phi_{i}^{*}+\beta \phi_{i}\right.
\end{aligned}
$$

where all unknowns have been moved to the left-hand side.

Setting $\beta=1$ gives the fully implicit form, $\beta=0$ gives the fully explicit form, and $\beta=0.5$ gives the Crank-Nicolson form. The plant domain solver switches dynamically between fully implicit and Crank-Nicolson methods when solving nodes within different plant components. This switching is determined by the ratio of the time-step to the component's time constant. This time constant is the product of a

\footnotetext{
${ }^{1}$ This is true for the plant networks implemented as part of this thesis.
} 
component's thermal resistance and heat capacitance; it characterizes response time to thermal excitations. If the time-step is more than $63 \%$ of the component's time constant, then the Crank-Nicolson method is used to solve that component's energy balance equations, otherwise the implicit method is used [7].

Equation 2.5 can be re-written in the following form, where $b_{i}$ is a constant:

$$
a_{i i} T_{i}+a_{i i-1} T_{i-1}=b_{i}
$$

Once similar energy balances have been written for all components in a plant network, the plant matrix equation can be formed:

$$
\mathbf{A} \vec{T}=\vec{B}
$$

For a network containing $n$ nodes, $\mathbf{A}$ is a $n \times n$ dimension matrix, and $\vec{T}$ and $\vec{B}$ are column vectors of length $n$.

$$
\left[\begin{array}{cccccc}
a_{11} & & & & & a_{1 n} \\
a_{21} & a_{22} & & & & \\
& \ddots & \ddots & & & \\
& & a_{i i-1} & a_{i i} & & \\
& & & \ddots & \ddots & \\
& & & & a_{n n-1} & a_{n n}
\end{array}\right]\left[\begin{array}{c}
T_{1} \\
T_{2} \\
\vdots \\
T_{i} \\
\vdots \\
T_{n}
\end{array}\right]=\left[\begin{array}{c}
b_{1} \\
b_{2} \\
\vdots \\
b_{i} \\
\vdots \\
b_{n}
\end{array}\right]
$$

Each node $i$ is coupled to the node that sends it mass, $i-1$. Other couplings can exist as well. Nodes that are part of the same component may be coupled with thermal resistances, or other relationships defined in a component model. For any such coupled nodes $i$ and $j, a_{i j} \neq 0$ is true. To find the future time-step temperatures $\vec{T}, \mathbf{A}$ is inverted by a process described in Clarke, 2001 [36].

Mass balance equations are also solved in matrix form by the plant solver. This process is similar the one described above, and has been omitted for brevity. Its full description can be found in Hensen [7]. 


\subsection{The Building Domain}

This section presents a summary of the way in which ESP-r represents heat and mass transfer within a building. For a more detailed description, the reader is referred to Clarke's Energy Simulation in Building Design [36].

As in the plant domain, ESP-r discretizes elements of a building into control volumes, which are represented by nodes. These nodes can represent solid volumes or air volumes. The laws of conservation of energy and momentum are applied at each node. The solution of these equations yields temperature and mass flow rates at each time-step.

Applying conservation of energy to a control volume gives:

$$
m c_{p} \frac{\mathrm{d} T}{\mathrm{~d} t}=\dot{q}_{p a t h, n e t}+\dot{\phi}_{g e n}
$$

where $m$ is the mass contained inside the $\mathrm{CV}[\mathrm{kg}], c_{p}$ is heat capacity of this mass $[\mathrm{J} / \mathrm{kgK}], T$ is its temperature $[\mathrm{K}], \dot{q}_{\text {path,net }}$ is the net rate of heat transfer through the relevant paths [W], and $\dot{q}_{g e n}$ is the rate of heat generation within the CV [W]. The form Equation 2.11 differs depending on the node's location within a building. The heat transfer paths relevant to solid nodes and air nodes are described below.

Each part of the building envelope (walls, roof, windows, etc.) is composed of one or more material layers. Each has thermo-physical properties associated with it, such as density, thermal conductivity, and specific heat capacity. These can be user-defined, or selected from a library of common materials. Each layer within the envelope is discretized into three solid nodes - one each face and one at the centre of the layer (see Figure 2.2). ${ }^{2}$ This means that a construction composed of $n$ layers will be represented by $2 n+1$ nodes. Figure 2.2 shows the heat transfer paths relevant for nodes within the building envelope. ${ }^{3}$ Conduction occurs between adjacent material layers within the building envelope. For an internal node $i$, only conduction with

\footnotetext{
${ }^{2} \mathrm{~A}$ parametric study performed by Clarke concluded that spatial discretization of 3 nodes or more per homogeneous layer will yield consistent results with acceptable accuracy [36].

${ }^{3}$ Generation is also possible at internal nodes. This is typically used to represent heat injection from an HVAC component and would not be present in an external wall.
} 


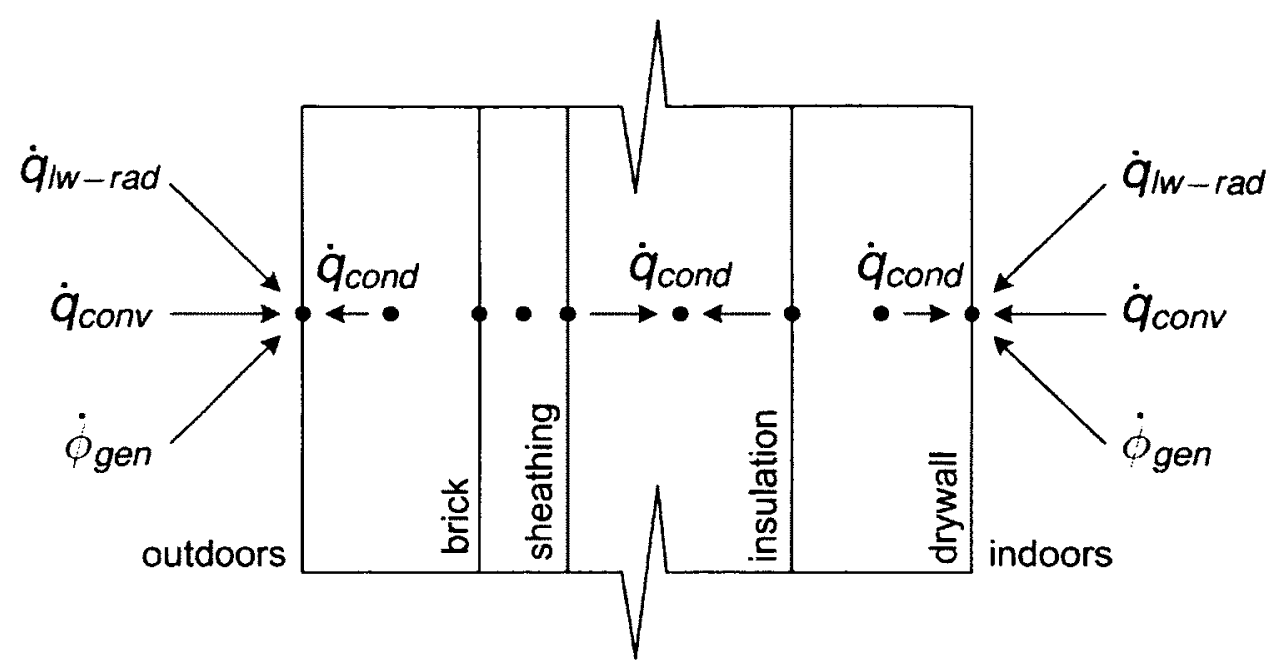

Figure 2.2: Heat transfer paths for internal construction and surface nodes within an external wall.

adjacent nodes $i-1$ and $i+1$ is included:

$$
\dot{q}_{\text {cond }}=\sum_{j=i-1}^{i+1}\left(\frac{k_{j \rightarrow i} A_{i j}}{\Delta x_{i j}}\left(T_{j}-T_{i}\right)\right)_{i \neq j}
$$

where $k_{j \rightarrow i}$ is the thermal conductivity between nodes $i$ and $j[\mathrm{~W} / \mathrm{mK}], A_{i j}$ is the contact area between them $\left[\mathrm{m}^{2}\right]$, and $\Delta x_{i j}$ is the distance between them [m].

Radiative heat transfer occurs over both short and long wavelengths of electromagnetic radiation. Short wave radiation, or solar radiation, is absorbed at external surfaces, and at internal surfaces after it is transmitted by a window glazing. Long wave radiation is emitted by all solid objects with a non-zero temperature. This provides a heat transfer path between internal surfaces, between external surfaces and the environment, and between occupants and appliances and internal surfaces. For a surface $i$, net heat transfer through long wave radiation exchange is given by:

$$
\dot{q}_{l w-r a d}=\sum_{s=1}^{p}\left(h_{r, s \rightarrow i} A_{i}\left(T_{s}-T_{i}\right)\right)_{i \neq s}
$$

where $h_{r, s \rightarrow i}$ is a linearized radiation heat transfer coefficient between surface $s$ and $i\left[\mathrm{~W} / \mathrm{m}^{2} \mathrm{~K}\right]$, and $A_{s}$ is the surface area of $s\left[\mathrm{~m}^{2}\right]$. This is summed over the number of surfaces $p$ in visual contact with $i$. Net convection to $i$ from an air node $a$ is given by 
Equation 2.14:

$$
\dot{q}_{c o n v}=h_{c, i} A_{i}\left(T_{i}-T_{a}\right)
$$

where $h_{c, i}$ is the convective heat transfer coefficient of surface $i\left[\mathrm{~W} / \mathrm{m}^{2} \mathrm{~K}\right] .{ }^{4}$ A generation term $\dot{\phi}_{g e n}$ is also included for both surface and internal construction nodes. This term can represent an injection of heat from the plant domain, a casual gain, ${ }^{5}$ or absorption of short wave solar radiation. Solar radiation is transmitted into the building through windows, represented by transparent multi-layered constructions (TMCs). These are defined with both thermo-physical and optical properties. The optical property set specifies reflectance, transmittance and absorption of light for 5 angles of incidence (values at other angles are interpolated). TMCs model convective and radiative heat transfer between glazing layers with a average cavity resistance.

The building air can be divided into however many discrete volumes the user sees fit. Each becomes a well-mixed thermal zone, since each control volume is assumed to be at one temperature. The relevant heat transfer paths for an air node include: (i) convection from internal surfaces, and (ii) advection from adjacent zones and the outdoors (infiltration).

For a model with $n$ thermal zones/air nodes, heat transfer to the air node $i$ by advection is as follows:

$$
\dot{q}_{a d v}=\sum_{j=1}^{n}\left(\dot{m}_{j \rightarrow i} c_{p}\left(T_{j}-T_{i}\right)+\dot{q}_{i n f}\right)_{i \neq j}
$$

where $\dot{m}_{j \rightarrow i}$ is the mass flow rate of air from zone $j$ to $i[\mathrm{~kg} / \mathrm{s}]$, and $\dot{q}_{\text {inf }}$ is the net rate of heat transfer due to infiltration [W]. $\dot{m}_{j \rightarrow i}$ is solved within the ESP-r air flow network using a mass balance approach coupled with wind-induced pressure differences at external openings [36]. $\dot{q}_{\text {inf }}$ can be set as a prescribed flow, can be determined by an air-flow network, or calculated using the Alberta Air Infiltration (AIM-2) model [38]. The net convection into $i$ is calculated with Equation 2.14, and summed over all inzone surfaces. Generation at the air node represents injections of heat from the plant domain and casual gains.

\footnotetext{
${ }^{4}$ For a thorough description of the convection coefficients available in ESP-r, see BeausoleilMorrison, 2000 [37].

${ }^{5}$ Casual gains are heat gains due to people, appliances and lighting. In ESP-r, these can be scheduled, calculated in the plant domain as skin heat loss of an HVAC component, or calculated in the electrical domain from a non-HVAC electrical load profile (see Subsection 3.4.2).
} 
Using the heat transfer path equations described above, Equation 2.11 is formulated as a finite-difference using present and future time-step quantitics, in a manner similar to that described in Subsection 2.2.2. This gives a system of equations that are solved at each time-step in the building domain.

The following section describes the electrical domain in ESP-r.

\subsection{The Electrical Domain}

This section describes the electric network model implemented in ESP-r. For more detail, see Kelly, 1998 [39] and Clarke, 2001 [36]. The electrical network is made up of loads, sources, and a distribution network. Loads are power draws on the network, such as those due to plant components. Sources supply power to the network, such as a grid connection. Electrical transmission between loads and sources is modelled with transmission components, such as cables. The junctions between loads, sources and transmission are represented by nodes.

Rather than conservation of mass and thermal energy applied in the building and plant domains, conservation of electrical energy is applied at nodes within an electrical network. This is given by Kirchoff's law:

$$
\sum_{q=1}^{n} \widetilde{I}_{p, q}=0
$$

which states that for a node $p$ with $n$ connected nodes, the sum of currents $\widetilde{I}_{p, q}$ [A] flowing in equals the sum of currents flowing out. $\tilde{I}$ is complex, so that both alternating current $(\mathrm{AC})$ and direct current $(\mathrm{DC})$ can be represented, and is given by $\widetilde{I}=I(\cos \theta+j \sin \theta)$, where $\theta$ is phase with respect to time, and $j$ is the imaginary unit.

Using Ohm's law, these currents can be written in terms of complex voltages and impedances:

$$
\widetilde{I}_{p, q}=\frac{\widetilde{V}_{p}-\tilde{V}_{q}}{\widetilde{Z}_{p, q}}
$$

where $\widetilde{V}$ terms are complex voltages [V], and $\widetilde{Z}_{p, q}$ is the impedance of connection $p-q$ $[\Omega]$.

Power consumption and generation at loads and sources are calculated outside the electrical network; these power flows are the boundary conditions of the electrical 
network. For plant components, this is an output of component models solved in the plant domain. To give power flows in terms of voltage and current, the following equation is used:

$$
\widetilde{S}_{p}=\widetilde{V}_{p} \widetilde{I}_{p}^{\prime}
$$

where $\widetilde{S}$ is complex power [W], and $\widetilde{I}^{\prime}$ the complex conjugate of $\widetilde{I}$. The complex power is composed of a real part $P$ and a reactive (imaginary) part $Q: \widetilde{X}=P+j Q$. When loads/sources are not purely resistive, the current and voltage within the network will be out of phase. This causes periodic variation in real power transfer, which is why the complex formulations are used. Voltage and phase angle are solved at each node in the network simultaneously, using a matrix approach similar to those described above.

The following chapter presents a description of the specific models implemented in ESP-r to accomplish the goals of this thesis. 


\section{Chapter 3}

\section{Model Construction}

\subsection{Introduction}

As stated in Chapter 1, the goal of this work is to evaluate the performance of a PEMFC device and associated HVAC components in typical, single-family detached Canadian households. Single-detached homes in Canada are diverse in terms of building characteristics, occupancy characteristics, and the weather they are exposed to. This chapter describes the building, occupant, weather, and plant models that have been used to represent a range of possible implementations of PEMFC devices in Canadian households. Section 3.2 describes the building model, Section 3.3 the weather data, Section 3.4 the occupancy model, Section 3.5 the plant component models, and Section 3.6 the household electrical model.

\subsection{Building Model}

In order to evaluate the performance of a PEMFC unit and associated HVAC components, this system of components should not be modeled in isolation. To capture interactions between the plant and the thermal and electrical load they are exposed to, it is desirable to model these domains concurrently. For this reason, it is necessary to select building models that have been implemented in whole-building simulation software. Also, these models should be accurate representations of typical Canadian single detached homes.

A database of building models representative of the Canadian housing stock was created as part of Residential Sector Energy and GHG Emissions Model for the Assessment of New Technologies, a 2010 PhD thesis by Swan [8]. This database was 
intended to be detailed enough to evaluate the performance of new technologies using building performance simulation software. This database consists of approximately 17,000 building models that were constructed based on data measured in approximately 200,000 single-detached, double (duplex), and row houses in Canada [40]. This data is publicly available through Natural Resources Canada's EnerGuide for Houses Database, and was collected as part of the national EnerGuide energy audit program between 1997 and 2006. Information recorded during these audits includes building geometry, construction materials, and air-tightness measured using a blowerdoor test.

Building models from Swan's database were chosen for the present work because of their basis on measured data, their high level of detail, and because they were implemented in whole building simulation software (ESP-r). Three building models were selected, representing houses with below average, approximately average, and above average space heating demand relative to the Canadian average of 131.5 GJ/household [5].

\subsubsection{Model Details}

This subsection presents a summary of the relevant aspects of the selected building models; the interested reader is referred to Swan, 2010 [8] for more details.

These building models are divided into thermal zones, with separate thermal zones assigned to conditioned living spaces on separate floors. A thermal zone was also used to represent the attic space within these models. For simplicity, details such as interior partition walls were omitted. Air flow between the thermal zones and with the outdoors was modelled with an air flow network. Within this network, air flow between zones and the outdoors was driven by wind-induced pressure at openings in the building envelope. Openings include attic vents and windows, which were operated based on a cooling strategy devised by Swan. Infiltration through smaller leakage paths in the building envelope was modelled using the Alberta Air Infiltration Model (AIM-2) [38]. Each building model was configured to represent a sample of houses for which blower-door test measurements were available. These inputs include air-tightness in air-changes per hour at $50 \mathrm{~Pa}$ depressurization $[\mathrm{AC} / \mathrm{h}]$ and estimated leakage area $\left[\mathrm{cm}^{2}\right]$.

In Swan's work, heating and cooling of the buildings was done through ideal zone 
Table 3.1: Comparison of the three building models selected from Swan's database.

\begin{tabular}{ccccc}
\hline & Building 1 & Building 2 & Building 3 & units \\
\hline No. of zones & 3 & 4 & 4 & - \\
No. of conditioned zones & 2 & 3 & 3 & - \\
Conditioned floor area & 166.9 & 315.0 & 209.6 & $\mathrm{~m}^{2}$ \\
Glazing area & 7.8 & 19.3 & 15.5 & $\mathrm{~m}^{2}$ \\
Air-tightness & 7.2 & 3.4 & 15.7 & $\mathrm{AC} / \mathrm{h}$ \\
Estimated leakage area & 976 & 884 & 2922 & $\mathrm{~cm}^{2}$ \\
Basement wall R-value & 2.5 & 2.2 & 1.7 & $\mathrm{~m}^{2} \mathrm{~K} / \mathrm{W}$ \\
Main wall R-value & 2.23 & 2.49 & 0.77 & $\mathrm{~m}^{2} \mathrm{~K} / \mathrm{W}$ \\
Window R-value & 0.53 & 0.53 & 0.53 & $\mathrm{~m}^{2} \mathrm{~K} / \mathrm{W}$ \\
Roof R-value & 5.05 & 5.11 & 0.23 & $\mathrm{~m}^{2} \mathrm{~K} / \mathrm{W}$ \\
Annual heating load & 64.2 & 95.9 & 210.0 & $\mathrm{GJ}$ \\
\hline
\end{tabular}

controls, which inject heating or cooling into the main floor thermal zone to maintain temperatures between $21^{\circ} \mathrm{C}$ and $25^{\circ} \mathrm{C}$. Energy consumption due to heating and cooling was dependent on HVAC system characteristics, which were specified using an idealized HVAC file. This approach does not model individual HVAC components in detail, but interacts with the building domain solver during simulation to calculate energy consumption. Natural gas or electricity consumption are calculated using the HVAC characteristics and the amount of heating or cooling provided at each time-step.

In Swan's original models, occupant behaviour was included through domestic hot water (DHW) draw profiles, non-HVAC electrical use profiles, and casual gains due to heat released by people and appliances. These profiles were created based on assumptions about the numbers of adult and child occupants residing in each household.

The annual heating loads presented in Table 3.1 were obtained by running simulations at a one-hour time-step with idealized zone controls. They do not represent primary energy consumption, but rather the amount of heating energy injected at the indoor air-point. These simulations were run without any casual heat gains due 


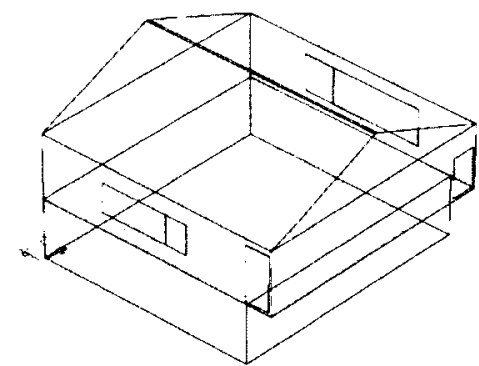

(a) Building 1

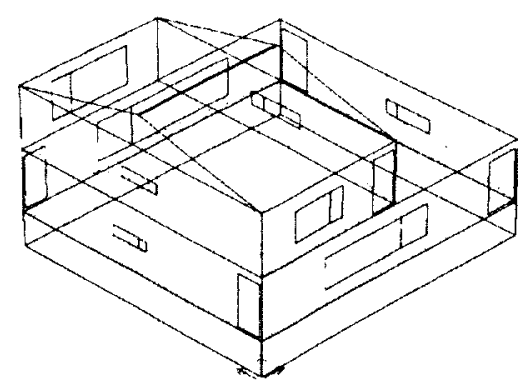

(b) Building 2

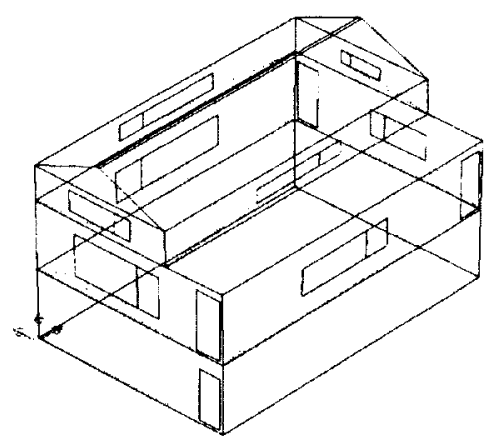

(c) Building 3

Figure 3.1: Wireframe representations of the single-detached building models selected from Swan's database [8].

to occupancy, using Ottawa weather data described in Section 3.3.

\subsubsection{Modifications to the building models}

Some modifications were made to the building models described above. These modifications either removed detail not required for the present work, or removed aspects inconsistent with the aims of the present work. Idealized zone heating control and idealized HVAC models were removed, since heating was to be provided by the PEMFC device and plant. Air flow between the basement and main zone was imposed at $0.5 \mathrm{~kg} / \mathrm{s}$ to give a temperature difference of approximately $3^{\circ} \mathrm{C}$ during winter. All aspects of building occupancy were removed, including Swan's DHW draw profiles, 
non-HVAC electric load profiles, and casual gains due to appliances and people. These were modelled according to the cases described in Section 3.4. Window operation behaviour was also removed, since this would primarily affect cooling loads during the summer rather than the heating load placed on the PEMFC device.

\subsection{Weather Data}

Canadian weather for energy calculations (CWEC) data was used in this work. CWEC files are composed of 12 typical meteorological months taken from Canadian Energy and Engineering Data Sets (CWEEDS) measured between 1953 and 1995. A CWEC file does not correspond to one particular year; rather it is a compilation of typical months that will produce average heating and cooling loads in a building model. Details about the statistical process used to compile CWEC files, as well as which years were used for each CWEC file are available in the user's manual provided by the National Climate Data and Information Archive [41].

The following six parameters contained in CWEC files are read by ESP-r during simulation: diffuse horizontal solar radiation $\left[\mathrm{W} / \mathrm{m}^{2}\right]$, external dry bulb temperature $\left[{ }^{\circ} \mathrm{C}\right]$, direct normal solar intensity $\left[\mathrm{W} / \mathrm{m}^{2}\right]$, wind speed $[\mathrm{m} / \mathrm{s}]$, wind direction $\left[{ }^{\circ}\right]$, and relative humidity. Data in CWEC files are given at one-hour intervals.

To limit the number of test cases requiring simulation, it was decided to use only one location and weather file. Ottawa is a population centre with relatively high heating loads by Canadian standards. This makes it a reasonable place to study micro-cogeneration viability, since the thermal output of a device is more likely to be well-utilized. For this reason, Ottawa was chosen for the study location. Weather data measured at the Ottawa International Airport was selected, and is available through the standard distribution of ESP-r (http://www.esru.strath. ac.uk/Programs/ESP-r_central.htm).

\subsection{Occupant Model}

The behaviour of occupants has an impact on the thermal and electrical performance of the building they reside in. Their behaviour determines the timing, magnitude, and duration of casual gains, DHW draws, and non-HVAC electrical loads. This behaviour is stochastic in nature, and was modelled using a combination of measured profiles, 
Table 3.2: Comparison of occupancy cases.

\begin{tabular}{cccc}
\hline Occupancy Type & Low & Medium & High \\
\hline \hline Number of adults & 1 & 2 & 2 \\
Number of children & 1 & 2 & 3 \\
Non-HVAC electrical load profile & $\mathrm{H} 2$ & $\mathrm{H} 6$ & $\mathrm{H} 9$ \\
Annual non-HVAC electrical load $[\mathrm{kWh}]$ & 2641 & 6373 & 10120 \\
Average daily DHW draw $[\mathrm{L}]$ & 100 & 200 & 300 \\
\hline
\end{tabular}

stochastic methods, and schedules. For the purposes of this work, the other effects of occupant behaviour were treated in less detail. Heating and cooling temperature set-points were assumed to remain constant throughout the year. The Low, Medium, and High occupancy cases modelled are compared in Table 3.2, and are elaborated on in the following subsections.

\subsubsection{Occupant Heat Gains}

Occupant heat gains are the heat gains released in buildings by the people inside them. It is important to model these heat gains because they can significantly impact the heating load that an HVAC system must meet, especially in low energy consuming homes. The amount of heat released by building occupants depends on the metabolic intensity of the activity they are performing. The heat released is both sensible and latent; it was assumed that the two make up fractions of 0.6 and 0.4 of the total, respectively. The sensible amount is transferred from the occupant convectively and radiatively; these amounts were assumed to be 0.5 and 0.5 of the total, respectively. These ratios are for the activity level "seated, very light work" and were measured by the American Society of Heating, Refrigerating, and Air-Conditioning Engineers (ASHRAE) Handbook of Fundamentals [1]. Typical values for metabolic heat generation for varying levels of activity are given in Table 3.3. These are total amounts that include both sensible and latent heat released.

Casual gains due to occupants were added to the main floor zone using a simple schedule given in Table 3.4. This schedule divides the day into 4 periods where the building occupants are either sleeping, awake, or out of the house. For simplicity, 
Table 3.3: Typical metabolic heat generation for adults and children due to different levels of activity [1].

\begin{tabular}{|c|c|c|}
\hline Activity & $\begin{array}{c}\text { Adult heat } \\
\text { generation }[\mathrm{W}]\end{array}$ & $\begin{array}{c}\text { Child heat } \\
\text { generation [W] }\end{array}$ \\
\hline Sleeping & 72 & 54 \\
\hline Sitting & 108 & 81 \\
\hline Standing & 126 & 95 \\
\hline
\end{tabular}

the same schedule was assumed for weekdays and weekends. Occupant heat gains for these periods were calculated by multiplying the values given in Table 3.3 by the number of adults and children present. To obtain values for the waking period, averages of the sitting and standing generation rates were taken. Occupant heat gains were added to the main floor thermal zone. This is a simplification, as these gains would also be present on the second floor in Building 2 and Building 3 . However, the circulation of air between occupied zones imposed by the air flow network distributes these gains throughout the building.

\subsubsection{Non-HVAC Electrical Load Profile}

Consumption of electricity within the building that is not due to the building's HVAC components or DHW production will be referred to as the non-HVAC electrical load. This load is due to the electrical consumption of appliances and lighting within a building. Consequently, this load is highly dependent on occupant behaviour. To model this load, measured data obtained as part of a project to characterize electricity use in 12 Ottawa-area single-detached residential houses [42] were used. These 12 profiles have a one minute resolution in time and are sorted into low, medium, and high energy consumption categories. These categories are based on those used by Armstrong et. al, which were determined to be typical based on government surveys and appliance manufacturer data [43]. Profiles H2, H6, and $\mathrm{H} 9$ were chosen from the low, medium, and high consumption categories, respectively (see Table 3.2). These were assigned to occupancy cases A, B and C, respectively. This assumes that households with more occupants will consume more electricity.

Appliances, lighting, and other electricity consuming equipment transfer heat to their surroundings. This can be understood by considering the energy balance on 
each of these components - high quality electrical energy enters a component and the same amount must leave as low quality heat energy. This heat is transferred to the component's surroundings both radiatively and convectively - these amounts were assumed to be 0.5 and 0.5 of the total electrical draw, respectively. In reality, this fraction varies greatly between devices [1]. However, the profiles used here do not differentiate between appliances, so the approximation of equal radiative and convective fractions was used. In ESP-r, this heat transfer was implemented by specifying the electrical load profile as a Type 5 casual gain. It was assumed that the heat gain due to appliances, lighting and other equipment is $100 \%$ sensible. Dishwashers and clothes dryers are exceptions to this, but for simplicity latent gains were assumed to be negligible.

\subsubsection{Stochastic DHW model}

DHW draws are also highly dependent on occupant behaviour, and are therefore stochastic in nature. It is important to model DHW draws accurately because they can represent a large part of the load heating systems must meet within a building, especially during summer. A stochastic DHW draw model was used rather than measured profiles since the model allowed for more freedom in choosing the average daily draw volume.

This model determines the DHW draw at each time-step during simulation based work presented in a 2000 paper by Jordan \& Vajen [44]. Four draw types are assumed: short load, medium load, bath and shower. Each has a constant duration, mean flow rate, standard deviation from the mean flow rate, and the fraction of the daily draw that is of this type. A probability function is used to determine what, if any, draw is present at each time-step. The model also includes seasonal sinusoidal variation and phase-shift to account for more DHW being used in winter. Draws are distributed throughout the day based on schedule consistent with the occupancy schedule given in Table 3.4, which can be found in the plant network files given in Appendix C, pg. 106. Make up water is drawn from the city water mains, and assumed to be at $10^{\circ} \mathrm{C}$. 
Table 3.4: Occupancy schedule. Note: heat gain values are combined radiative and sensible amounts.

\begin{tabular}{ccccc}
\hline Time (hh:mm) & Activity & $\begin{array}{c}\text { Adult occupant } \\
\text { heat gain [W] }\end{array}$ & $\begin{array}{c}\text { Child occupant } \\
\text { heat gain [W] }\end{array}$ & $\begin{array}{c}\text { DHW draw } \\
\text { distribution }\end{array}$ \\
\hline \hline 23:00-07:00 & Sleeping & 72 & 54 & 0.1 \\
07:00-09:00 & Awake & 117 & 88 & 0.5 \\
09:00-17:00 & Unoccupied & 0 & 0 & 0.1 \\
17:00-23:00 & Awake & 117 & 88 & 0.3 \\
\hline
\end{tabular}

\subsection{Plant Components}

HVAC components were selected from a database of built-in models available in the standard distribution of ESP-r. Detailed descriptions of many of these components can be found in Henson, 1991 [7], and other publications cited below. The full list of configuration parameters for each plant component model used in this thesis can be found in the plant network files in Appendix C.

\subsubsection{Annex 42 Fuel Cell Model and PEMFC Calibration}

This study uses the fuel cell (FC) cogeneration device model developed by participants in Annex 42 of the International Energy Agency's Energy Conservation in Buildings and Community Systems Programme (IEA/ECBCS). A detailed description of the model can be found in the Annex 42 final report [30] and in Beausoleil-Morrison \& Kelly, 2007 [45]. The Annex 42 FC model is based on a 'grey box' approach, where both analytical and empirical relationships are used to represent mass and energy balances on the model's 14 control volumes. These volumes represent: (i) the fuel cell power module (FCPM), where the main energy balance determining electrical efficiency and fuel consumption is solved, (ii) the power conditioning unit (PCU), where FCPM DC output is converted to AC power, and (iii) the stack cooler subsystem, where the rate of heat transfer to coolant water is calculated. AC power consumption of components internal to the FC device and heat loss to the surroundings are also modelled. Changes in FCPM DC output are constrained by maximum increasing and decreasing rates of change $[\mathrm{W} / \mathrm{s}]$. Start-up and shut-down time, net power production, and fuel composition are also included as model inputs. 
The Annex 42 FC model accepts 134 input parameters, allowing it to be calibrated to represent the steady-state and transient behaviour of real FC devices. Experimental calibration of the Annex 42 model to represent a Solid Oxide Fuel Cell (SOFC) is presented in Beausoleil-Morrison \& Lombardi, 2009 [31], and the empirical validation of this calibrated model is presented in Beausoleil-Morrison, 2010 [17]. The model used in this work has been experimentally calibrated to represent a $1.0 \mathrm{~kW}_{A C}$ PEMFC unit by Johnson et al., 2012 [9]. Steady-state tests were performed to determine electrical and thermal efficiency over a range of operating conditions, and transient tests were performed to estimate maximum FCPM DC modulation rates. This calibration has been validated by compared measured and modelled performance [9]. The calibration parameters found are given in the ESP-r plant network files in Appendix C.

The model accepts a unitless control signal $S_{p e m f}$, which sets $P_{e l}$, the DC output of the FCPM. $P_{e l}$ is constrained by the PEMFC's maximum and minimum DC output. These are $P_{e l, \max }=1113 \mathrm{~W}$, and $P_{e l, \min }=314 \mathrm{~W}$, respectively. Within these limits, the control signal sets $P_{e l}$ as a fraction of its maximum, according to Equation 3.1:

$$
P_{e l}=P_{e l}=S_{p e m f} \eta_{p c u f c} \eta_{p c u} \eta_{p a x} P_{e l}+P_{e l, a n c}+P C U_{\text {losses }}
$$

The first right-hand side term gives the demand for power in $\mathrm{AC}$ using the $\mathrm{PCU}$ efficiency $\eta_{p c u}$, which is a polynomial function of $P_{e l}$ at the previous iteration. A DC value is obtained by adding losses from the PCU $\left(P_{l o s s}\right)$ and ancillary power consumption $P_{e l, a n c}$. The following equation gives the total efficiency $\eta_{t o t}$ as a function of the PEMFC DC output and inlet water temperature $T_{w-i n}$ :

$$
\eta_{t o t}\left(P_{e l}, T_{i n}\right)=\eta_{e l, d c}\left(P_{e l}\right) \eta_{p c u}\left(P_{e l}\right)+\eta_{t h e r m}\left(P_{e l}, T_{w-i n}\right)
$$

The first right-hand side term is the AC electrical efficiency, which is a product of the DC efficiency $\eta_{e l, d c}$ and the PCU efficiency (both functions of $P_{e l}$ ). The thermal efficiency $\eta_{\text {therm }}$ is a function of both $P_{e l}$ and the inlet coolant water temperature. This total efficiency for the calibrated PEMFC device model is shown in Figure 3.2. 


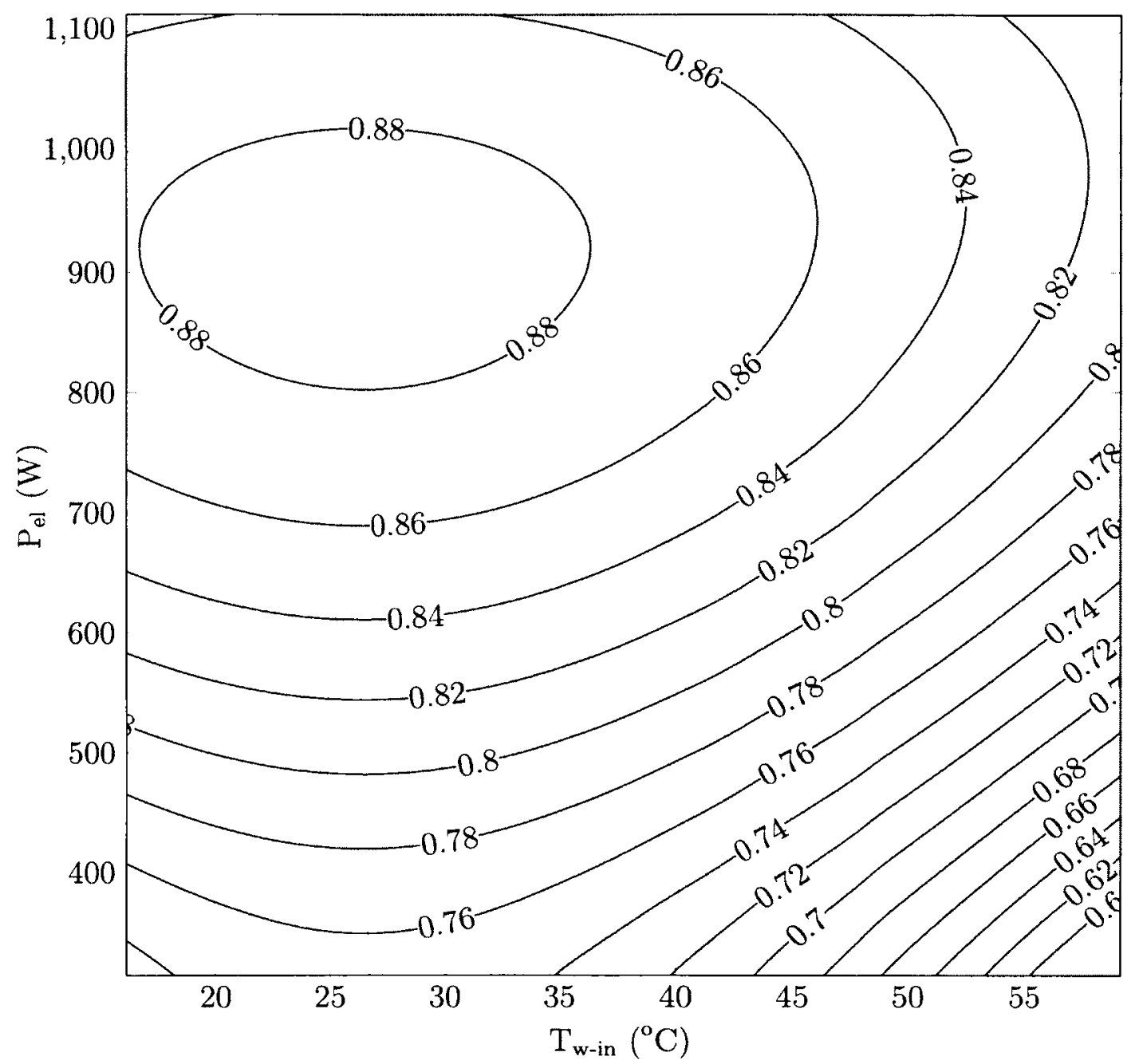

Figure 3.2: PEMFC total efficiency (LHV) map calculated using the Annex 42 fuel cell model with calibration data from Johnson et al., 2012 [9].

\subsubsection{Other HVAC Component Models}

To model the water tanks used to store thermal energy in the plant domain, a 3node stratified tank component was used. This tank model is based on the TRNSYS Type 60 component, the development of which is described in a 1995 Master's thesis by Newton [46]. The implementation of this model in ESP-r was carried out by Thevenard \& Haddad in 2010 [47]. The model includes up to two immersed helical coil heat-exchangers and an open inlet and outlet. The tanks modelled in this research were assumed to be cylindrical, $1.5 \mathrm{~m}$ in height, and highly insulated with an R-value 
of $10 \mathrm{~m}^{2} \mathrm{~K} / \mathrm{W}$.

To model the heat dump used to dissipate excess heat generated by the PEMFC, a single-node water cooling component was used. This component accepts one control variable that sets the heat extraction rate $[\mathrm{W}]$ from the water passing through it. Implementing a real heat dump in a residential building would require a number of HVAC components. One possible implementation of a heat dump was demonstrated in Bell et al., 2005 [48]. This experimental study used a glycol loop and heat exchanger to transfer heat generated by an SOFC device to an air-handling unit. This heat was then dissipated to the outdoors using a fan. Such a sytem would include a fan and pump, and might consume approximately $125 \mathrm{~W}$ of electricity during heat dump operation (see Section 3.6). This would impose a cost on heat dump operation, and heat extraction rates would vary dynamically with the temperatures of coolant water and outdoor air. In the present work, a simpler approach was taken to reduce the complexity of the modelled plant configurations.

Pumps and fans were modelled using single-node variable flow-rate components. These models accept one control variable that sets the volumetric fluid flow $\left[\mathrm{m}^{3} / \mathrm{s}\right]$ through the component. In-line heaters were modelled using single-node gas boiler components. This model accepts one control variable that sets the heat flux [W] delivered to the water passing through it. Water-air heat exchangers were modelled using a 3-node air heating coil component. Control volumes containing air surrounding the coil, water within the coil, and the coil itself are each represented by a node. The air and water nodes are coupled to the solid node by two thermal resistances that depend on the coil geometry and material properties.

The stratified tank and in-line heaters both transfer heat to their surroundings according to the equation:

$$
\dot{q}=U A \Delta T
$$

where $\dot{q}$ is the rate of heat loss, $U$ is the component's overall heat transfer coefficient $\left[\mathrm{W} / \mathrm{Km}^{2}\right], A$ is the component's surface area $\left[\mathrm{m}^{2}\right]$, and $\Delta T$ is the temperature difference between the component and the air of its containment zone [K]. For all building models, the containment zone was assumed to be the basement. 


\subsubsection{Component Sizing}

It is important to size HVAC components to meet the load that will be placed on them. For example, an over-sized furnace will cycle on and off rapidly since it will deliver more heat to the indoor air than necessary. If undersized, it will not deliver enough heat to meet peak loads, and the zone will fall below a comfortable temperature. Table 3.5 shows the component sizes used for the three building/occupant models. Tank volumes are not included in Table 3.5 as they are part of the optimization described in Chapter 5.

Space heating components were sized for each building model with the medium occupancy level. The space-heating pump, fan, and in-line heater $\cdots$ sh-pump, fan, and spc-heater, respectively - were sized to meet the heating load of the coldest week of the year, which occurred over January 25-31 in the weather data. Simulations to determine sizing were run at a one-minute time-step over this week. The sh-pump and fan component flow rates were set to keep the fluid heat capacity rate $(\dot{c})$ the same for both air and water streams $\left(\dot{c}_{w}=\dot{c}_{a}\right)$. The fan flow rate $\left(\dot{v}_{a}\right)$ was determined using the following equation:

$$
\dot{v}_{a}=\frac{c_{p, w} \rho_{a}}{c_{p, a} \rho_{w}} \dot{v}_{w}
$$

where $\dot{v}_{w}$ is the volumetric flow rate of water through the heat exchanger $\left[\mathrm{m}^{3} / \mathrm{s}\right], \rho_{a}$ and $\rho_{w}$ are the densities of air and water $\left[\mathrm{kg} / \mathrm{m}^{3}\right]$, respectively, and $c_{p, a}$ and $c_{p, w}$ are the heat capacities of air and water $[\mathrm{J} / \mathrm{kgK}]$, respectively, all at STP. The in-line heater capacity was set to ensure that the main zone temperature did not fall below $20.5^{\circ} \mathrm{C}$ during the design week.

The DHW heater was sized to meet the peak DHW load. This heat output was not changed between occupancy cases, since flow rates and durations of the DHW draw types remained constant between cases. Though the total daily draw differed between occupancy cases, this served to increase the frequency of draws rather than the instantancous demand for heat. The flow rate of the fc-pump was set to $0.07 \mathrm{~L} / \mathrm{s}$, which is at the centre of the range explored experimentally by Johnson \& BeausoleilMorrison [9]. The rate of heat extraction by the heat-dump component was sized to be substantially greater than the maximum rate of heat production by the PEMFC. 
Table 3.5: Component sizing by building model. Note: * indicates component is only present in the 2-tank plant (described in Chapter 4).

\begin{tabular}{ccccc}
\hline & Building 1 & Building 2 & Building 3 & units \\
\hline \hline fc-pump & 0.07 & 0.07 & 0.07 & $\mathrm{~L} / \mathrm{s}$ \\
sh-pump & 0.15 & 0.20 & 0.25 & $\mathrm{~L} / \mathrm{s}$ \\
bt-pump* & 0.15 & 0.15 & 0.15 & $\mathrm{~L} / \mathrm{s}$ \\
fan & 0.52 & 0.69 & 0.86 & $\mathrm{~m}^{3} / \mathrm{s}$ \\
spc-heater & 15 & 20 & 25 & $\mathrm{~kW}$ \\
dhw-heater & 10 & 10 & 10 & $\mathrm{~kW}$ \\
heat-dump & 5 & 5 & 5 & $\mathrm{~kW}$ \\
\hline
\end{tabular}

\subsection{Electrical Model}

The power producing/consuming components described above are assumed to be connected to a central bus bar which is capable of importing or exporting power from the grid. The non-HVAC electrical load profile described in Subsection 3.4.2 is also connected to this bus. All components are assumed to be single-phase and $120 \mathrm{~V}$. The full definition of this network can be found in the ESP-r electrical network files referenced in Appendix E, pg. 122.

Pump and fan models calculate electricity consumption using the following equation:

$$
P_{d r a w}=\left(\frac{\dot{V}}{\dot{V}_{r}}\right)^{3} P_{\text {rated }}
$$

where $P_{\text {draw }}$ and $P_{\text {rated }}$ are the present time-step and rated electricity consumption [W], respectively, and $\dot{V}$ and $\dot{V}_{r}$ are the present time-step and rated volume flow rates $\left[\mathrm{m}^{3} / \mathrm{s}\right]$, respectively. This calculation is actually performed in the plant domain but is passed to the electrical network.

Pumps were assumed to be Grundfos model UP 10-16 B5 pumps, which have a power draw of $25 \mathrm{~W}$ and flow rates in the range specified in Table 3.5 [49]. Space heating fans were assumed to be high-efficiency electronically commutated motor (ECM) models, with a power consumption of $100 \mathrm{~W}$. This value is typical for ECM fans for space heating according to a study conducted by the Canadian Centre of Housing Technology (CCHT) [50]. 
The following chapter describes the configuration and control of the two plant networks implemented as part of thesis. 


\section{Chapter 4}

\section{Plant Configuration and Control}

\subsection{Plant Configuration}

The thermal plant is defined here as the system of HVAC components that stores, adds to, and delivers the thermal output of a micro-cogeneration unit. The thermal plant must meet the following requirements:

- dispatch PEMFC thermal output to meet space-heating and DHW loads

- integrate auxiliary heaters to meet household demands exceeding PEMFC thermal production

- integrate thermal storage appropriate to the PEMFC heat output and building loads

- accommodate the chosen control strategy

A survey of past simulation-based and experimental research shows that thermal plants for cogeneration containing both one or two storage tanks have been studied [22], [29], [32], [51]. 2-tank plant configurations can be more costly to implement and more complex to control compared to 1-tank plants. They have been studied primarily for two reasons: (i) they allow space heating water and DHW to be provided at different temperatures, and (ii) they can more easily include a large, seasonal storage volume. In keeping with the goals outlined in Section 1.3, both 1 and 2-tank plant configurations were designed as part of the present work. These plants and their control are described in the following subsections. For details about the modelling and sizing of these components, see Chapter 3 . 
The capacity to provide space cooling was not included in the thermal plants implemented as part of this research. It was assumed that cooling would be provided through other HVAC equipment such as an air-conditioner or air-source heat pump. To model this, the ideal zone controls facility in ESP-r was used. Up to $10 \mathrm{~kW}$ of cooling was injected at the main zone air node to keep the dry bulb temperature from exceeding $25^{\circ} \mathrm{C}$ during the cooling season. This served to keep zone temperatures within realistic limits during the cooling season.

\subsubsection{1-tank Configuration}

Figure 4.1 is a schematic diagram of the 1-tank plant designed as part of this work. Heat exchangers are represented by resistors, and the locations marked with letters indicate where temperature/mass flow rates are measured for the purpose of control (described in Section 4.2). In this configuration, water from the thermal storage tank (volume $V_{1}$ ) is circulated directly to the PEMFC by a pump. In order to minimize the PEMFC inlet temperature, coolant water is drawn from the tank bottom and returned to the tank top. A heat-dump is located at the inlet of the PEMFC to limit the inlet temperature to $60^{\circ} \mathrm{C}$, which is required to prevent overheating of the device.

In this configuration, DHW water is not stored as it would be in a typical Canadian house; rather it is drawn from the mains and heated on-demand. This is done because of conflicting requirements for the storage tank temperature. If DHW were stored inside the tank, the tank temperature would need to be at or above $51{ }^{\circ} \mathrm{C}$ as recommended by ASHRAE Guideline 12-2000 [52] to prevent the growth of legionella bacteria. However, because the PEMFC inlet temperature is limited to $60^{\circ} \mathrm{C}$, this would leave little potential for charging and discharging the tank of thermal energy. Instead of this, mains water is heated as it passes through a heat exchanger extending the full height of the tank when a DHW draw exists. An in-line heater at the tank outlet ensures that DHW does not leave the plant below a temperature required for domestic uses $\left(45^{\circ} \mathrm{C}\right)$.

Space heating is delivered using a fan coupled with an air-water heat exchanger. Hot water from a heat exchanger internal to the storage tank is circulated to the air-water heat exchanger when a space-heating load exists. An in-line heater in this circuits ensures that heating loads exceeding the PEMFC capacity are met. 


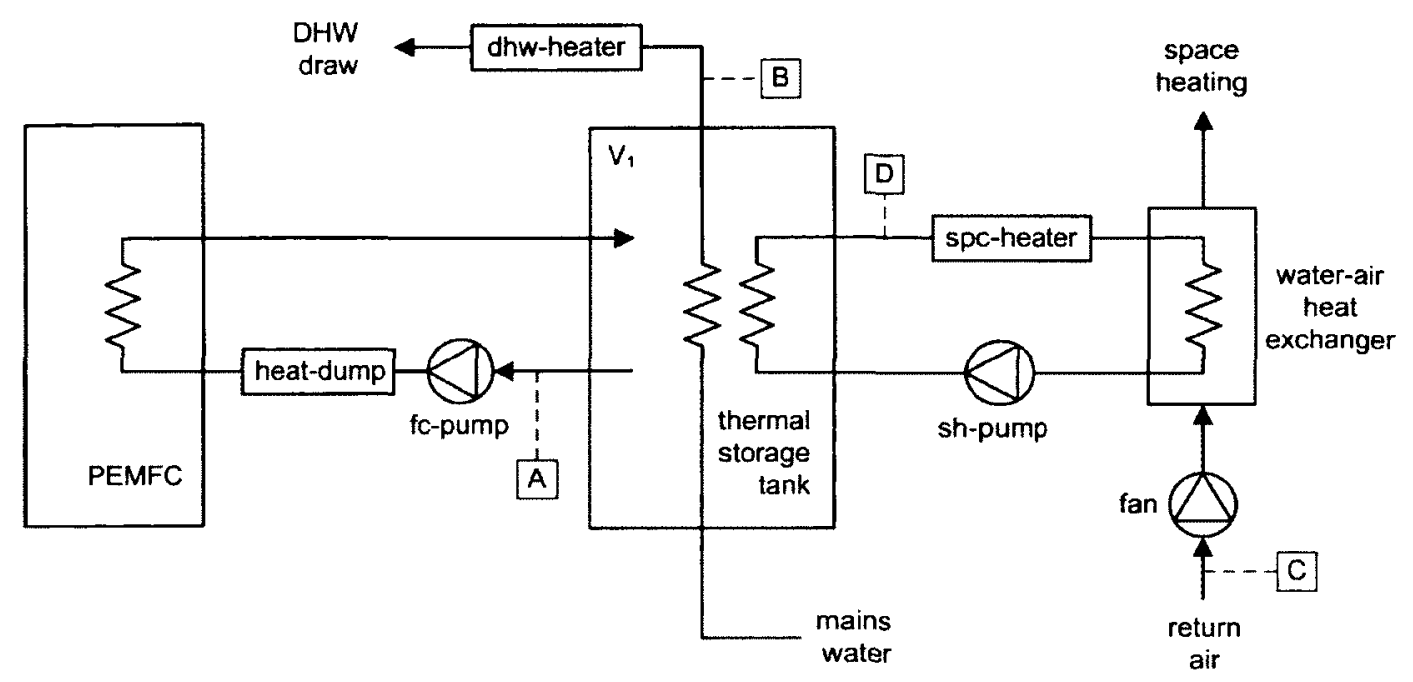

Figure 4.1: 1-tank thermal plant configuration.

\subsubsection{2-tank Configuration}

Figure 4.2 is a schematic diagram of the 2-tank plant modelled. In this configuration, coolant water for the PEMFC device is circulated to the DHW tank (volume $V_{1}$ ) by a pump. Coolant water is circulated through a heat exchanger extending the full height of the tank, exiting at the cooler tank bottom in order to minimize PEMFC inlet temperature.

In this configuration, DHW is stored rather than drawn on-demand. The DHW tank top should be maintained at $55^{\circ} \mathrm{C}$ in order to prevent the growth of legionella. This means that the inlet temperature of the PEMFC will likely be higher in the 2-tank configuration than the 1-tank configuration, and that the device's electrical efficiency will be somewhat lower. DHW water is drawn directly from the tank top, and mains water is added to the tank bottom to replace it.

The pump between the two tanks transfers heat from the DHW tank to the space-heating tank. This prevents the DHW tank from overheating, thus limiting the PEMFC inlet temperature to a safe range. This heat transfer also provides heat to the space-heating circuit. The space-heating circuit is identical to that of the 1-tank configuration, except for the addition of a heat dump downstream of the space-heating pump. The heat dump is placed here rather than at the PEMFC inlet to ensure that the space-heating tank is kept at a temperature low enough to allow the transfer of heat from the DHW tank, even when no demand for space heating exists. This allows 


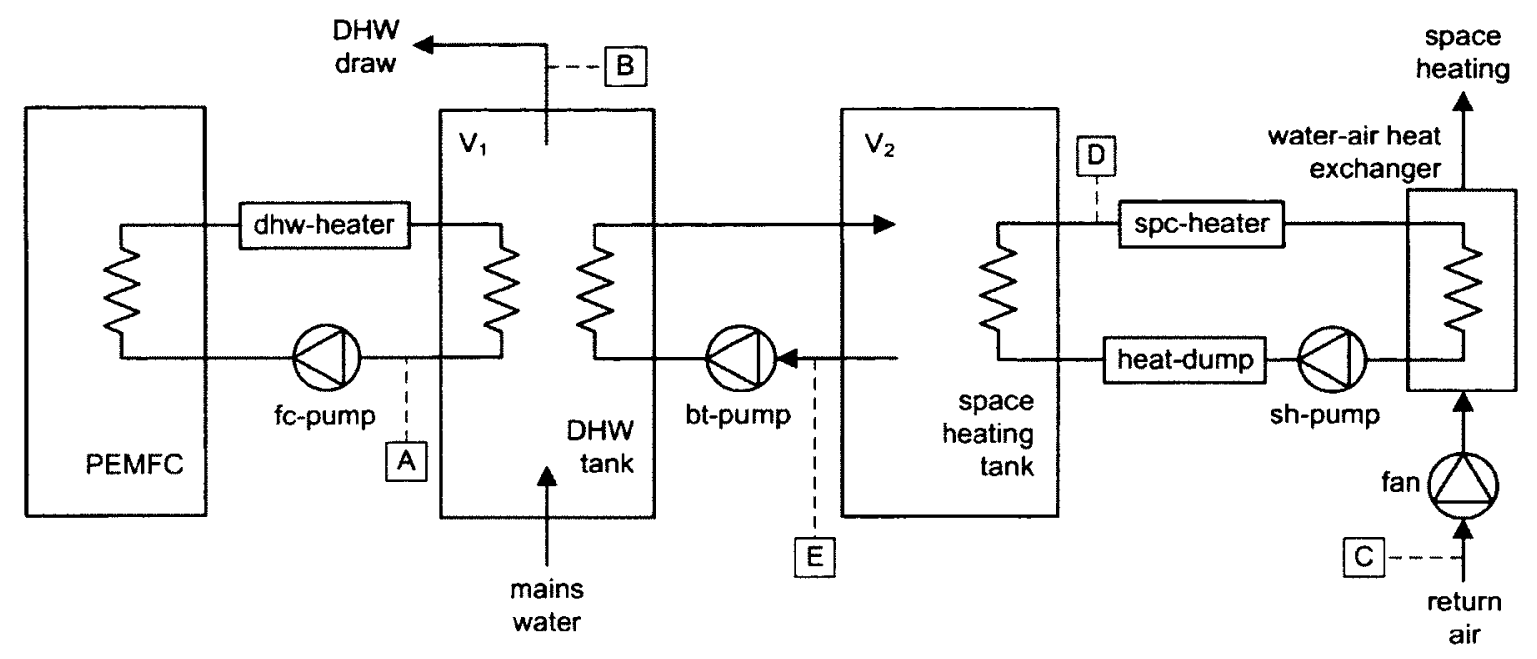

Figure 4.2: 2-tank thermal plant configuration.

the between-tank pump to be controlled in the same manner year round. Locating the heat dump in the space heating water circuit does reduce the applicability of this configuration to Canadian households. The air-water heat exchanger used for space heating during winter is often used to provide space cooling during summer. This means that circulating hot water through this heat exchanger would have the unwanted side effect of heating the house during summer. If this configuration were to be implemented in a real building, more plumbing would be required to re-direct hot water around the air-water heat exchanger during summer.

A heater was placed at the PEMFC outlet to maintain the DHW set-point, should the PEMFC thermal output not be enough. The possibility that this heater is not required to maintain set-point will be discussed further in Chapter 7 . In this configuration, DHW drawn from the tank is hotter than the $45^{\circ} \mathrm{C}$ necessary for domestic use. In a typical residential HVAC plant, this water would be mixed with mains water in a mixing valve to decrease its temperature. Rather than modelling this, The DHW draws described in Subsection 3.4.3 are reduced for this configuration. The reduced mass flow rate from the tank can be calculated with an energy balance on the mixing valve:

$$
\dot{m}_{t} h_{f, t}+\dot{m}_{m} h_{f, m}=\dot{m}_{v} h_{f, v}
$$

where $h_{f}$ terms are enthalpies of liquid water and $\dot{m}$ terms are mass flow rates. The subscripts $t, m$, and $v$ denote water from the tank outlet, mains, and mixing valve 
outlet, respectively. These are assumed to be at $10^{\circ} \mathrm{C}, 55^{\circ} \mathrm{C}$, and $45^{\circ} \mathrm{C}$, respectively. Applying conservation of mass and assuming constant water density, Equation 4.1 becomes:

$$
\frac{V_{t, \text { daily }}}{V_{v, \text { daily }}}=\frac{h_{f, v}-h_{f, m}}{h_{f, t}-h_{f, m}}
$$

where $V_{t, \text { daily }}$ and $V_{v, \text { daily }}$ are the nominal daily hot water draws measured at the tank outlet and the valve outlet, respectively. The draws given in Table 3.2 occur downstream of the mixing valve, so these amounts should be multiplied by the volume fraction $\frac{V_{t, \text { daily }}}{V_{v, \text { daily }}}$ for the 2-tank plant. Using $h_{f, m}=42.022 \mathrm{~kJ} / \mathrm{kg}, h_{f, t}=230.26 \mathrm{~kJ} / \mathrm{kg}$, and $h_{f, v}=188.44 \mathrm{~kJ} / \mathrm{kg}$ [3], Equation 4.2 gives a volume fraction of 0.77783 , yielding modified daily DHW draws of $77.78 \mathrm{~L}, 155.57 \mathrm{~L}$, and $233.35 \mathrm{~L}$ for the Low, Medium, and High occupancy cases, respectively.

\subsection{Control}

Control signals set the state of plant components at each future time-step during simulation of the plant domain. These signals are determined using sensed temperatures and mass flow rates within the plant and building domains. This control action is performed by a new ESP-r subroutine ${ }^{1}$ that was written as part of the present research. The ESP-r source code was modified to include a call to this subroutine at each iteration of the plant solver immediately before the plant matrices are updated. The following subsections describe the logic and structure of the plant control subroutine.

\subsubsection{PEMFC Control}

Control of the PEMFC was structured so that four modes of operation were possible; these are listed in Table 4.1. The mode number was set in a text input file, which was read by the controller at the beginning of simulation. ${ }^{2}$

The constant control was the simplest mode implemented. For this control, the PEMFC DC electrical output $\left(P_{e l}\right)$ was set to maximum during the heating season and minimum during the cooling season. These outputs correspond to control signals

\footnotetext{
${ }^{1}$ Fortran source code for the control subroutine is included in Appendix B, pg. 96.

${ }^{2}$ Details of this process can be found in Section 5.5 , pg. 55 .
} 
Table 4.1: Modes of control implemented for the PEMFC.

\begin{tabular}{cc}
\hline Mode & Control \\
\hline \hline 1 & Constant \\
2 & Tank Temperature Following \\
3 & Electrical Price Following \\
4 & Hybrid \\
\hline
\end{tabular}

of 1 and $S_{\min }$, respectively, where $S_{\min }$ is given by:

$$
S_{\min }=\frac{P_{e l, \min }}{P_{e l, \max }}
$$

The minimum output was chosen for the cooling season because of the lower demand for heat during this time.

In tank temperature following mode, the PEMFC output is modulated with the outlet water temperature ( $T_{A}$ in Figs. 4.1 and 4.2) of the tank it is coupled to. Outlet rather than average tank temperature was used to eliminate the need for the array of internal sensors necessary to determine average tank temperature in an actual implementation. The control signal $S_{\text {therm }}$ is calculated using the following equation:

$$
S_{\text {therm }}^{t+\Delta t}=\left\{\begin{array}{cl}
S_{\min } & \text { if } T_{A}^{t}>T_{2}, \\
\frac{S_{\min }-1}{T_{2}-T_{1}} T_{A}^{t}+\frac{T_{2}-S_{\min } T_{1}}{T_{2}-T_{1}} & \text { if } T_{1} \leq T_{A}^{t} \leq T_{2}, \\
1 & \text { if } T_{A}^{t}<T_{1} .
\end{array}\right.
$$

where $T_{1}$ and $T_{2}$ are set-point temperatures that satisfy the condition $T_{1}<T_{2}$. PEMFC output is at a maximum when $T_{A}^{t}$ is less than $T_{1}$, and a minimum when $T_{A}^{t}$ is greater than $T_{2}$. For $T_{A}^{t}$ between $T_{1}$ and $T_{2}$, PEMFC output increases with decreasing tank outlet temperature. This relationship is shown graphically in Figure 4.3. This control attempts to match the PEMFC thermal output to the heating load in the house. In general, the tank temperature decreases as heat is delivered to meet demands for space heating and DHW. This should cause an increase in PEMFC output to meet the load. The appropriate temperature range for modulation may depend on building and occupancy characteristics, the annual range of temperatures experienced by the coupled tank, and behaviour of other plant components. Note 
that for $T_{1}$ and $T_{2}$ above or below the annual tank temperature range, this control can set PEMFC output to be always at a maximum or minimum, respectively. Since the choice of $T_{1}$ and $T_{2}$ has a significant effect on the performance of the tank temperature following control, these parameters are the subject of an optimization described in the following chapter. Sensing temperature was chosen over directly sensing heat dump operation because the continuously variable temperature was simpler to map to the continuously variable PEMFC electrical output.

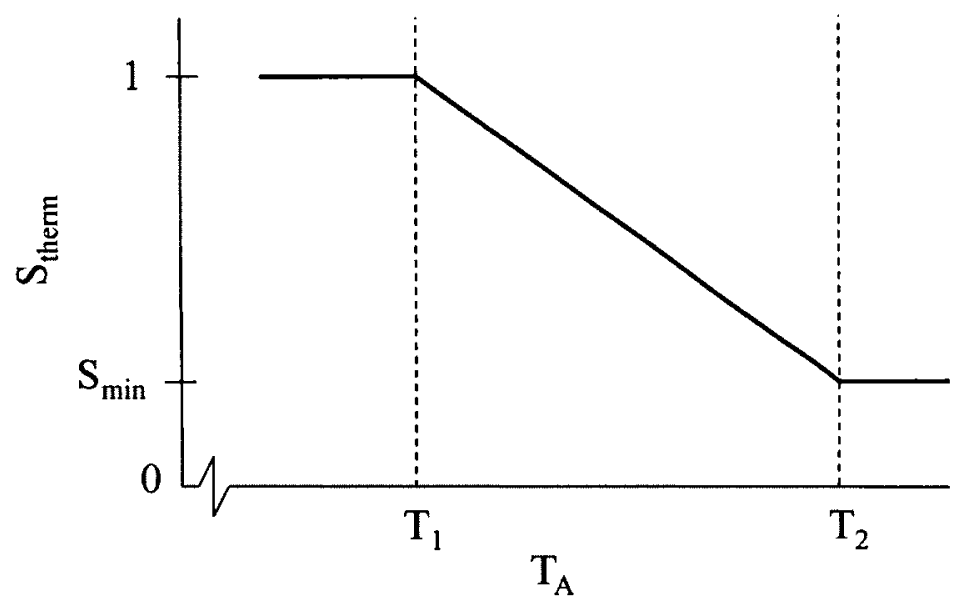

Figure 4.3: Graphical representation of Equation 4.4.

In electrical price following mode, PEMFC output was modulated to follow the buy-back electricity price $R_{\text {elec }}^{t}[\mathrm{c} / \mathrm{kWh}$. Price following was used rather than load following for this mode because parity was assumed between the buying and selling price of electricity (see Subsection 5.4.2 for a discussion of this). As a consequence of this, the non-HVAC load has no effect on the net revenue from PEMFC electrical generation. The control signal $S_{\text {elec }}$ for this mode is calculated as follows:

$$
S_{e l e c}^{t+\Delta t}=\left(\frac{1-S_{\min }}{R_{\max }-R_{\min }}\right) R_{e l e c}^{t}+\frac{S_{\min } R_{\max }-R_{\min }}{R_{\max }-R_{\min }}
$$

where $R_{\min }$ and $R_{\max }$ are the minimum and maximum buy-back prices [ $\mathrm{c} / \mathrm{kWh}$, respectively, and are given in Table 5.3. Equation 4.5 gives a minimum PEMFC output for the minimum buy-back price, and a maximum output for the maximum buy-back price. 
The hybrid mode of operation is a combination of tank temperature following and electrical price following. The hybrid control signal $S_{\text {hybrid }}$ is determined as follows:

$$
S_{\text {hybrid }}=\alpha S_{\text {therm }}+(1-\alpha) S_{\text {elec }}
$$

where $\alpha$ is a weighting factor that meets the condition $0 \leq \alpha \leq 1$. $\alpha$ serves to bias the control signal towards either tank temperature following or electrical price following. $S_{\text {hybrid }}$ is essentially a weighted average of these two signals.

Within the control subroutine, the signal $S_{\text {pemfc }}$ (described in Subsection 3.5.1) is set to the value calculated for the specified control mode. The values of parameters $T_{1}$, $T_{2}$, and $\alpha$ are not specified here as they are the subject of the optimization described in the following chapter.

\subsubsection{Control of Supporting Plant Components}

The fc-pump component was controlled such that it was always on, with a constant flow rate given in Table 3.5. All other components, with the exception of the PEMFC and the dhw-heater in the 1-tank plant, were switched on and off during simulation using a temperature deadband control.

The logic for the deadband control is shown in Figure 4.4. For a heating deadband, an on switch occurs when a sensed temperature $T_{\text {sensed }}$ falls below a set-point $T_{\text {low }}$, and an off switch occurs when $T_{\text {sensed }}$ rises above $T_{\text {high }}$. With a cooling deadband control, an on switch occurs at $T_{\text {high }}$ and off switch at $T_{\text {low }}$. The term deadband is used because no action is taken while the sensed temperature is inside the deadband, i.e. when $T_{\text {low }} \leq T_{\text {sensed }} \leq T_{\text {high }}$ is true. For all dead-band controlled components, set-points $T_{\text {low }}$ and $T_{\text {high }}$, deadband types, and locations at which $T_{\text {sensed }}$ is measured are given in Table 4.2. These locations correspond to the letters shown in Figures 4.1 and 4.2. Previous time-step values of $T_{\text {sensed }}$ are used in order to avoid oscillations in temperature during solver iterations that can result from interactions between the plant solver and control decisions. This should have a negligable impact on the control decisions, as most sensed temperatures within the plant network do not change significantly over one time-step (one minute). For both plant configurations, components in the space-heating circuit - spc-heater, sh-pump, and fan - were operated using a heating deadband to maintain a main zone dry bulb temperature between 
Table 4.2: Control parameters for plant components actuated using a deadband control.

\begin{tabular}{cccccc}
\hline Component & Configuration & Type & Location & $T_{\text {low }}\left[{ }^{\circ} \mathrm{C}\right]$ & $T_{\text {high }}\left[{ }^{\circ} \mathrm{C}\right]$ \\
\hline \hline heat-dump & 1-tank & cooling & A & 57 & 59 \\
heat-dump & 2-tank & cooling & D & 49 & 51 \\
dhw-heater & 2-tank & heating & B & 53 & 54 \\
spc-heater & both & heating & C & 20.5 & 21.5 \\
sh-pump & both & heating & C & 20.5 & 21.5 \\
fan & both & heating & C & 20.5 & 21.5 \\
bt-pump & 2-tank & cooling & B & 54.5 & 55.5 \\
\hline
\end{tabular}

20.5 and $21.5^{\circ} \mathrm{C} .{ }^{3}$ An additional constraint was placed on the spc-heater component - this was switched off if the tank outlet temperature (location D) exceeded $45^{\circ} \mathrm{C}$. This served to prevent the heater from operating when enough stored thermal energy was available to meet a demand for space heating. Components in the space-heating circuit were switched off for the duration of the cooling season, which was assumed to be between June 1 and September 15. For the heat-dump in the 1-tank plant, a

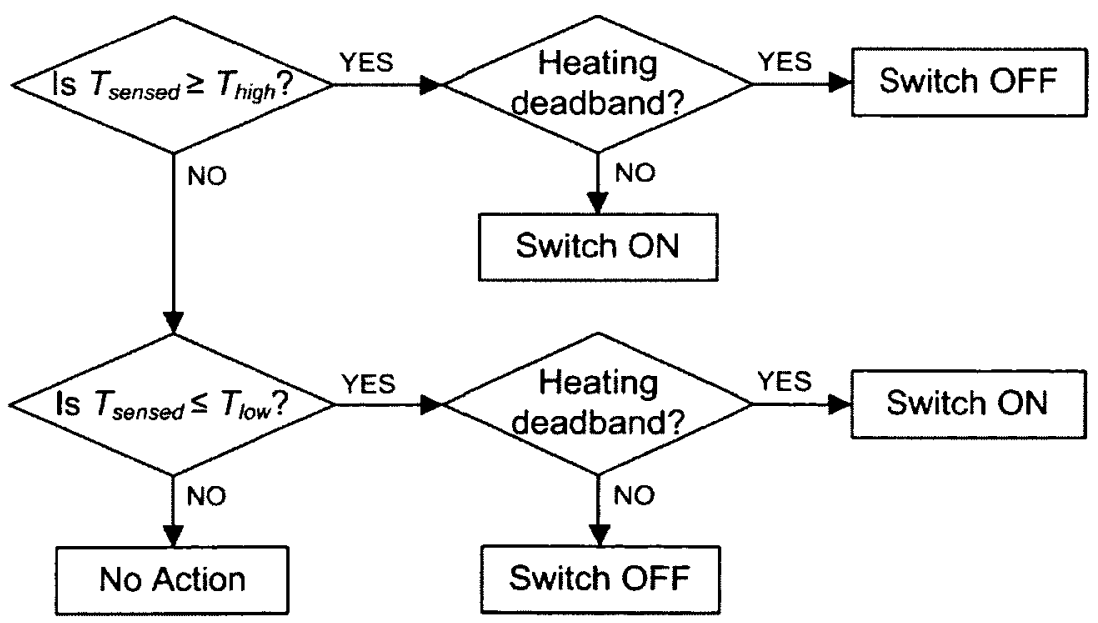

Figure 4.4: Deadband control logic for plant components.

\footnotetext{
${ }^{3}$ The main zone dry-bulb temperature was assumed to be the return air temperature at location $\mathrm{C}$ in Figures 4.1 and 4.2 .
} 
cooling deadband from 57 to $59^{\circ} \mathrm{C}$ was used in order to keep the PEMFC inlet temperature below the $60^{\circ} \mathrm{C}$ limit mentioned in Subsecion 4.1.1. In the 2-tank plant, control over the PEMFC inlet temperature is provided by the bt-pump, which maintains a dhw-tank outlet temperature close to $55^{\circ} \mathrm{C}$. This ensures that water drawn from the tank bottom and sent to the PEMFC inlet will be less than $60^{\circ} \mathrm{C}$. This also keeps the tank at a temperature appropriate for the storage of DHW. The dhw-heater in the 2-tank configuration operates on a heating deadband just below that of the bt-pump, to quickly bring the dhw-tank outlet back up to temperature should it fall below $53^{\circ} \mathrm{C}$. In order for the bt-pump to cool the dhw-tank, the spc-tank heat-exchanger outlet temperature (location E) should be somewhat less than the average dhw-tank temperature. To ensure that this is true even when no space heating load exists, the heat-dump in the 2-tank plant is controlled on a cooling deadband centred on $50^{\circ} \mathrm{C}$.

\subsubsection{Aquastatic DHW Control}

In the 1-tank plant, heat output for the dhw-heater component $\left(\dot{q}_{D H W}\right)$ was modulated to maintain an outlet temperature of $45^{\circ} \mathrm{C}$. Heat output at future time-steps was calculated as follows:

$$
\dot{q}_{d h w}^{t+\Delta t}=\dot{m}_{B}^{t+\Delta t} c_{p, w}\left(T_{d h w}-T_{B}^{t+\Delta t}\right)
$$

where $\dot{m}_{d h w}$ is the DHW mass flow rate $[\mathrm{kg} / \mathrm{s}], \dot{m}_{B}$ the mass flow rate at the heater inlet $[\mathrm{kg} / \mathrm{s}], c_{p, w}$ the heat capacity of water $[\mathrm{J} / \mathrm{kgK}], T_{d h w}$ the DHW set-point temperature $\left(45^{\circ} \mathrm{C}\right)$, and $T_{B}$ the water temperature at the heater inlet $\left[{ }^{\circ} \mathrm{C}\right]$. For this control, all sensed quantities were future time-step values updated at each iteration of the plant solver, as described in Section 2.2. Given that $\dot{m}_{B}$ changes quickly during DHW draw events, using future time-step values helped provide a more constant temperature at the dhw-heater outlet compared to using past time-step values. This did not result in a significant increase in solver iterations.

The following chapter describes the optimization constructed around FC control and thermal storage, as well as the software coupling used to implement it. 


\section{Chapter 5}

\section{Optimization Methodology}

\subsection{Introduction}

\subsubsection{Optimization Problem}

This thesis aims to: (i) compare the performance of 1 and 2-tank PEMFC microcogeneration plants, (ii) determine the volume(s) appropriate for thermal storage, (iii) implement and optimize a hybrid control strategy, and (iv) examine the sensitivity of results obtained to changes in building and occupancy characteristics.

As described in Chapter 3, an ESP-r model has been assembled so that different plant configurations and controllers can be compared in order to meet these objectives. To make these comparisons, a performance metric must be chosen. A summary of some of the metrics used previously in the literature was presented in Section 1.2. From these, operation cost was chosen for the present work. This metric was selected because of its importance to the homeowner and because it is crucial to the success of any power generation plant.

Objective (i) requires that simulations be run with both plant configurations. Objective (iii) requires that simulations be run with varying hybrid ratios $\alpha$, and tank set-points $T_{1}$ and $T_{2}$, to determine what values minimize cost. Objective (ii) requires that simulations be performed with varying tank volumes $V_{1}$ and $V_{2}$, to determine for what volume(s) the cost is minimized. Objective (iv) requires that all simulations be

performed with the three household models to determine their sensitivity to variations in building and occupancy.

To find a combination of parameter values that performs well, it is necessary to either manually vary the input parameters or to use an optimization tool. This first 
option can be very time-consuming. If simulations were performed with the restriction that input parameters could only take on 10 values each, the number of possible combinations would be $10^{4}$ or $10^{5}$, depending on whether one or two tank volumes need to be determined. For the models used in this study, the computation time for an annual ESP-r simulation is approximately 1 hour. This means that simulations for cach plant configuration in each household would take between 1 and 10 years, which is clearly unfeasible. Reducing the number of possible values would decrease computation time, but the likelihood of missing a region of optimal performance would increase. For this reason, optimization was chosen for the present work.

\subsubsection{GenOpt}

The open-source software tool GenOpt was chosen to perform this optimization. GenOpt is a generic optimization program developed by Lawrence Berkeley National Laboratories. This program was chosen for two reasons: it can be used with any simulation program that reads and writes to text files, and it has a library of multivariable optimization algorithms suitable for use with building simulation programs. Using it with ESP-r required writing scripts and a Fortran program to facilitate the passing of information between ESP-r and GenOpt. The details of this are described in Section 5.5 .

The remainder of this chapter is dedicated to describing the details of setting up the optimization problem, the algorithms employed to solve it, the calculation of the objective function, and how the software coupling was carried out.

\subsection{Setting Up the Optimization}

\subsubsection{Objective Function}

The first step in setting up an optimization problem is to define the objective function, which defines the quantity that will be minimized through optimization. As mentioned in Subsection 5.1.1, this function is the annual operating cost $C_{a}$ :

$$
C_{a}(x)=C_{\text {elec }}(x)+C_{f u e l}(x)
$$


Table 5.1: Box-constrained independent parameters varied during optimization (described in Chapter 4).

\begin{tabular}{cccccc}
\hline Variable & $V_{1}\left[\mathrm{~m}^{3}\right]$ & $V_{2}\left[\mathrm{~m}^{3}\right]$ & $T_{c}\left[{ }^{\circ} \mathrm{C}\right]$ & $\Delta T\left[{ }^{\circ} \mathrm{C}\right]$ & $\alpha$ \\
\hline \hline Minimum & 0.05 & 0.05 & 30 & 0.5 & 0 \\
Maximum & 1.00 & 1.00 & 65 & 10 & 1 \\
\hline
\end{tabular}

$C_{\text {elec }}$ denotes the net annual cost of HVAC and non-HVAC electricity consumption and generation [\$], and $C_{f u e l}$ is the annual cost of fuel consumed by the PEMFC and in-line heaters $[\$]$. These quantities can all be calculated from the simulation results output by ESP-r, and this calculation is described in Section 5.4. These quantities are all functions of the ESP-r input parameters $x$, described above.

\subsubsection{Independent Parameters}

In order to ensure that no values of $T_{1}$ and $T_{2}$ were chosen such that $T_{2} \leq T_{1}, T_{c}$ and $\Delta T$ were chosen as independent parameters. In terms of these variables, $T_{1}$ and $T_{2}$ are:

$$
\begin{aligned}
& T_{1}=T_{c}-\Delta T \\
& T_{2}=T_{c}+\Delta T
\end{aligned}
$$

The ESP-r inputs $x$ are varied by GenOpt in order to minimize $C_{a}$. For the 1-tank plant $x=\left\{V_{1}, \Delta T, T_{c}, \alpha\right\}$, and for the 2-tank plant $x=\left\{V_{1}, V_{2}, \Delta T, T_{c}, \alpha\right\}$. These will be referred to as the independent parameters. To limit the parameter space that will be searched over, the independent variables must be constrained such that they fall within reasonable bounds. These bounds are termed box constraints [10]. These ranges are shown in Table 5.1. Tank volumes were constrained between $50 \mathrm{~L}$ and 1000 L. Storage volumes examined in the studies described in Section 1.2 (pg. 3) all fall inside this range. $\Delta T$ and $T_{c}$ were limited to values that seemed reasonable given that the heat dump control (described in Section 4.2) maintains the tank temperature below $56^{\circ} \mathrm{C}$. The hybrid weighting factor $\alpha$ is constrained between 0 and 1 as it must be a ratio of 1 (see Eqn. 4.6, pg. 43).

Note that all of these parameters are continuous. In the following section, the 
notation of Wetter, 2011 is be used. $x$ refers to one particular combination of independent parameter values, and $X$ refers to the set of all allowable combinations.

\subsection{Optimization Algorithms}

An optimization algorithm is a procedure by which the independent parameters are varied based on previous values of the objective function. The algorithms used in the present work are intended for multi-variable optimizations. They do not require a linearization of the cost function, as was carried out in Gahler et al., 2008 [33]. There is no guarantee that any minimizer found is a global minimum rather than a local one, but is an improvement over the non-optimized case.

Optimizations where the objective function is evaluated by a building simulation program require the use of derivative-free algorithms [53]. This is because the numerical solvers described in Chapter 2 only obtain an approximate solution to the energy and mass transfer equations that they solve. The number of solver iterations taking place within ESP-r can change with the independent parameters $x$, which leads to discontinuities in the objective function [54], [55]. For the present work, two algorithms - the Particle Swarm Optimization and Generalized Pattern Search - were used. Following the method of Peeters et al. [56], the minimum found by the first algorithm is used as the starting point for the second. The implementations of these algorithms in GenOpt are described in Wetter, 2011 [10], and summarized in the following subsections.

\subsubsection{Particle Swarm Optimization}

The Particle Swarm Optimization (PSO) is a non-derivative based algorithm that explores feasible solutions to the optimization problem based on the behaviour of groups of animals. The optimization procedure is shown in Figure 5.1. The algorithm begins by randomly creating $n_{p}$ feasible solutions to the optimization problem. These solutions are termed particles, and denoted by $x_{i}(k)$, where $i$ is the particle number and $k$ is the generation number. Note that $x_{i}(k)$ is a $n_{i p}$-dimensional number, where $n_{i p}$ is the number of independent parameters. Each particle is given a velocity with Equation 5.4, which serves to attract it towards solutions that minimize the objective function. The position of each particle is then updated at each generation of the algorithm, according to Equation 5.5. This process continues until a user-specified 
number of generations is reached, $n_{g}$.

$$
\begin{gathered}
v_{i}(k+1)=v_{i}(k)+c_{1} \rho_{1}(k)\left(p_{l, i}(k)-x_{i}(k)\right)+c_{2} \rho_{2}(k)\left(p_{g, i}(k)-x_{i}(k)\right) \\
x_{i}(k+1)=x_{i}(k)+v_{i}(k+1)
\end{gathered}
$$

$p_{l, i}(k)$ is the location for particle $i$ that has resulted in the minimum cost for any generation, and $p_{g, i}(k)$ is the best location for any particle in the neighbourhood of $i$ for any generation. $c_{1}$ is termed the cognitive acceleration, and $c_{2}$ is the social acceleration. These constants were set to $c_{1}=2.8$ and $c_{2}=1.3$, based on the suggestion of Carlisle \& Dozier, $2001[57] . \rho_{1}(k)$ and $\rho_{2}(k)$ are random numbers between 0 and 1 that change at each generation. Other parameters that set neighbourhood size, maximum velocity, maximum velocity gain, and constriction are given in the input file included in Appendix D, pg. 119, and were set to the values suggested in Wetter, $2011[10]$.

\subsubsection{Generalized Pattern Search}

The Generalized Pattern Search (GPS) is a derivative-free algorithm that works by searching over a mesh, each point of which is a feasible solution to the optimization problem. The mesh is refined as the optimization progresses according to the procedure shown in Figure 5.2. This mesh has $n_{i p}$ dimensions. The normalized distance between mesh points at iteration $k$ is $\Delta_{k}$, given by Equations 5.6 and 5.7. $r$ is the mesh size divider, $s_{0}$ is the initial mesh size exponent, and $t_{i}$ is the mesh size exponent increment. $r=2, s_{0}=0$, and $t_{i}=1$ were set at the suggestion of Wetter, 2011 [10].

$$
\begin{gathered}
\Delta_{k}=\frac{1}{r^{s_{k}}} \\
s_{k}=s_{0}+\sum_{i=0}^{k-1} t_{i} \text { for } k>0
\end{gathered}
$$

During the optimization, a global and a local search set are constructed. The global search set does not include all points on the mesh, but changes throughout the optimization to include mesh points in directions that have led to cost reductions at previous iterations. The local set includes only points one mesh division away from 


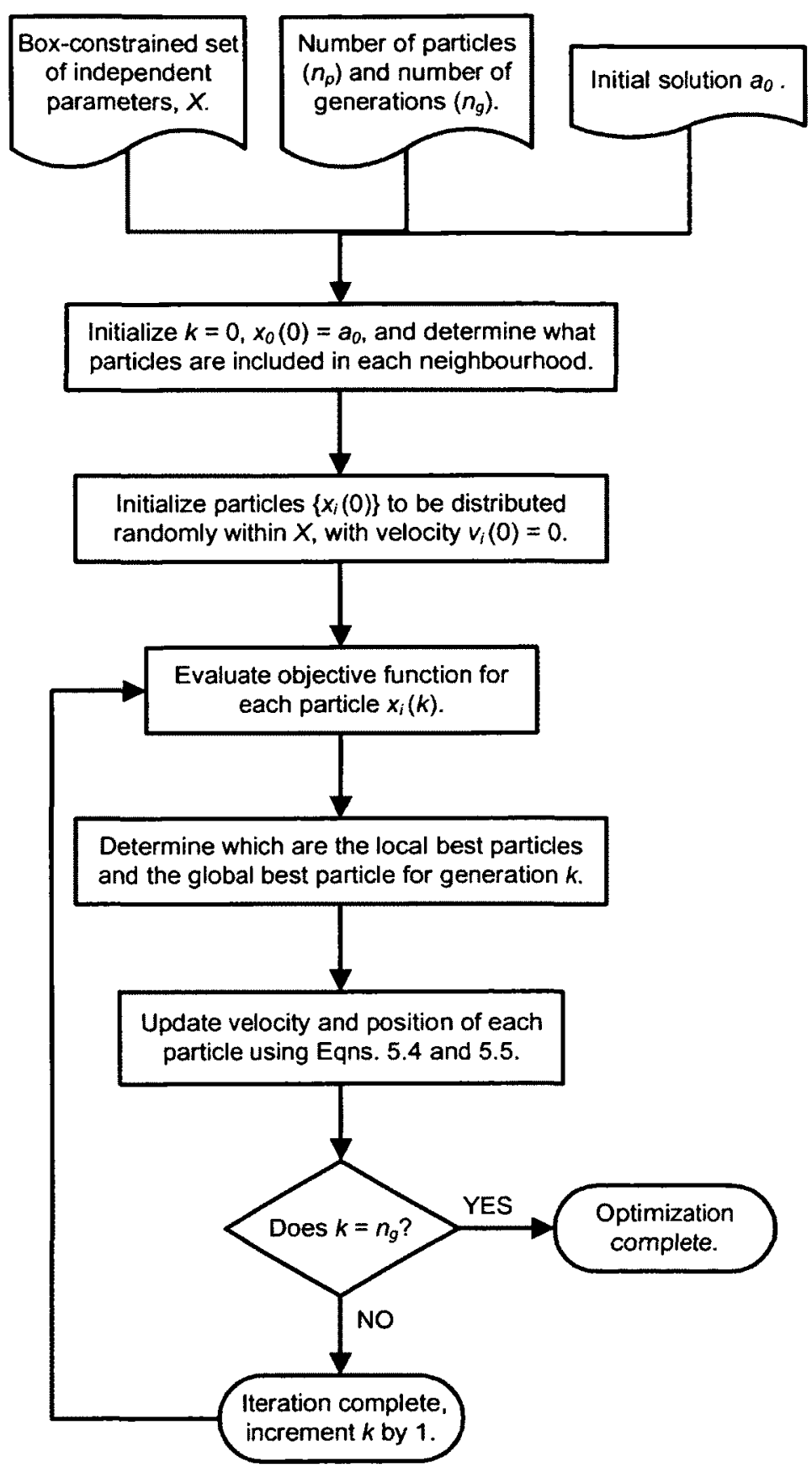

Figure 5.1: PSO procedure as implemented in GenOpt [10]. 


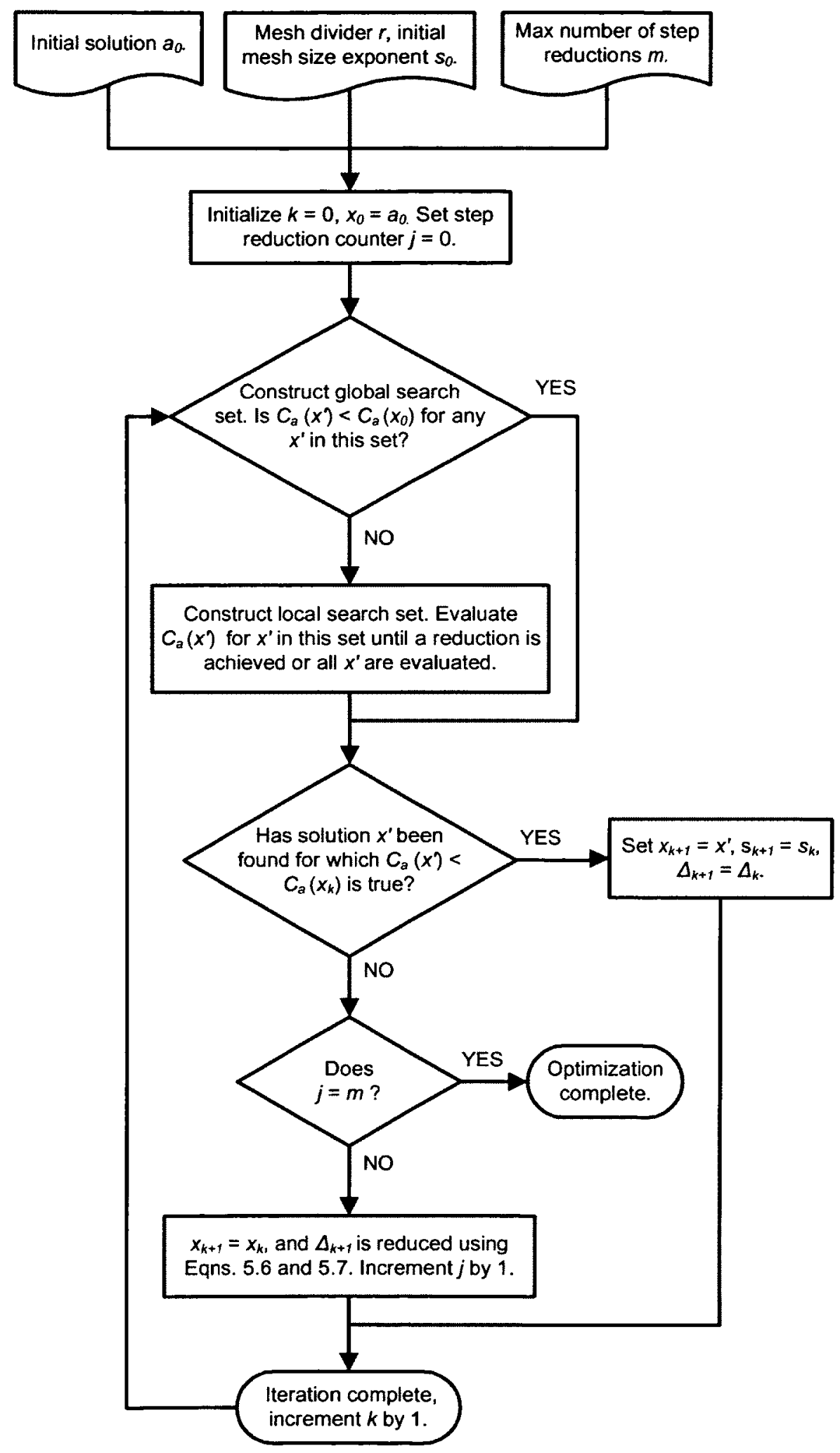

Figure 5.2: GPS procedure as implemented in GenOpt [10]. 
the current iterate. Once the best point is found in the global search set, the local set is searched. When no reduction in the objective function can be obtained on either of these sets, the mesh step-size is reduced and the procedure begins again. The GPS algorithm terminates after a user-specified number of step-size reductions, $m$. This was set to 4 , at the suggestion of Wetter, 2011 [10].

\subsection{Results Processing}

\subsubsection{Mathematical Processing}

Equation 5.8 gives the hourly operating $\operatorname{cost} C_{h}^{t}$ at hour $t$. The notation $C_{h}^{t}$ is used rather than $C_{h}(t)$ because the equation is only evaluated at discrete time-steps, rather than continuously. $V_{\text {fuel }}^{t}$ is the natural gas consumption of the PEMFC device and in-line heaters at hour $t\left[\mathrm{~m}^{3}\right]$. $E_{\text {elec }}^{t}$ is the total electricity consumption at hour $t$ in $\mathrm{kWh}$ (including HVAC and non-HVAC draws). $G_{\text {elec }}^{t}$ is the AC electricity generated at hour $t$ by the PEMFC device in $\mathrm{kWh}$.

$$
C_{h}^{t}=E_{\text {elec }}^{t} R_{\text {elec }}^{t}-G_{\text {elec }}^{t} R_{\text {elec }}^{t}+V_{\text {fuel }}^{t} R_{\text {fuel }}
$$

The electricity buying/selling price $R_{\text {elec }}^{t}$ is the Time-of-Use rate for Ontario, given in Table 5.3. The natural gas price $R_{\text {fuel }}$ is $0.2365 \$ / \mathrm{m}^{3}$, which is the residential consumer price for Ontario as of 2012. This price includes supply, transportation, and delivery charges [2].

$E_{\text {elec }}^{t}$ and $G_{\text {elec }}^{t}$ can be calculated from the average hourly power consumption/generation rates output by ESP-r. $V_{f u e l}^{t}$, however, requires an additional calculation:

$$
V_{\text {fuel }}^{t}=\frac{R T}{P}\left(n_{f c}^{t}+\frac{q_{h}^{t}}{\eta_{h} \mathrm{MM}_{\text {gas }} \mathrm{HHV}_{\text {gas }}}\right)
$$

evaluated at STP. Equation 5.9 was derived by applying the ideal gas law and a simple model that relates the heat production of the in-line heaters to their fuel consumption. $n_{f c}^{t}$ is the molar fuel consumption of the PEMFC, which is output by PEMFC model. The second term gives the molar fuel consumption of the in-line heaters. This is calculated assuming non-condensing natural gas-fired burners with an efficiency $\left(\eta_{h}\right)$ of $85 \%$ relative to the higher heating value (HHV) of natural gas. $q_{h}^{t}[\mathrm{MJ}]$ is the hourly heat production of the in-line heaters, and $\mathrm{HHV}_{\text {gas }}[\mathrm{MJ} / \mathrm{kg}]$ and $\mathrm{MM}_{\text {gas }}[\mathrm{kg} / \mathrm{mol}]$ are 
Table 5.2: Molar composition of natural gas in Ontario, for July to December, 2011 [2]. HHVs from Cengel, 2008 [3].

\begin{tabular}{ccccc}
\hline Chemical Name & Formula & Molar Fraction & Molar Mass [g/mol] & HHV [MJ $/ \mathrm{kg}]$ \\
\hline \hline Methane & $\mathrm{CH}_{4}$ & 0.9612 & 16.043 & 55.53 \\
Ethane & $\mathrm{C}_{2} \mathrm{H}_{6}$ & 0.0198 & 30.070 & 51.90 \\
Nitrogen & $\mathrm{N}_{2}$ & 0.0092 & 28.014 & 0 \\
Carbon Dioxide & $\mathrm{CO}_{2}$ & 0.0082 & 44.009 & 0 \\
Propane & $\mathrm{C}_{3} \mathrm{H}_{8}$ & 0.0013 & 44.097 & 50.33 \\
Butane & $\mathrm{C}_{4} \mathrm{H}_{10}$ & 0.0003 & 58.123 & 49.15 \\
\hline Mass-Average & & & 16.709 & 54.48 \\
\hline
\end{tabular}

the mass-averaged HHV and molar mass of natural gas, respectively. These values were calculated using a typical natural gas composition for Ontario, shown in Table 5.2 .

$$
C_{a}=\sum_{t=1}^{8,760} C_{h}^{t}
$$

The annual operating cost $C_{a}$ is calculated by summing the hourly costs over the entire year, using Equation 5.10.

\subsubsection{Electrical Generation Revenue}

At the time of writing, micro-cogeneration was not included in the Ontario Power Authority's Feed-in-Tariff (OPA/FIT) program. This program compensates operators of renewable energy generation projects such as solar photovoltaics and wind turbines. At the time of writing, the OPA's cogeneration policy was directed at institutional and industrial size facilities. The Standard Offer Program (SOP) exists for plants of this size. This program aims to reduce the peak electrical load that central generation facilities must meet. To this end, cogeneration facilities that are part of the SOP are required to turn on during times of peak electricity usage. They are guaranteed a fixed income of $28,900 \$ / \mathrm{MW}$-month, or $0.04 \$ / \mathrm{kWh}$ [58]. Since this policy is not directed at micro-cogeneration, a different cost structure was used for the current work. Equation 5.8 assumes parity between the selling price and the TOU rate (see 
Table 5.3: Time-of-Use electricity rates for Ontario as of January, 2012. Summer rates apply May through October, winter rates apply November through April [4].

\begin{tabular}{ccc}
\hline Time Period [hh:mm] & Summer Rate $[\$ / \mathrm{kWh}]$ & Winter Rate $[\mathrm{c} / \mathrm{kWh}]$ \\
\hline \hline $07: 00-11: 00$ & 10.0 & 11.7 \\
$11: 00-17: 00$ & 11.7 & 10.0 \\
$17: 00-19: 00$ & 10.0 & 11.7 \\
$19: 00-07: 00$ & 6.5 & 6.5 \\
\hline
\end{tabular}

Table 5.3). Transmission and distribution costs were not included in Table 5.3; these vary between locations (approximately $4-5 \$ / \mathrm{kWh}$ ) and depend on the population density of the service area [59].

\subsection{Software Coupling}

To use GenOpt, the user must create a number of input files read by the software. These are as follows: (i) a configuration file that specifies how to start ESP-r, (ii) input templates, or ESP-r input files that include a flag in place of each independent parameter, (iii) a command file that specifies the optimization algorithm as well as the input parameters for that algorithm, and (iv) an initialization file that specifies the locations of (i)-(iii), a log file, and the location of the cost function value. These files were written using the work of Peeters et al. [56] as a guide. The optimization algorithm input files are included in the appendices (Appendix D), while other files are available electronically (see Appendix E, pg. 122) due to space constraints.

The optimization flow for one itcration is shown in Figure 5.3. The procedure is as follows:

Step 1: GenOpt updates the independent parameter values using the specified algorithm with the cost value from the last iteration

Step 2: Independent parameters are written into ESP-r input files according to the two templates

Step 3: GenOpt calls shell script Meta Script 
Step 4: Meta Script initiates ESP-r simulation

Step 5: Simulation is completed, Meta Script calls Post-processor Script

Step 6: Post-processor Script interacts with ESP-r results module, calls Fortran Post-processor

Step 7: Fortran Post-processor writes annual operating cost to text file, control is passed back to GenOpt

If it is the first iteration, Step 1 is modified so that the independent variables are initialized at user-specified values, given in the command file.

Steps 1-3 are internal to GenOpt, while Steps 4-7 were implemented as part of the present work. Meta Script (see Appendix E) specifies the ESP-r configuration file to be used for simulation and sets the time-step and duration.

Post-processing script (Appendix E) interacts with the built-in ESP-r results processing module. This script specifies an annual output time period, hourly results averaging, and also what variables are to be output. It directs the output to two text files - one contains the hourly fuel consumption rate of the PEMFC [mmol/s] and heat production of the in-line heaters [W], the other contains electrical generation rates [W] and grid power balance [W]. Results are averaged hourly to limit the size of output files and the amount of data stored in random access memory in the second post-processing step.

Fortran post-processor (Appendix E) reads the text files output by the ESP-r results module (RES). Using the average hourly rates given in the text files, a calculation is performed to find total hourly values of PEMFC fuel consumption [mol], in-line heater heat production [J], and net grid electricity balance [kWh]. Equations $5.9,5.8$, and 5.10 are applied to find the annual operating cost. This cost is output to a text file which can be read by GenOpt.

It should be noted that iterations are carried out in parallel during optimization runs to decrease the computation time. 


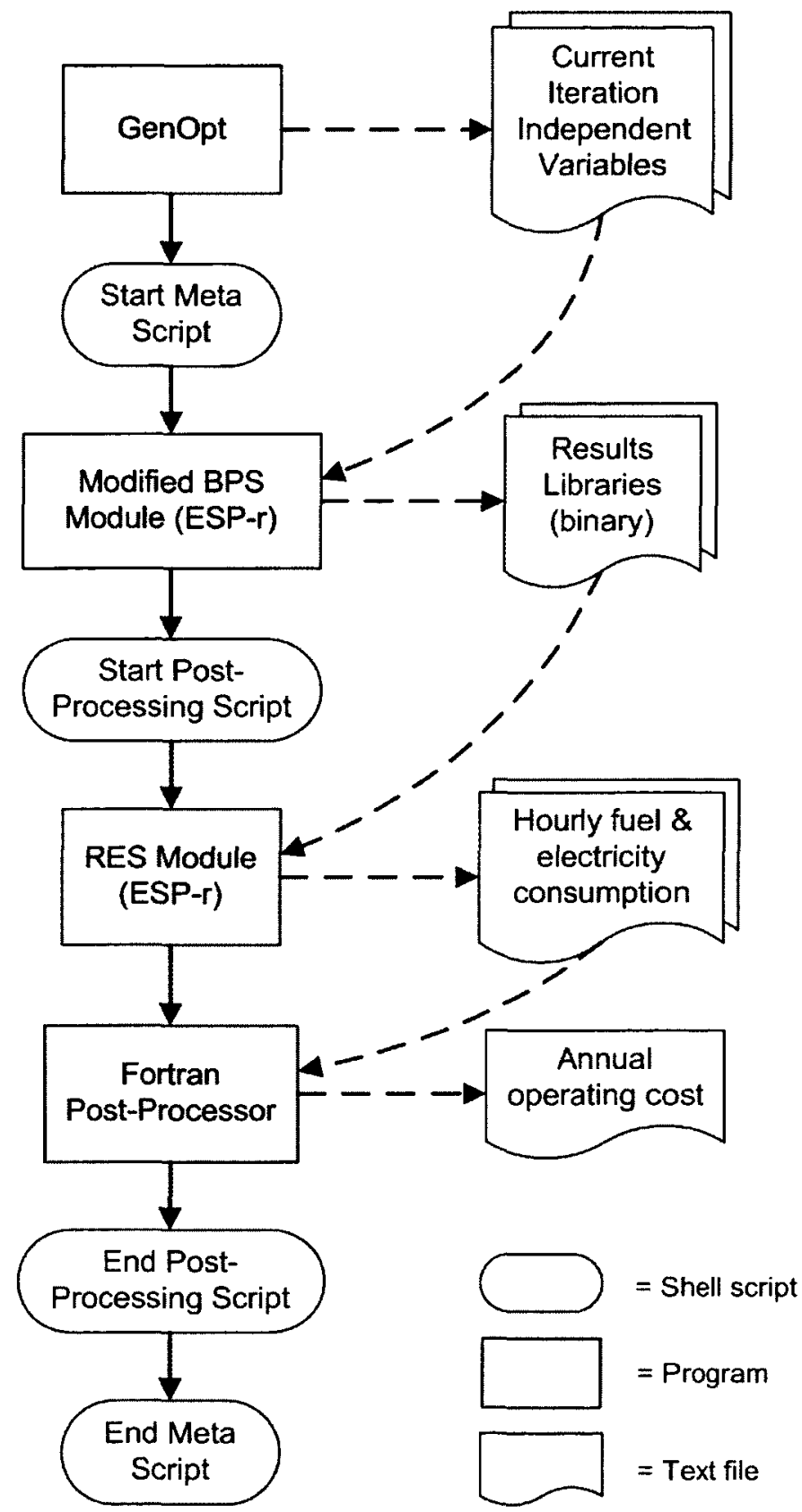

Figure 5.3: GenOpt - ESP-r coupling. This procedure occurs once per optimization iteration. 


\section{Chapter 6}

\section{Results}

This chapter presents results obtained through optimization, where the objective function was evaluated using annual ESP-r simulations. These simulations use the building/occupancy models described in Chapter 3, and the plant configurations and controls described in Chapter 4.

Section 6.1 describes the effects of changing the number of PSO particles used during optimization, in order to determine the number appropriate for this thesis. Sections 6.2 and 6.3 present the system behaviour of the 1 and 2-tank plants and discuss the meaning of the independent parameter values arrived at through optimization. Section 6.4 details the performance results for the optimized 1 and 2-tank plants coupled to each building/occupant model. Section 6.5 makes a comparison of the optimized hybrid controls to the constant, tank temperature following, and electrical price following control modes described in Section 4.2. Section 6.6 summarizes the findings and concludes the chapter.

All of these results were obtained for both the 1 and 2-tank plants, with the exception of the optimization algorithm sensitivity study, which was conducted only for the 1-tank plant to limit computation time. For ease of comparison, results described in Sections 6.1, 6.2, 6.3, and 6.5 were obtained using the Medium building/occupancy model described in Chapter 3. In the following sections, the Low, Medium, and High building/occupancy models are referred to as B1, B2, and B3, respectively.

\subsection{Optimization Algorithm Sensitivity}

This section presents the results of a sensitivity study that examines the effect of changing the number of PSO particles used during optimization. This analysis uses 
Table 6.1: Independent parameter values and annual operating cost for PSO-GPS optimizations using three different particle numbers. Results for 1-tank plant coupled with B2.

\begin{tabular}{c|c|cc|cc|cc}
\hline & & \multicolumn{2}{|c|}{4 particles } & \multicolumn{2}{|c|}{8 particles } & \multicolumn{2}{|c}{16 particles } \\
& mean & value & diff. & value & diff. & value & diff. \\
\hline $\mathrm{V}_{1}\left[\mathrm{~m}^{3}\right]$ & 0.756 & 0.853 & $12.9 \%$ & 0.740 & $-2.1 \%$ & 0.674 & $-10.8 \%$ \\
$T_{1}\left[{ }^{\circ} \mathrm{C}\right]$ & 52.8 & 52.1 & -0.8 & 52.0 & -0.8 & 54.5 & 1.6 \\
$T_{2}\left[{ }^{\circ} \mathrm{C}\right]$ & 67.7 & 66.6 & -1.1 & 70.5 & 2.8 & 66.0 & -1.7 \\
$\alpha[-]$ & 0.909 & 0.906 & $-0.4 \%$ & 0.938 & $3.2 \%$ & 0.884 & $-2.8 \%$ \\
Cost $[\$]$ & 879.5 & 879.4 & -0.1 & 879.0 & -0.4 & 880.0 & 0.6 \\
\hline
\end{tabular}

the 1-tank plant and the building/occupancy case B1. The purpose of this analysis is to determine what number of particles is appropriate for solving the optimization problem described in Chapter 5. To limit the scope of the study, other algorithm parameters were not varied, but fixed based on the advice of Wetter, 2011 [10] and are given in Section 5.3. As mentioned in Chapter 5, it is difficult to know if a given set of independent parameters $\left(x_{i}\right)$ represent a global minimum. For this reason, the $x_{i}$ found through optimization will be referred to as the termination point of the algorithm, rather than the optimal point.

For each optimization, the PSO and GPS algorithms were run in succession, with the termination point of the PSO becoming the initial point of the GPS. Figure 6.1 shows the normalized independent parameters and calculated annual operating costs over an 8 particle PSO-GPS optimization. A vertical line shows the point where the PSO terminates and the GPS begins. This optimization required 413 annual ESP-r simulations and terminated at a set of independent parameter values yielding a annual operating cost of $\$ 879 .^{1}$

Optimizations using 4,8 , and 16 particles were performed. It was found that the number of ESP-r simulations required increased with increasing particle numbers. It was also found that the termination point of the PSO varied not only with changing particle numbers but also with different random number seeds. These seeds determine the initial position and velocity of the PSO particles [10]. For this reason, two PSO

\footnotetext{
${ }^{1}$ For comparison, the maximum cost calculated during these optimizations was $\$ 1074$.
} 

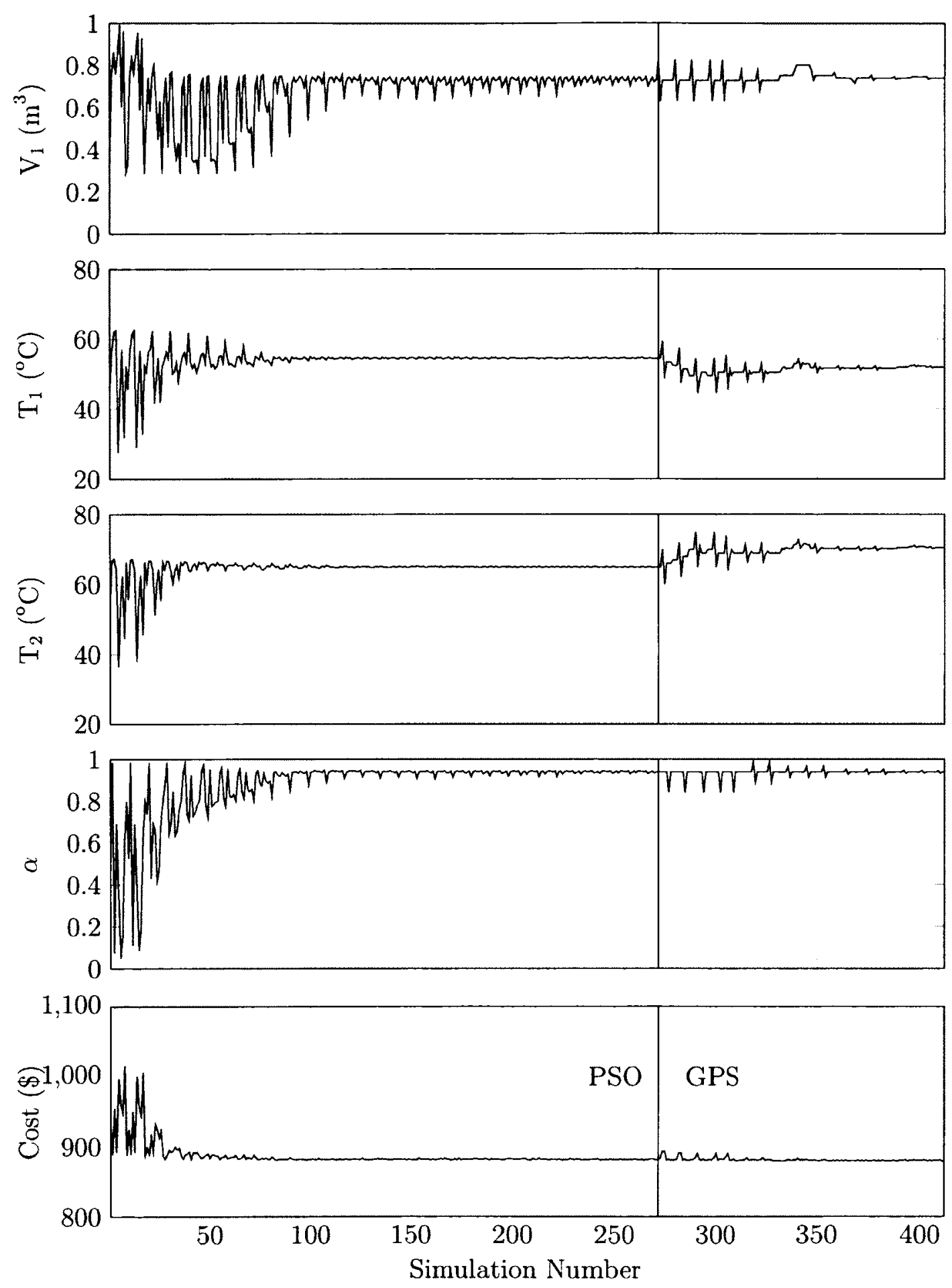

Figure 6.1: Independent parameter values and annual operating cost plotted for the 8-particle PSO-GPS optimization. Results for 1-tank plant coupled with building/occupancy model B2. 
runs with differing random number seeds were performed for each of the 4,8 , and 16 particle optimizations. For each particle number, the termination point with lower of the two costs was chosen to be the initial point of the GPS. The results of these optimizations are shown in Table 6.1. The control parameters $T_{1}$ and $T_{2}$ are reported rather than the parameters $T_{c}$ and $\Delta T$ described in Subsection 5.2.2. These are related by Equations 5.2 and 5.3 (pg. 48). $T_{1}$ and $T_{2}$ are used in an effort to present the results more intuitively - these are the temperature set-points between which the PEMFC electrical output is modulated.

Temperature set-points varied by at most $2.8^{\circ} \mathrm{C}$ from mean values, tank volumes by $12.9 \%$ at most, and $\alpha$ by a maximum of $3.2 \%$. All optimizations performed resulted in similar annual operating costs at the termination point, with costs varying by at most $\$ 0.6$ from the mean.

It is interesting to note that the most computationally intensive optimization, the 16 particle PSO-GPS, resulted in a slightly higher annual operating cost compared to the others. However, the differences in the cost function were too small to be considered relevant. The number of particles had no significant impact upon the cost function, and therefore the increased computation time associated with increasing the number of particles could not be justified. For this reason, the 4 particle PSO-GPS was chosen to perform the optimizations reported in the remainder of this chapter.

\subsection{1-tank Plant Performance}

The 4 particle PSO-GPS optimization was performed again for the 1-tank plant coupled with building/occupancy cases B1 and B3. The independent parameters obtained through optimization are given in Table 6.2, and aggregated performance results are given in Table 6.4 (pg. 71). This section presents a discussion of the 1-tank plant behaviour and the meaning of the independent parameter values arrived at through optimization.

Tank volume $V_{1}$ varied a maximum of $13.3 \%$ from the mean value for all cases of $0.790 \mathrm{~m}^{3}$. The smallest tank volume was found for $\mathrm{B} 3$, the household with the highest demand for heat. This finding is contrary to the assumption that a greater demand for heat would require a larger store of heat. To investigate this, additional simulations were carried out with the building/occupancy model B2. Tank volume was varied from 0.1 to $0.9 \mathrm{~m}^{3}$, while other independent parameters were held constant 
Table 6.2: 1-tank plant independent parameter values obtained through optimization for B1, B2, and B3.

\begin{tabular}{c|c|cc|cc|cc}
\hline & & \multicolumn{2}{|c|}{ B1 } & \multicolumn{2}{c|}{ B2 } & \multicolumn{2}{c}{ B3 } \\
& mean & value & diff. & value & diff. & value & diff. \\
\hline \hline$V_{1}\left[\mathrm{~m}^{3}\right]$ & 0.790 & 0.832 & $5.3 \%$ & 0.853 & $8.0 \%$ & 0.686 & $-13.3 \%$ \\
$T_{1}\left[{ }^{\circ} \mathrm{C}\right]$ & 52.4 & 53.0 & 0.6 & 52.1 & -0.3 & 52.0 & -0.3 \\
$T_{2}\left[{ }^{\circ} \mathrm{C}\right]$ & 66.7 & 68.8 & 0.1 & 66.6 & -0.1 & 66.6 & 0.0 \\
$\alpha[-]$ & 0.927 & 0.940 & $1.4 \%$ & 0.906 & $-2.2 \%$ & 0.934 & $0.8 \%$ \\
\hline
\end{tabular}

at the terminal values given in Table 6.2. The resulting operating costs are shown in Figure 6.2. It was found that reducing tank volume to 0.5 and $0.3 \mathrm{~m}^{3}$ only increased operating costs by $\$ 2.7$ and $\$ 6.1$, respectively. This indicates that the cost function is not sensitive to tank volume over this range. Therefore, it is not surprising that the 'optimal' tank volume would vary between building/occupancy cases, as there was only a weak correlation between this variable and cost performance for the 1-tank plant.

That tank volume did not strongly influence the operating cost may be due in part to the high level of insulation specified. For a highly insulated tank there is little penalty, in terms of heat lost to the surroundings, for specifying a large volume. It is possible that, in a system with less tank insulation, smaller volumes would have resulted in better cost performance. It should also be noted that the increased investment and system footprint associated with a large tank were not accounted for in the optimization.

$T_{1}$ varied by at most $0.6^{\circ} \mathrm{C}$ from the mean value of $52.4^{\circ} \mathrm{C}$, and $T_{2}$ varied by at most $0.1^{\circ} \mathrm{C}$ from the mean value of $66.7^{\circ} \mathrm{C}$. For most of the cooling season, the average tank temperature is below the set-point $T_{1}{ }^{2}$ This means that the tank temperature following control signal $S_{\text {therm }}$ was 1 for much of the heating season. During the cooling and shoulder seasons, tank temperature was greater than $T_{1}$ but less than $T_{2}$ (see Fig. A.3). This means that $S_{\text {therm }}$ decreases from 1 over this time period, but never reaches $S_{m i n}$.

The hybrid parameter $\alpha$ varied by at most $2.2 \%$ from the mean value of 0.927 .

\footnotetext{
${ }^{2}$ Averaged over the simulation year, water at the tank outlet $\left(T_{A}\right.$ in Fig. 4.1, pg. 38$)$ was $1.8^{\circ} \mathrm{C}$ cooler than the average tank temperature for the 1-tank plant.
} 


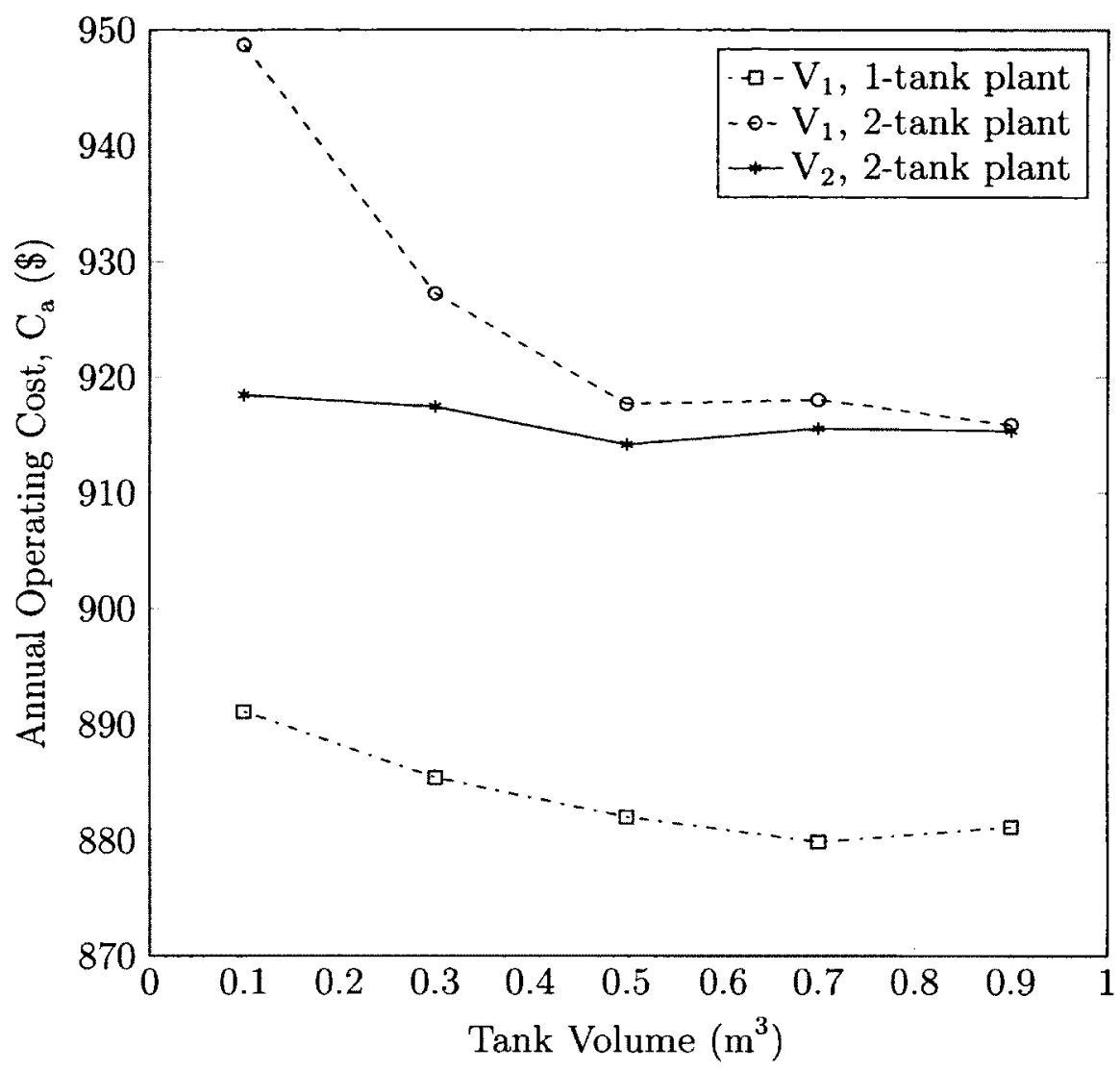

Figure 6.2: Sensitivity of annual operating cost to tank volume. Results for both 1 and 2-tank plants coupled to building/occupancy model B2.

This means that the hybrid control was biased heavily towards tank temperature following (see Eqn. 4.6, pg. 43). This is apparent in Figure 6.3-the PEMFC AC output varied more in response to changing tank temperature than changing electrical price.

Figure 6.3 shows the PEMFC AC electrical output and the average temperature of the coupled tank for a weekday in early May. Vertical lines mark the boundaries between TOU pricing periods, which are the Summer rates in Table 5.3 (pg. 55). While the $\mathrm{AC}$ output closely follows the average tank temperature, there are slight mismatches because the controller senses temperature at the tank outlet. Rapid changes in $\mathrm{AC}$ output occur when the electricity price changes. While the price is constant, PEMFC AC output decreases proportionately to increasing tank temperature.

Figure 6.4 shows the daily heat dump and PEMFC AC output (averaged daily) 


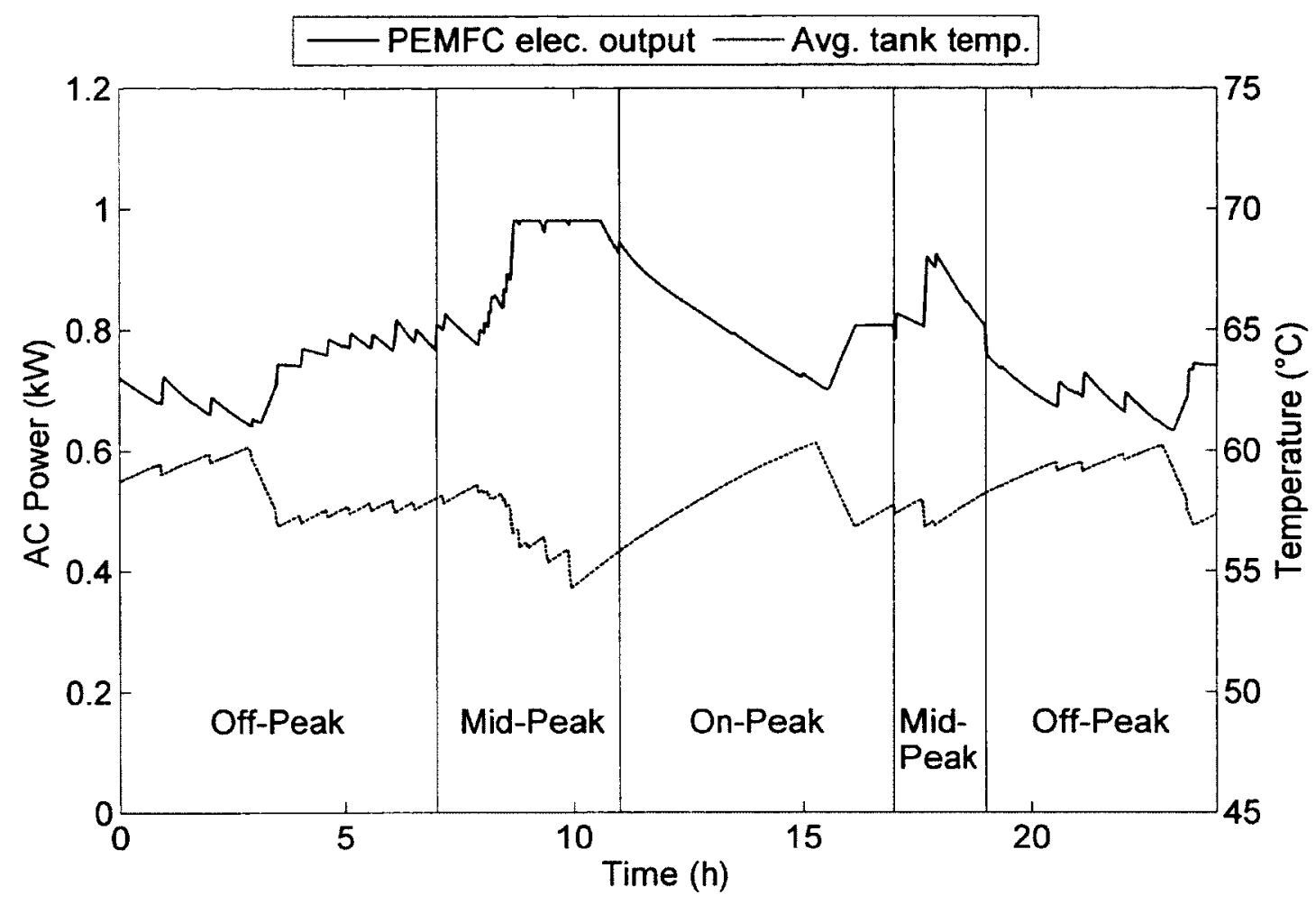

Figure 6.3: PEMFC AC electrical output and average tank temperature for a weekday in Spring (day \# = 150). Results for 1-tank plant coupled with B2.

over an entire year. Vertical lines denote the boundaries between the heating and cooling seasons. The heat dump is the amount of thermal energy removed by the heat-dump component, whose location in the plant network is shown in Figure 4.1 (pg. 38). The average daily $\mathrm{AC}$ output was relatively constant during most of the heating season. This results from the fact that the tank temperature was below $T_{1}$ at this time. This caused the thermal signal to go to 1 and the AC output to depend solely on the electricity price. The AC output oscillated between $0.96 \mathrm{~kW}$ on weekdays, and $0.95 \mathrm{~kW}$ on weekends. This is due to different average TOU electricity prices for these day types - electricity is sold at an average of $8.7 \mathrm{\Phi} / \mathrm{kWh}$ on weekdays and $6.5 \$ / \mathrm{kWh}$ on weekends.

Figure 6.4 shows that PEMFC AC output decreases during the cooling and shoulder seasons, coinciding with an increase in daily heat dump. This is a consequence of the heat dump deadband control (see Section 4.2, pg. 40) - when the tank outlet 


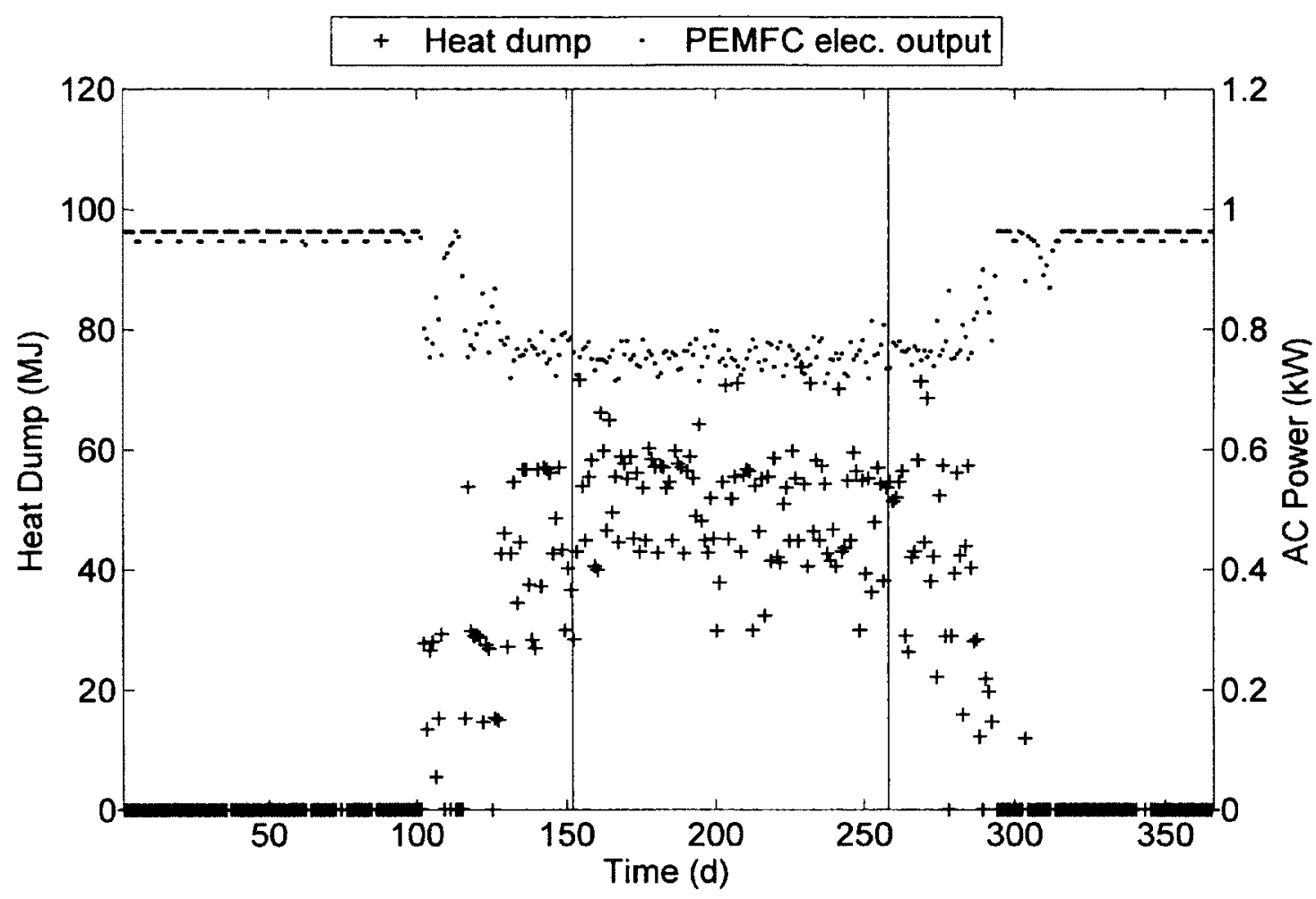

Figure 6.4: Daily heat dump and PEMFC AC electrical output (averaged daily) for one year. Results for 1-tank plant coupled with B2.

temperature reaches $59^{\circ} \mathrm{C}$, the heat dump becomes active. This behaviour is also due to the $T_{1}$ and $T_{2}$ values found through optimization. These were such that the tank temperature following control acted to follow thermal loads to some extent. It is interesting to note that, for this plant configuration and control algorithm, it was not profitable to reduce electrical output to a minimum in the presence of high tank temperatures. This may indicate that the control reduced thermal output to compromise between minimizing heat dump and maximizing profits from electrical generation.

\subsection{2-tank Plant Performance}

The 4 particle PSO and GPS optimization was performed for the 2-tank plant coupled with the building/occupancy cases B1, B2 and B3. The independent parameters obtained through optimization are given in Table 6.3, and aggregated performance results are given in Table 6.4 (pg. 71). This section presents a discussion of the 2-tank 
Table 6.3: 2-tank plant independent parameter values obtained through optimization for B1, B2, and B3.

\begin{tabular}{c|c|cc|cc|cc}
\hline & & \multicolumn{2}{|c|}{$\mathrm{B} 1$} & \multicolumn{2}{c|}{$\mathrm{B} 2$} & \multicolumn{2}{c}{$\mathrm{B} 3$} \\
& mean & value & diff. & value & diff. & value & diff. \\
\hline \hline$V_{1}\left[\mathrm{~m}^{3}\right]$ & 0.804 & 0.488 & $-39.3 \%$ & 0.979 & $21.8 \%$ & 0.944 & $17.5 \%$ \\
$V_{2}\left[\mathrm{~m}^{3}\right]$ & 0.701 & 0.644 & $-8.2 \%$ & 0.497 & $-29.1 \%$ & 0.963 & $37.2 \%$ \\
$T_{1}\left[{ }^{\circ} \mathrm{C}\right]$ & 55.2 & 55.2 & 0.0 & 54.1 & -1.1 & 56.4 & 1.1 \\
$T_{2}\left[{ }^{\circ} \mathrm{C}\right]$ & 66.3 & 60.2 & -6.1 & 69.3 & 3.0 & 69.3 & 3.1 \\
$\alpha[-]$ & 0.862 & 0.781 & $-9.5 \%$ & 0.871 & $1.0 \%$ & 0.935 & $8.4 \%$ \\
\hline
\end{tabular}

plant behaviour and the independent parameter values found through optimization. A detailed performance comparison of the 1 and 2-tank plants is presented in the following section.

Tank volume $V_{1}$ varied by at most $39.3 \%$ from the mean value between households of $0.804 \mathrm{~m}^{3} . V_{2}$ varied by at most $37.2 \%$ from the mean value of $0.701 \mathrm{~m}^{3}$. While the combined volume $V_{1}+V_{2}$ increases with increasing building load, there is substantial variation in the individual parameters between household cases. To determine the cause of this, additional simulation were carried out for case B2. Tank volumes $V_{1}$ and $V_{2}$ were varied over the range 0.1 to $0.9 \mathrm{~m}^{3}$, while other independent parameters were held constant at the values in Table 6.3. These results are shown in Figure 6.2. Holding $V_{2}$ constant at $0.497 \mathrm{~m}^{3}$ and decreasing $V_{1}$ to 0.7 and $0.5 \mathrm{~m}^{3}$ yielded cost increases of $\$ 4.9$ and $\$ 4.5$, respectively. Holding $V_{1}$ constant at $0.979 \mathrm{~m}^{3}$ and increasing $V_{2}$ to 0.7 and $0.9 \mathrm{~m}^{3}$ yielded cost increases of $\$ 2.4$ and $\$ 2.2$, respectively. This suggests that for the 2-tank plant, annual operating cost is not sensitive to tank volumes in this range. The effect high insulation values may have had on this results is described in Section 6.2.

$T_{1}$ varied by at most $1.1^{\circ} \mathrm{C}$ from the mean value of $55.2^{\circ} \mathrm{C}$, and $T_{2}$ varied by as much as $6.1^{\circ} \mathrm{C}$ from the mean value of $66.3^{\circ} \mathrm{C}$. The average dhw-tank temperature averaged over the simulation year was $55.0^{\circ} \mathrm{C}$, and remained relatively constant throughout the simulation year as seen in Figure A.4. ${ }^{3}$ For all households, $T_{2}$ was 5.2 to $14.3^{\circ} \mathrm{C}$ above the average dhw-tank temperature. This means that all of the combinations of

\footnotetext{
${ }^{3}$ Averaged annually, water sent to the PEMFC from the dhw-tank $\left(T_{A}\right.$ in Fig. $4.2, \mathrm{pg}$. 39) was $0.1^{\circ} \mathrm{C}$ cooler than the average dhw-tank temperature in the 2-tank plant.
} 


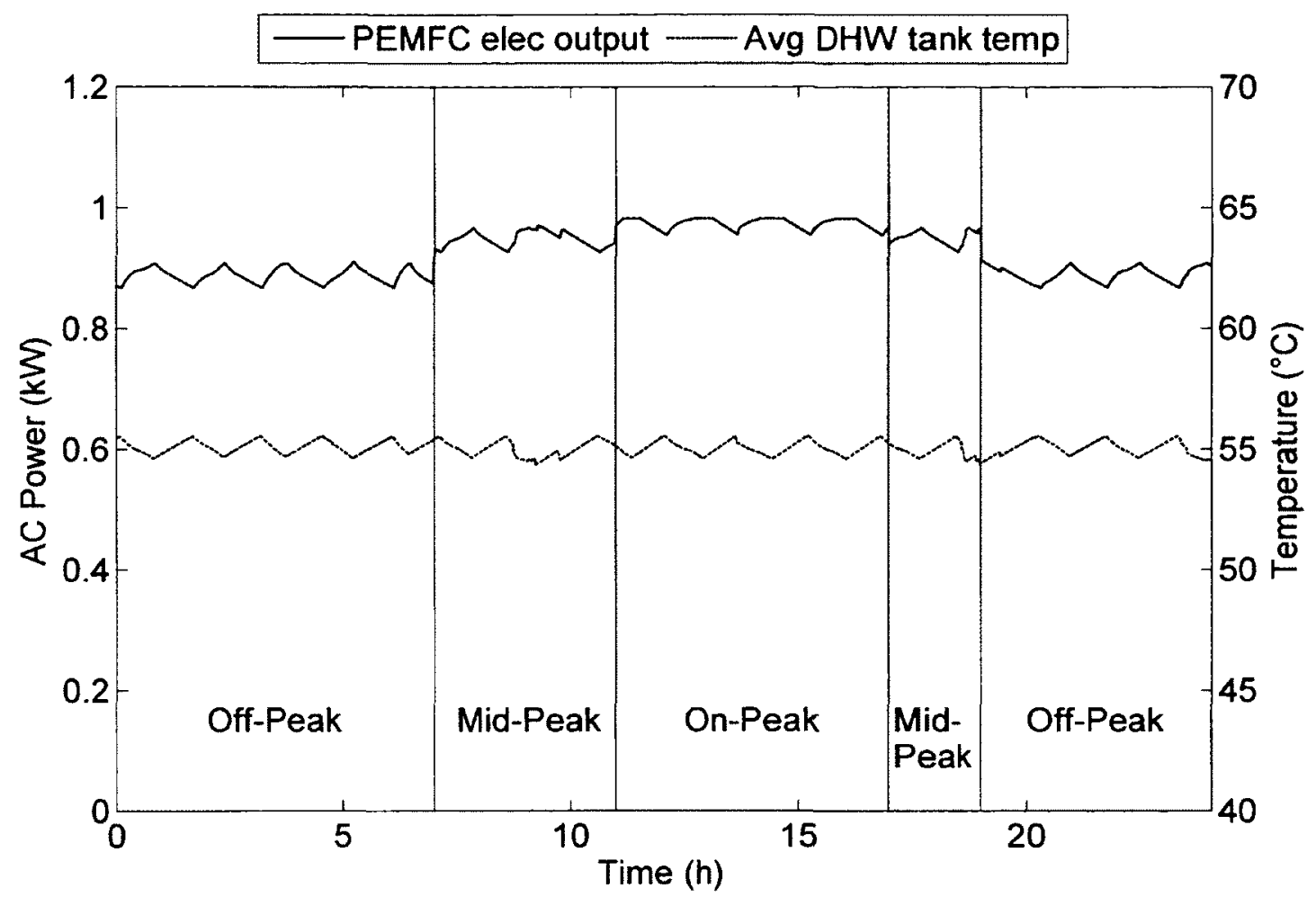

Figure 6.5: PEMFC AC electrical output and average DHW tank temperature for a weekday in Spring (day \# = 150). Results for 2-tank plant coupled with B2.

$T_{1}$ and $T_{2}$ result in a temperature following control signal close to the maximum for the entire year, regardless of the exact value of $T_{2}$.

The hybrid parameter $\alpha$ varied by up to $9.5 \%$ from the mean value of 0.862 . Table 6.3 shows that $\alpha$ increases with building/occupant load between households. Since the temperature following signal is relatively constant and close to a maximum for the entire year, $\alpha$ serves to increase the average PEMFC output as the household demand for heat increases. This conclusion is supported by the electrical generation results reported in Table 6.4, which increase with $\alpha$. This indicates that the hybrid control is functioning differently in the 2-tank plant than the 1-tank plant, leading to less seasonal variation in PEMFC output.

Figure 6.5 shows the modulation of the PEMFC AC electrical output and the average temperature of the coupled tank for a weekday in early May. There is considerably less variation in the PEMFC output than for the 1-tank plant, due to less 


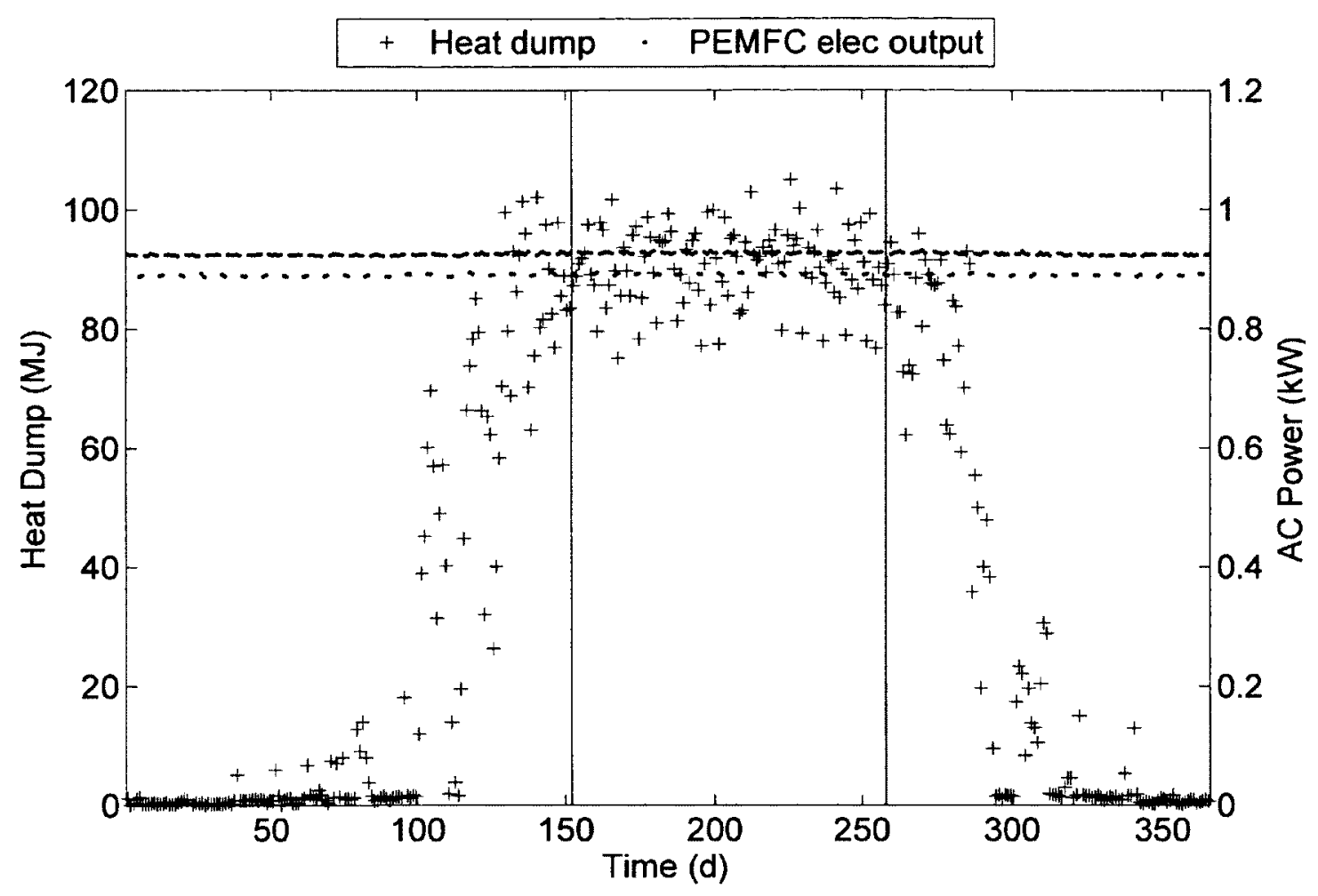

Figure 6.6: Daily heat dump and PEMFC AC electrical output (averaged daily) for one year. Results for 2-tank plant coupled with B2.

variation in tank temperature.

Figure 6.6 shows the daily heat dump and average daily PEMFC AC output over the year. The 2-tank plant shows no substantial difference in AC output between the heating and cooling seasons. This is partly due to the strict temperature control of the coupled dhw-tank, made necessary by the DHW storage temperature requirement (see Chapter 4). It is also due to the values of $T_{1}$ and $T_{2}$ found through optimization. These were such that the tank temperature following control did not follow thermal loads, but set a constant electrical output throughout the year. This results in a greater daily heat dump in the cooling and shoulder seasons. The average daily AC output oscillates between $0.92 \mathrm{~kW}$ on weekdays, and $0.89 \mathrm{~kW}$ on weekends. This difference is again due to a lower average TOU electricity price on weekends, resulting in a lower electrical price following signal. There is a greater difference between weekday and weekend electrical production for the 2 -tank plant because of the lower $\alpha$ value for 
this plant, compared to the 1-tank configuration.

Other details of the system behaviour are not included here, but can be found in Appendix A, pg. 91.

\subsection{Plant Performance Comparison}

This section presents performance results for both plant configurations coupled with building/occupancy combinations B1, B2, and B3. Table 6.4 shows a summary of the results obtained. This table lists annual operating cost and other performance indices, which are described below. Independent parameter values corresponding to these optimizations are provided in Tables 6.2 and 6.3 .

DHW and space heating energy delivered are included in Table 6.4 to demonstrate the extent to which each plant configuration met the building loads. These two metrics are normalized to ease comparison between cases. The normalized DHW energy delivered $\left(\hat{q}_{d h w}\right)$ is the ratio of the DHW energy delivered to the expected amount:

$$
\hat{q}_{d h w}=\frac{\sum_{t=1}^{525,600} \dot{m}_{d h w}^{t} \Delta t c_{p, w}\left(T_{c}^{t}-T_{m}\right)}{m_{d h w, r e q^{\prime} d} c_{p, w}\left(T_{c}-T_{m}\right)}
$$

where $\dot{m}_{d h w}^{t}$ is the mass flow rate of DHW at time $t[\mathrm{~kg} / \mathrm{s}], \Delta t$ is the time-step length $[\mathrm{s}], c_{p, w}$ is the heat capacity of water $[\mathrm{kJ} / \mathrm{kgK}], T_{c}^{t}$ is the supply water temperature at time $t\left[{ }^{\circ} \mathrm{C}\right], T_{m}$ is the mains water temperature $\left[{ }^{\circ} \mathrm{C}\right], m_{d h w, r e q^{\prime}}$ is the annual mass of DHW expected $[\mathrm{kg}]$, and $T_{c}$ is the expected supply temperature. Note that $T_{c}$ is $45^{\circ} \mathrm{C}$ for the 1-tank plant and $55^{\circ}$ for the 2 -tank plant (see Section 4.1, pg. 36 for details). The numerator is summed over the number of annual time-steps.

The 1-tank plant over-provided DHW energy by 10-20\%. Since the total mass of DHW was the same in both the delivered and required cases, this indicates that the water was delivered warmer than the $45^{\circ} \mathrm{C}$ set-point. This is not surprising, given that the annual-average average tank temperature is $52.0^{\circ} \mathrm{C}$. In a real installation this would be adjusted for with a mixing valve, which would introduce cooler mains water into the stream. The effect of a mixing valve was not included for this plant because of the variable nature of the tank temperature over the year (see Figure A.3). This meant that a reduction of DHW draws could not be calculated in the same manner as for the 2-tank plant, as the reduction would have had to change with tank temperature. 
The 2 -tank plant delivered within $2 \%$ of the required DHW amount. This was due to a stricter temperature control on the DHW tank, resulting in an average dhw-tank temperature of $55.0^{\circ} \mathrm{C}$ averaged over the year (see Figure A.4). The effect of a mixing valve was included for this plant by reducing the volume of daily DHW draws as described in Subsection 4.1.2.

The normalized space heating energy delivered $\left(\hat{q}_{s p c}\right)$ is calculated as follows:

$$
\hat{q}_{s p c}=\frac{\sum_{t=1}^{525,600} \dot{q}_{s p c, \text { delivered }}^{t} \Delta t}{q_{s p c, r e q^{\prime} d}}
$$

where $\dot{q}_{s p c, \text { delivered }}^{t}$ is the rate of heat transfer to building air through the air-water heat exchanger at time $t[\mathrm{~W}]$, and $q_{s p c, r e q^{\prime} d}$ is the heat required annually to keep the building air at $21^{\circ} \mathrm{C}[\mathrm{J}] . q_{s p c, r e q^{\prime} d}$ was calculated through annual simulation with ideal zone controls. $q_{s p c, \text { ideal }}$ was found to be $55.5 \mathrm{GJ}, 79.8 \mathrm{GJ}, 184.1 \mathrm{GJ}$ for B1, B2, and B3, respectively. These values are less than those given in Table 3.1 (pg. 23) as they include heat gains due to the occupancy model.

Space heating energy delivered was the same for both plants in each building/occupancy model to within $1 \%$. This is due to the fact that the space heating loop was controlled and sized the same way for both plants. Differences between $\mathrm{B} 1, \mathrm{~B} 2$, and B3 were likely due to differences in sizing of space heating components relative to the building load. These components were sized to meet the load over the coldest week in the simulation year (see Subsection 3.5.3, pg. 33). While this design-conditions sizing approach is common in the HVAC profession, it does not necessarily result in component sizes that are matched well to the most common load conditions. Differences in part-load conditions relative to peak load conditions likely account for the differences in the provision of space heating between B1, B2, and B3. Despite this, the comparison between plants for a single building/occupancy case was not compromised as space heating component sizing was consistent between plants.

The amount of heat dumped annually $\left(q_{d u m p}\right)$ by the heat-dump component is calculated using Equation 6.3:

$$
q_{d u m p}=\sum_{t=1}^{525,600} \dot{m}_{w}^{t} \Delta t c_{p, w}\left(T_{w, \text { in }}^{t}-T_{w, \text { out }}^{t}\right)
$$

where $\dot{m}_{w}^{t}$ is the mass flow rate of water through the heat dump component $[\mathrm{kg} / \mathrm{s}]$, 
Table 6.4: Performance metric results of the building/occupant sensitivity study for both plant configurations.

\begin{tabular}{|c|c|c|c|c|c|c|c|}
\hline \multirow{2}{*}{$\begin{array}{c}\text { Building/occupancy model } \\
\text { Plant }\end{array}$} & \multicolumn{2}{|c|}{ B1 } & \multicolumn{2}{|c|}{$\mathrm{B} 2$} & \multicolumn{2}{|c|}{ B3 } & \multirow[b]{2}{*}{ units } \\
\hline & $1-\tan k$ & 2-tank & 1-tank & 2 -tank & $1-\operatorname{tank}$ & $2-\operatorname{tank}$ & \\
\hline PEMFC fuel use & 2242 & 2325 & 2236 & 2395 & 2389 & 2616 & $\mathrm{~m}^{3}$ \\
\hline dhw-heater fuel use & 2 & 32 & 11 & 30 & 34 & 98 & $\mathrm{~m}^{3}$ \\
\hline spc-heater fuel use & 969 & 1093 & 1622 & 1728 & 5090 & 5133 & $\mathrm{~m}^{3}$ \\
\hline Electical generation & 7432 & 7704 & 7402 & 7883 & 7785 & 8363 & $\mathrm{kWh}$ \\
\hline DHW energy delivered $\left(\hat{q}_{d h w}\right)$ & 1.20 & 0.99 & 1.16 & 0.99 & 1.10 & 0.98 & - \\
\hline SH energy delivered $\left(\hat{q}_{s p c}\right)$ & 0.91 & 0.91 & 0.91 & 0.92 & 1.04 & 1.04 & - \\
\hline Heat dump $\left(q_{d u m p}\right)$ & 12.0 & 18.7 & 8.3 & 16.0 & 5.1 & 12.4 & GJ \\
\hline Net elec. cost & -357 & -378 & -36 & -69 & 255 & 216 & $\$$ \\
\hline Fuel cost & 760 & 816 & 915 & 982 & 1777 & 1856 & $\$$ \\
\hline Electrical generation cost & 7.14 & 7.14 & 7.14 & 7.18 & 7.26 & 7.40 & $\mathbb{c} / \mathrm{kWh}$ \\
\hline Total cost $\left(C_{a}\right)$ & 403 & 438 & 879 & 913 & 2032 & 2072 & $\$$ \\
\hline
\end{tabular}


$T_{w, i n}^{t}$ is the water temperature at the component's inlet $\left[{ }^{\circ} \mathrm{C}\right]$, and $T_{w, \text { out }}^{t}$ is the temperature at the outlet $\left[{ }^{\circ} \mathrm{C}\right]$, all at time $t$.

Figure 6.7 shows the annual heat dump for the three household cases and two plant configurations. For both plants, heat dump decreases as the building load increases, indicating that a greater demand for heat results in less wasted heat. As is expected from the detailed plant behaviour described in Sections 6.2 and 6.3, the heat dump is considerably greater for the 2-tank plant for all households. This is due to the fact that the 1-tank plant tends to reduce PEMFC output during heat dump operation, while the 2-tank plant does not. The annual heat dump was between 6.7 and 7.7 GJ less for the 1-tank plant.

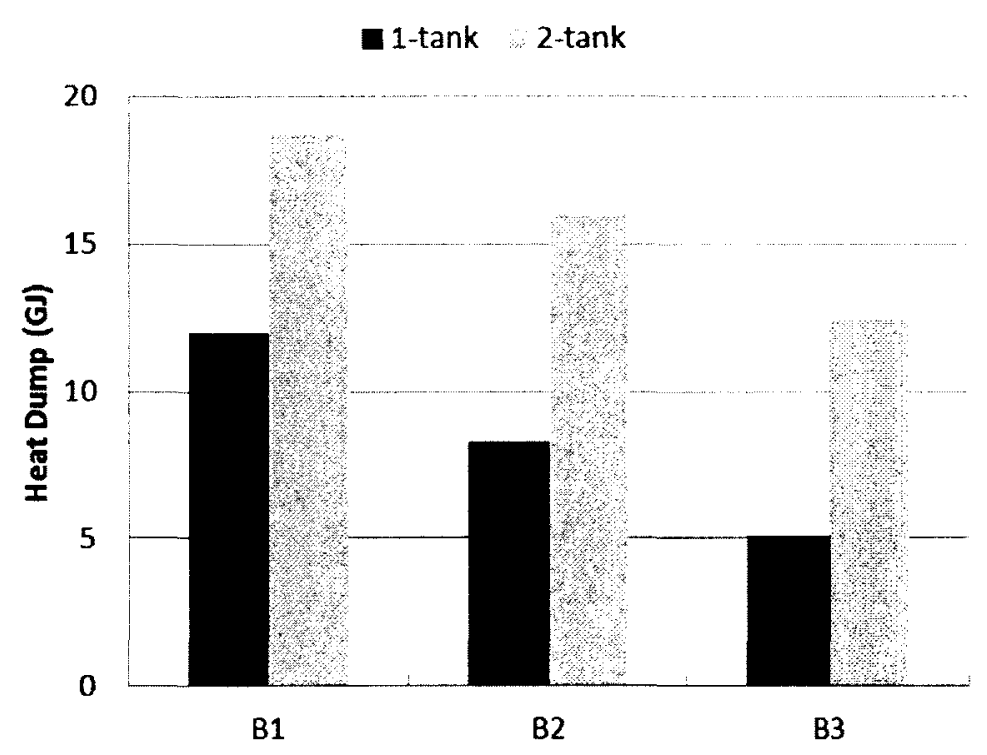

Figure 6.7: Annual heat dump for 1 and 2-tank plant configurations, for each of the three building/occupancy models.

The annual electricity generated was between $2.2 \%$ and $3.6 \%$ higher for the 2 -tank plant. This resulted in $\$ 21$ and $\$ 39$ more in electrical generation revenue. Greater electrical production, along with increased fuel consumption by in-line heaters resulted in fuel costs $\$ 56$ to $\$ 79$ more than for the 1-tank plant. Greater fuel costs were largely attributable to the increased heat dump for this plant. Increased heat loss due to a larger combined tank surface area may have also contributed.

Electricity production costs were calculated by dividing the cost of fuel consumed 
by the PEMFC by the annual gross electricity production. These costs ranged between 7.14 and $7.40 \mathrm{\Phi} / \mathrm{kWh}$, with higher costs for the 2-tank plant coupled with households B2 and B3.

Figure 6.8 shows the annual operating cost for each plant and household combination. For all households, the 1-tank plant outperformed the 2-tank plant by between $\$ 34$ and $\$ 40$ (see Table 6.4).

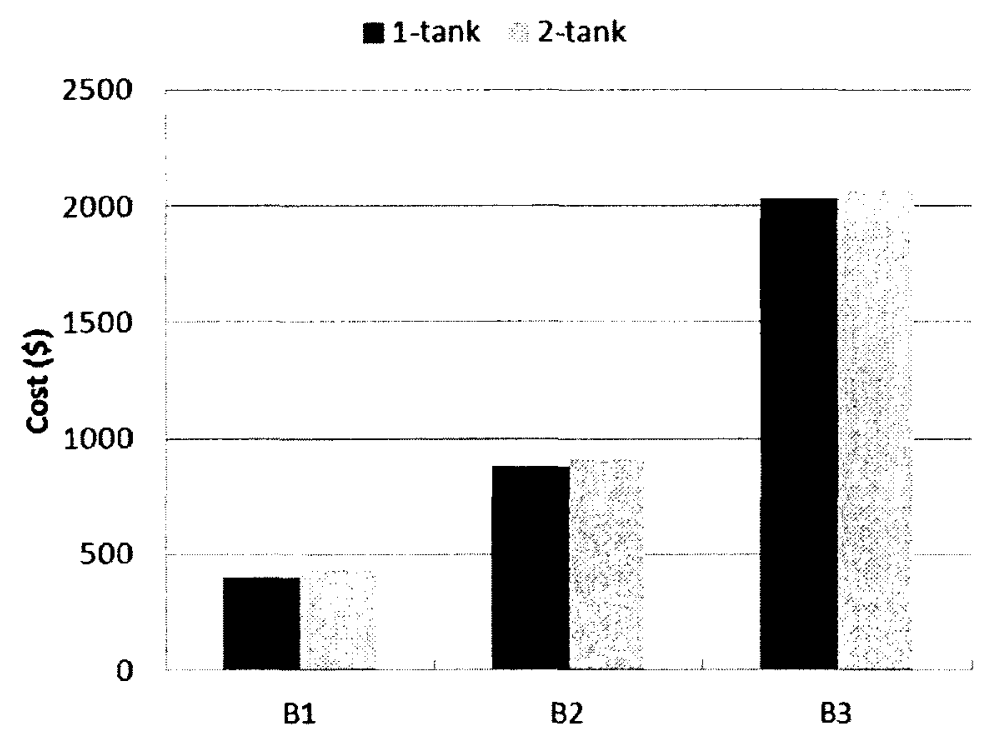

Figure 6.8: Annual operating cost comparison between 1 and 2 tank configurations, for $\mathrm{B} 1, \mathrm{~B} 2$, and $\mathrm{B} 3$.

\subsection{Control Method Comparison}

This section presents the results of a comparison between the four PEMFC control modes described in Section 4.2 (pg. 40), with the building/occupancy case B2. All tank volumes were chosen to be $0.5 \mathrm{~m}^{3}$ so that only the control varied between test cases for each plant. Control of in-line heaters, heat-dump components, fans and pumps was not altered between test cases. Results for both plant configurations operating in each of the four modes are presented in Table 6.5.

The hybrid mode used optimized $T_{1}, T_{2}$, and $\alpha$ values given for 1 and 2 -tank B2 cases (see Tables 6.2 and 6.3). This mode resulted in the lowest operating cost of any examined - $\$ 879$ and $\$ 913$ for the 1 and 2-tank plants, respectively. It is interesting to 
note that while tank volumes were smaller than those determined through optimization $\left(0.853 \mathrm{~m}^{3}\right.$ and $\left.0.979 \mathrm{~m}^{3}\right)$, the annual operating costs did not show a significant change. This provides additional evidence that annual operating cost is not sensitive to storage tank volume over this range.

The most basic control examined was the constant mode, which sets the PEMFC electrical output to maximum during the heating season and minimum during the cooling season. This resulted in annual operating costs $\$ 31$ and $\$ 30$ higher than the hybrid mode for the 1 and 2-tank plants, respectively. It also resulted in less electrical production than all but the electrical price following mode. As illustrated in Section 6.3 , the hybrid control for the 2-tank plant did not actually follow thermal loads. However, it still resulted in a lower annual cost than the constant control that, at least simplistically, did follow thermal loads. This may indicate that the electricity and natural gas prices chosen were such that maintaining maximum output was profitable, even while the heat dump operated.

The tank temperature following mode used $T_{1}$ and $T_{2}$ values obtained through the $\mathrm{B} 2$ optimizations described above. This mode resulted in the highest electrical production and heat dump for both plants. Operating costs were both $\$ 8$ higher than those for the 1 and 2-tank plants with the hybrid control. That the difference in costs was small is not surprising given that the hybrid control was biased heavily towards temperature following.

The electrical price following mode set the PEMFC DC output to its maximum during on-peak times, and minimum during off-peak times. This mode resulted in the highest annual costs - $\$ 212$ and $\$ 202$ greater than those of the hybrid mode for the 1 and 2-tank plants, respectively. This poor performance seems to be due to the low electricity production that resulted from this strategy - only $31 \%$ and $30 \%$ of the gross electrical generation of the hybrid cases were produced for the 1 and 2-tank electrical cases, respectively. This mode also resulted in the lowest heat dump of any control, with a value of $0.00 \mathrm{GJ}$ for the 1-tank plant and $1.29 \mathrm{GJ}$ for the 2-tank plant. The 1-tank plant delivered within $15 \%$ of the required DHW energy, and within $9 \%$ of the required space heating energy for all controls. The 2-tank plant delivered within $3 \%$ of the required DHW energy and within $9 \%$ of the required space heating energy for all controls examined. This variation is explained by the discussion presented in the previous section.

Figures 6.9 and 6.10 show the annual operating cost and heat dump for all controls 
Table 6.5: Results of the control mode comparison for both plant configurations coupled with B2.

\begin{tabular}{|c|c|c|c|c|c|c|c|c|c|}
\hline \multirow{2}{*}{$\begin{array}{l}\text { Plant } \\
\text { Control }\end{array}$} & \multicolumn{4}{|c|}{$1-\operatorname{tank}$} & \multicolumn{4}{|c|}{ 2-tank } & \multirow[b]{2}{*}{ units } \\
\hline & constant & thermal & electrical & hybrid & constant & thermal & electrical & hybrid & \\
\hline Total fuel use & 3747 & 3940 & 3022 & 3869 & 3867 & 4181 & 3122 & 4154 & $\mathrm{~m}^{3}$ \\
\hline Electrical generation & 6722 & 7611 & 2330 & 7402 & 6727 & 7887 & 2329 & 7883 & $\mathrm{kWh}$ \\
\hline DHW energy delivered $\left(\hat{q}_{d h w}\right)$ & 1.11 & 1.15 & 1.02 & 1.15 & 0.98 & 0.98 & 0.97 & 0.99 & - \\
\hline SH energy delivered $\left(\hat{q}_{s p c}\right)$ & 0.91 & 0.91 & 0.93 & 0.91 & 0.91 & 0.92 & 0.93 & 0.92 & - \\
\hline Heat dump $\left(q_{\text {dump }}\right)$ & 6.13 & 9.37 & 0.00 & 8.61 & 9.44 & 16.93 & 1.29 & 15.97 & GJ \\
\hline Net electrical cost & 24 & -48 & 376 & -36 & 29 & -69 & 377 & -69 & $\$$ \\
\hline Fuel cost & 886 & 932 & 715 & 915 & 914 & 989 & 738 & 982 & $\$$ \\
\hline Total cost $\left(C_{a}\right)$ & 910 & 884 & 1091 & 879 & 943 & 920 & 1115 & 913 & $\$$ \\
\hline
\end{tabular}




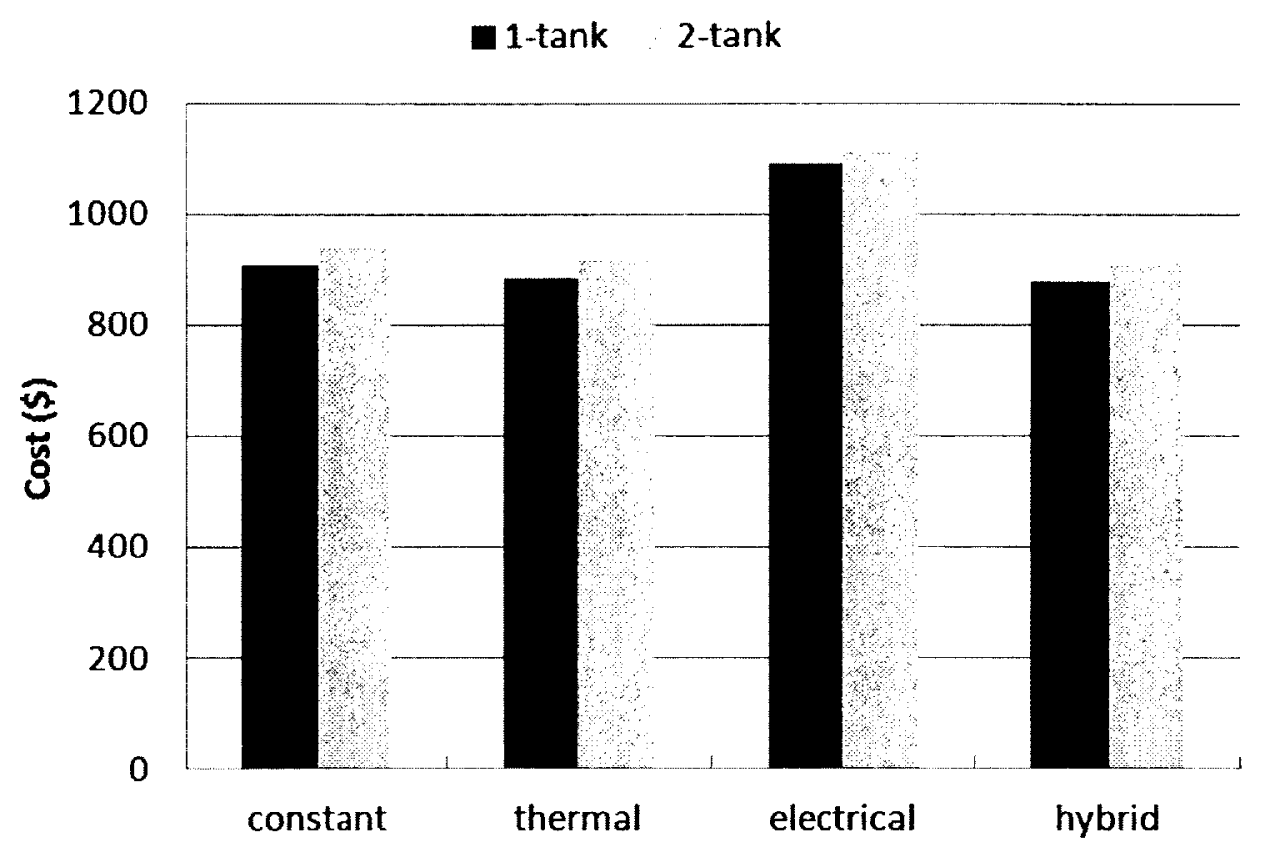

Figure 6.9: Annual operating cost comparison between 1 and 2-tank plants, for each control mode.

examined. In each case, the 1-tank plant outperforms the 2-tank plant for both metrics. The lowest annual operating cost is obtained with the hybrid mode for both plants, and the lowest heat dump is obtained for the electrical price following mode, for both plants. The tank temperature following mode compared most favourably to the hybrid mode, providing additional evidence that the high values of $\alpha$ determined through optimization were appropriate.

\subsection{Concluding Remarks}

These results show that with the implemented controls, the 1-tank plant configuration outperforms the 2-tank plant in terms of operating cost and heat dump. Over the simulation year, the 1-tank plant resulted in 34 to $40 \$$ lower operating cost, and 6.7 to 7.7 GJ less heat dumped compared to the 2-tank plant. These results show that the hybrid PEMFC control mode outperforms the others examined here in terms of cost by $\$ 4$ to $\$ 212$. The control mode comparison supports the conclusion that 


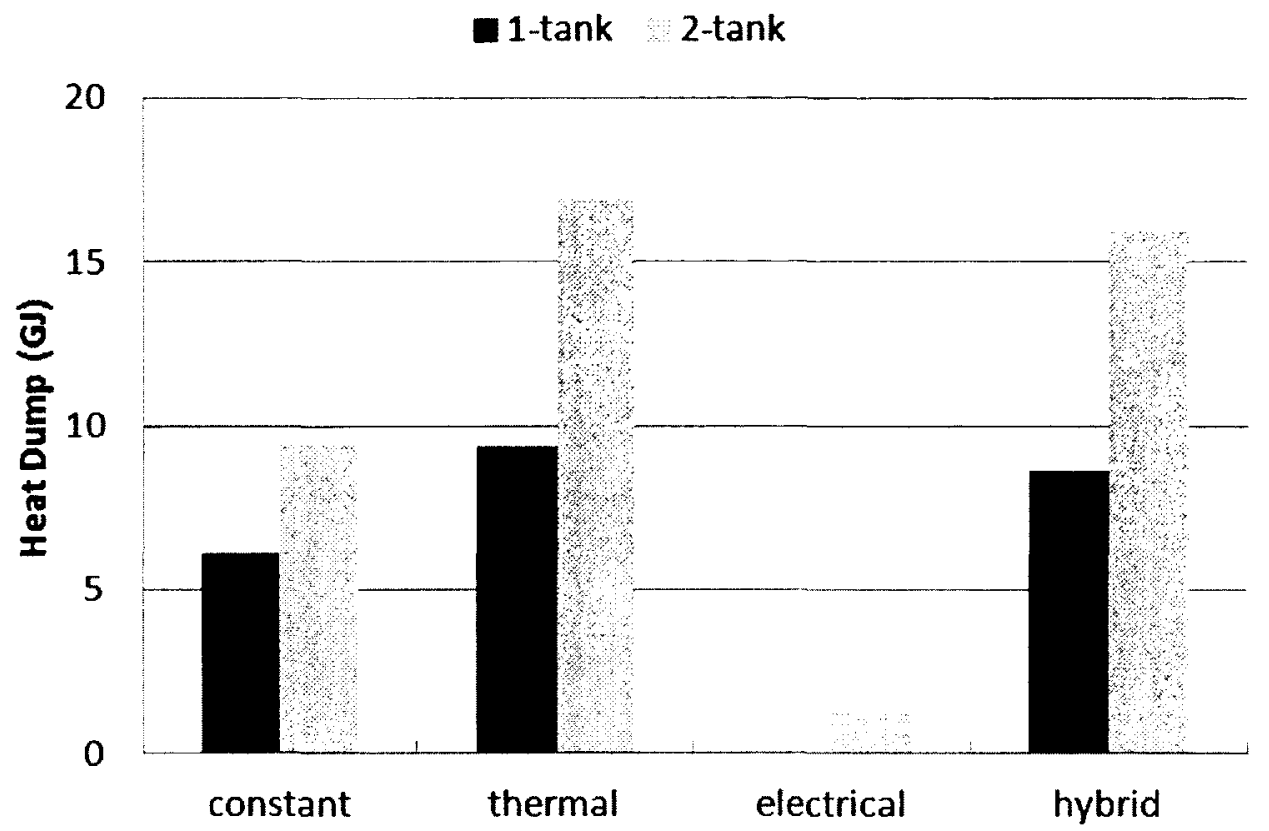

Figure 6.10: Annual heat dump comparison between 1 and 2-tank plants, for each control mode.

it is desirable to bias a hybrid control towards tank temperature following rather than electrical price following. This bias should be done by using a weighting factor between 91 and $94 \%$ for the 1-tank plant, or between 78 and $93 \%$ for the 2-tank plant. For optimized simulations using the 1-tank plant, PEMFC output decreases in the presence of a heat dump. This supports the conclusion that minimizing heat dump improves the financial viability of a fuel cell cogeneration system.

The following chapter summarizes and concludes this thesis and gives recommendations for future work. 


\section{Chapter 7}

\section{Conclusions and Recommendations}

As stated in Chapter 1, the goals of this thesis were to:

- compare the performance of 1 and 2-tank PEMFC micro-cogeneration plants

- determine the volume(s) appropriate for thermal storage

- implement and optimize a hybrid control strategy

- examine the sensitivity of results obtained to changes in building and occupancy characteristics

These goals have been accomplished using building simulation software to implement the building, occupant, and plant models described, and by the optimization methodology described in Chapter 5. Section 7.1 summarizes the work performed and the main results of this thesis. Section 7.2 gives recommendations for further research in this area.

\subsection{Conclusions}

\section{ESP-r Models}

This thesis used the building simulation program ESP-r to concurrently model thermal and electrical behaviour of buildings, occupants, and fuel cell micro-cogeneration plants. Models of single-family, detached Canadian houses developed by Swan [8] were used. These were coupled to occupancy models using casual gains schedules, experimentally measured non-HVAC electrical draw profiles, and a stochastic DHW model. This yielded three household models of varying space heating, DHW, and 
electrical loads: B1, B2, and B3. Ottawa weather data from CWEC was chosen for use in simulations.

The PEMFC was represented by an experimentally calibrated model of a 1.0 $\mathrm{kW}_{A C}$ PEMFC device, the result of work performed by Johnson et al. [9]. The output heat from this device was stored and dispatched to building loads using two thermal plants. These included one and two thermal storage volumes, and were referred to as the 1-tank and 2-tank plants, respectively. These plants integrated water tanks with internal heat-exchangers to provide storage of the heat generated by the PEMFC device. The ability to dump heat was included so that thermal production exceeding the household load and storage capacity could be eliminated. In-line, natural gas fired heaters were placed within the plants to meet demands for space heating and DHW exceeding the PEMFC capacity. These plants used a fan and air-water heat exchanger arrangement to meet space heating loads. DHW was provided on-demand, rather than stored, in the 1-tank plant. This configuration heated city mains water in

a heat exchanger internal to the storage tank. In the 2-tank plant, DHW was stored at a temperature of $55^{\circ} \mathrm{C}$ and drawn out as required to meet household demand.

\section{Thermal Plant and PEMFC Control}

Plant controls were implemented using a new ESP-r subroutine, written as part of this work. This subroutine used temperatures and flow rates within the plant and building domains to determine the control signals sent to components.

Plant components in the space heating circuit were switched on when the building air temperature fell below $20.5^{\circ} \mathrm{C}$, and off when it rose above $21.5^{\circ} \mathrm{C}$. The heat-dump components were controlled to prevent over-heating of the tanks in order to keep the PEMFC coolant water from overheating. In-line DHW heaters were controlled to keep DHW at the chosen set-point temperature for each plant configuration. In the space heating circuit, in-line heaters supplemented the PEMFC heat production when loads exceeded it.

To make a control comparison possible, four modes of operation were implemented for the PEMFC: (i) constant output, (ii) tank temperature following, (iii) electrical price following, and (iv) hybrid. The constant mode set the device output to maximum in the heating season and minimum in the cooling season. The tank temperature following control set the device output to a maximum when the outlet temperature of the coupled tank fell below a set-point $T_{1}$, and minimum when the temperature 
rose above $T_{2}$. Between these temperatures the PEMFC DC electrical output was decreased proportionally to increasing temperature. The electrical price following control set the PEMFC output to maximum when the TOU electricity price was at a maximum, and minimum when the price was minimum. Between these, PEMFC output was increased proportionally to increasing price. The hybrid mode of operation was a linear combination of thermal and electrical modes, with a weighting factor $\alpha$.

\section{Optimization Methodology}

Tank volumes $V_{1}$ and $V_{2}$, as well as PEMFC control parameters $\Delta T, T_{c}$, and $\alpha$ were chosen as the independent parameters for optimization. $\Delta T, T_{c}$ were linear combinations of $T_{1}$ and $T_{2}$, and were used to ensure that the values found through optimization satisfied $T_{1}<T_{2}$.

Annual operating cost was chosen as the objective function for the optimization, because of its importance to to homeowners and its impact on viability of FC microcogeneration in residential homes. This cost was calculated with the current (at the time of writing) natural gas price and TOU electricity rates for Ontario.

GenOpt was chosen for this research because of its ability to use an external simulation program for an optimization, and for its library of algorithms. GenOpt was configured to communicate with ESP-r by reading and writing to text files that were passed between the two programs. The process of calling ESP-r, reading in independent variables, and calculating the value of the cost function was automated using Fortran and shell scripting.

A combination of PSO and GPS algorithms was chosen to perform the optimization. These algorithms were run in succession, with the termination point of the PSO used as the initial point of the GPS. This was done to utilize the strengths of each

algorithm. The PSO searches a wide range of independent parameter values before terminating, and the GPS then searches the independent parameter space in a smaller region around the PSO termination point.

\section{Optimization Sensitivity Study}

An optimization algorithm sensitivity study was performed to determine the number of PSO particles appropriate for use during optimization. The 1-tank plant and household model B2 were used as the test case. Optimizations were performed with 
4,8 , and 16 PSO particles. It was found that the number of particles had no significant impact upon the cost function. Therefore, the increased computational expense associated with the higher particle numbers could not be justified, and 4 particles were chosen for use in optimizations.

It is difficult to know if an optimization has found a global minimum without doing an extensive search over the entire independent parameter space. For this reason, the independent parameter combinations found through optimization were referred to as termination points, rather than optimal solutions.

\section{1-tank Plant Performance}

4 particle PSO-GPS optimizations were performed with the 1-tank plant coupled to households B1, B2, and B3. This was done in order to determine the sensitivity of control parameters and tank volume to varying building and occupancy characteristics.

Between households, tank volume at the termination point varied by a maximum of $13.3 \%$ from the mean value for all cases of $0.790 \mathrm{~m}^{3}$. Additional simulations for which tank volume was varied indicated that operating cost was not sensitive to tank volume over this range. The hybrid parameter $\alpha$ varied by at most $2.2 \%$ from the mean value of 0.927 . This resulted in a hybrid control that was biased towards tank temperature following. $T_{1}$ varied by at most $0.6^{\circ} \mathrm{C}$ from the mean value of $52.4^{\circ} \mathrm{C}$, and $T_{2}$ varied by at most $0.1^{\circ} \mathrm{C}$ from the mean value of $66.7^{\circ} \mathrm{C}$. This resulted in a tank temperature following signal of 1 for much of the heating season. During the cooling and shoulder seasons, the signal decreased due to increasing tank temperature. The $T_{1}$ and $T_{2}$ values found through optimization resulted in a tank temperature following control that followed thermal loads to some extent. Given the high value of $\alpha$ for the 1-tank plant, the PEMFC output was largely determined by the temperature following signal. This resulted in $\mathrm{AC}$ electrical production close to a maximum for much of the heating season, and decreased production during the shoulder and cooling seasons.

Annual operating costs were $\$ 403, \$ 879$, and $\$ 2032$ for the households B1, B2, and B3, respectively. Heat dump ranged between 5.1 and $12.0 \mathrm{GJ}$, and decreased with increasing household demand for heat. Throughout the simulation year, PEMFC output tended to decrease in the presence of a heat dump for the optimized hybrid controls. 


\section{2-tank Plant Performance}

Optimizations were also performed with the 2-tank plant coupled to each of the three household models.

At the termination points of the optimizations, tank volume $V_{1}$ varied between households by at most $39.3 \%$ from the mean value of $0.804 \mathrm{~m}^{3} . V_{2}$ varied by at most $37.2 \%$ from the mean value of $0.701 \mathrm{~m}^{3}$. Additional simulations for which tank volumes were varied indicated that cost was not sensitive to tank volumes in this range. This was presented as an explanation of the variation between households. $T_{1}$ varied by at most $1.1^{\circ} \mathrm{C}$ from the mean value of $55.2^{\circ} \mathrm{C}$, while $T_{2}$ varied by as much as $6.1^{\circ} \mathrm{C}$ from the mean value of $66.3^{\circ} \mathrm{C}$. Despite the variation in $T_{2}$, all set-point combinations resulted in similar temperature led behaviour. The $T_{1}$ and $T_{2}$ found through optimization were such that the tank temperature following control did not follow thermal loads, but maintained a thermal signal close to 1 throughout the year. The hybrid parameter $\alpha$ varied by up to $9.5 \%$ from the mean value of 0.862 . $\alpha$ increased with increasing household heat demand. Due to the temperature following control behaviour described above, increasing $\alpha$ acted to increase average heat and electrical production of the PEMFC.

Annual operating costs were $\$ 438, \$ 913$, and $\$ 2072$ for households B1, B2, and B3, respectively. Heat dump ranged from 12.4 to $18.7 \mathrm{GJ}$, decreasing with increasing household demand for heat. In general, PEMFC output did not decrease in the

presence of a heat dump for the 2-tank plant, due to the control behaviour described above.

\section{Control Comparison}

Annual ESP-r simulations were performed with the implemented PEMFC control modes for both plants. For these simulations, household B2 was used. All tank volumes were held constant at $0.5 \mathrm{~m}^{3}$, while optimal values for $T_{1}, T_{2}$, and $\alpha$ were used.

These controls resulted in annual operating costs ranging from $\$ 879$ to $\$ 1091$ for the 1-tank plant, and from $\$ 913$ to $\$ 1115$ for the 2 -tank plant. Heat dumps ranged from 0 to $9.37 \mathrm{GJ}$ for the 1-tank plant, and from 1.29 to $16.93 \mathrm{GJ}$ for the 2-tank plant.

For both plants, the best cost performance was obtained for the hybrid control, and the smallest heat dumps for the electrical price following mode. The small heat 
dumps for the electrical mode were the result of decreased annual production of heat and electricity. The tank temperature following mode compared most favourably to the hybrid mode in terms of cost, providing additional evidence that the high values of $\alpha$ determined through optimization were appropriate.

\section{Closing Remarks}

These results show that with the implemented controls, the 1-tank plant configuration outperforms the 2-tank plant in terms of annual operating cost and heat dump. For the three households considered, the 1-tank plant resulted in $\$ 34$ to $\$ 40$ lower operating cost and 6.7 to 7.7 GJ less heat dumped compared to the 2-tank plant.

In the 1-tank plant, the lowest costs were obtained for storage tank volumes ranging from 0.686 to $0.853 \mathrm{~m}^{3}$ between household cases. For the 2-tank plant, the best cost performance was obtained for DHW tank volumes ranging from 0.488 to $0.979 \mathrm{~m}^{3}$, and space heating tank volumes from 0.497 to $0.963 \mathrm{~m}^{3}$. It was found that variations in tank volume were due to low sensitivity of the cost function to tank volumes in this range.

These results indicate that for the PEMFC controller and plant configurations studied, the control should be biased towards tank temperature following. This bias should be between 91 and $94 \%$ for the 1-tank plant, and between 78 and $93 \%$ for the 2 -tank plant. For the 1-tank plant, the values of $T_{1}$ and $T_{2}$ found through optimization caused PEMFC output to decrease in the presence of a heat dump. This supports the conclusion that minimizing heat dump improves the financial viability of a fuel cell micro-cogeneration system.

These results show that the hybrid PEMFC control outperforms the others examined here in terms of cost by $\$ 4$ to $\$ 212$ in a typical single-family detached household. The control mode comparison supports the conclusion that it is desirable to bias a hybrid PEMFC controller towards thermal load following for the 1-tank plant configuration.

Though effort was made to implement the plants and controls sensibly and in a manner consistent with past studies, these results should not be over-generalized. In

particular, the conclusions do not necessarily apply to all possible plant configurations using one or two storage tanks, or all possible controls that could be designed for them.

It should be noted that these results are sensitive to assumptions about electricity buy-back price. At the time of writing, the regulatory framework in Ontario 
did not specify an electricity buy-back price for fuel cell micro-cogeneration plants. The results are also sensitive to the ratio of fuel price to electricity price. As these prices change, it is likely that the optimal ratio of temperature following to electrical following will as well.

\subsection{Recommendations for Future Work}

This work represents a step towards an optimal hybrid strategy of PEMFC control, and answers the questions posed in Chapter 1 for a particular set of input costs, plant configurations, and control methods. This section presents recommendations for future research that would generalize these results, and new directions to go in.

The results obtained may be sensitive to input parameters that were not varied as part of this study. In particular, the high level of tank insulation assumed may impact plant performance. Future work should examine the sensitivity of performance to varying levels of tank insulation.

In the research presented, the controls and plants that were able to reduce PEMFC output in the presence of a heat dump performed better than those that were not. It would be interesting to examine a PEMFC controller that directly sensed the occurrence of a heat dump. Such a controller may outperform the one implemented as part of this thesis.

Annual operating cost from the perspective of the homeowner was used as the objective function in this thesis. However, this is not the only way to calculate cost. The value of electricity from the utility's perspective is different from the homeowner's perspective. It would be interesting to determine the optimal configuration and control for a utility-owned device, as the optimal plant configuration and control may differ.

It would be useful to follow up this thesis with an optimization study using other objective functions entirely, such as annual GHG emissions or source energy consumption. It would be interesting to see if this result differed in terms of optimal control parameters and tank volumes. Ideally, the optimal control and storage size for a FC micro-cogeneration plant would perform well across all three metrics. This direction of study would aid the development of more meaningful performance metrics, and may be useful to policy makers considering if or how to encourage the adoption of micro-cogeneration. 
One challenge in the implementation of a physical micro-cogeneration plant is to find an economical way to provide a heat dump. This issue was not addressed here as it was deemed to be beyond the scope of the present research. However, it warrants consideration in the future. If it is not practical to have a heat dump in a physical implementation, it may make sense to conduct optimizations that impose a cost penalty to heat dumps. This would act to discourage, and perhaps eliminate, the over-production of heat.

It was noted above that the results presented here are sensitive to assumptions about the electricity buy-back price and the price of natural gas. The assumption that the price homeowners pay for electricity is the same as the buy-back price also has an effect. For a buy-back price less than what the homeowner pays to purchase electricity, a different type of electric following may be desirable. In this case, providing electricity to the homeowner becomes more cost effective than selling to the grid, and electrical load following may outperform price following. This could be examined in a study of the sensitivity of controls to a range of electricity price structures. Such a study would also be useful from a policy perspective. This could shed light on the following question: to what degree would micro-cogeneration electrical production need to be subsidized in order to encourage adoption?

The recommendations presented here give some indication of directions future research could take. Apart from modelling studies, experimental work to characterize other micro-cogeneration devices is necessary. Increasing the number of calibrated models available allows the performance of devices with different characteristics to be explored. The results of any simulation study are limited by the accuracy of the models used to predict physical behaviour. 


\section{List of References}

[1] American Society of Heating Refrigerating and Air-Conditioning Engineers, 2009 ASHRAE Handbook-Fundamentals (SI Edition). 2009.

[2] Enbridge Gas Distribution, "New Rate Information July 2012." https:// www.enbridgegas.com/homes/accounts-billing/residential-gas-rates/ purchasing-gas-from-enbridge.aspx, 2012. Accessed: 01/08/2012.

[3] Y. Cengel and M. Boles, Thermodynamics: An Engineering Approach, Sixth Edition. New York, USA: McGraw Hill, 6 ed., 2008.

[4] Ontario Energy Board, "Electricity Prices." http://www . ontarioenergyboard. ca/OEB/Consumers/Electricity/Electricity+Prices. $01 / 06 / 2012$.

[5] Natural Resources Canada - Office of Energy Efficiency, "Energy Use Data Handbook, 1990 to 2009 ," 2012.

[6] U.S. Department of Energy, "Types of Fuel Cells." http://www1.eere. energy.gov/hydrogenandfuelcells/fuelcells/fc_types.html, 2011. Accessed: $28 / 11 / 2012$.

[7] J. L. M. Hensen, On the Thermal Interaction of Building Structure and Heating and Ventilating System of Building Structure. Phd thesis, University of Strathclyde, 1991.

[8] L. Swan, Residential Sector Energy and GHG Emissions Model for the Assessment of New Technologies. Phd thesis, Dalhousie University, 2010.

[9] G. Johnson, I. Beausoleil-Morrison, B. Strathearn, E. Thorsteinson, and T. Mackintosh, "The calibration and validation of a model for simulating the thermal and electrical performance of a $1 \mathrm{~kW}$ AC proton-exchange membrane fuel-cell micro-cogeneration device," Journal of Power Sources, vol. 221, pp. 435$446,2013$.

[10] M. Wetter, "GenOpt, Generic Optimization Program, User Manual, Version 3.1.0," 2011.

[11] Intergovernmental Panel on Climate Change, "Climate Change 2007 : Synthesis Report," Tech. Rep. November, IPCC, 2007. 
[12] Carbon Dioxide Information Analysis Center - U.S. Department of Energy, "National CO2 Emissions from Fossil-Fuel Burning, Cement Manufacture, and Gas Flaring: 1751-2008," 2011.

[13] The World Bank, World Development Indicators. World Bank Publications, cdr editio ed., Apr. 2012.

[14] U. C. Colpier and D. Cornland, "The economics of the combined cycle gas turbine - an experience curve analysis," Energy Policy, vol. 30, no. 4, pp. 309-316, 2002.

[15] T. DeMoss, "They're he-e-re (almost): the 60\% efficient combined cycle," Power Engineering, vol. 100, no. 7, pp. 17 21, 1996.

[16] I. Beausoleil-Morrison, "Micro-Cogeneration System Performance Prediction," in Building Performance Simulation for Design and Operation (J. L. Hensen and R. Lamberts, eds.), ch. 12, Routledge, 1 ed., 2010.

[17] I. Beausoleil-Morrison, "The empirical validation of a model for simulating the thermal and electrical performance of fuel cell micro-cogeneration devices," Journal of Power Sources, vol. 195, pp. 1416-1426, Mar. 2010.

[18] J. E. Brown, C. N. Hendry, and P. Harborne, "An emerging market in fuel cells? Residential combined heat and power in four countries," Energy Policy, vol. 35, pp. 2173-2186, Apr. 2007.

[19] N. Bergman, A. Hawkes, D. Brett, and E. al., "Review of UK microgeneration. Part I: policy and behavioural aspects," Proceedings of the Institution of Civil Engineers, Energy, vol. 162, no. 1, pp. 23-36, 2009.

[20] Carbon Trust, "Micro-CHP Accelerator - Final Report," Tech. Rep. March, Carbon Trust, 2011.

[21] K. Alanne, N. Söderholm, K. Sirén, and I. Beausoleil-Morrison, "Technoeconomic assessment and optimization of Stirling engine micro-cogeneration systems in residential buildings," Energy Conversion and Management, vol. 51, pp. 2635-2646, Dec. 2010.

[22] V. Dorer and A. Weber, "Energy and CO2 emissions performance assessment of residential micro-cogeneration systems with dynamic whole-building simulation programs," Energy Conversion and Management, vol. 50, pp. 648-657, Mar. 2009 .

[23] I. Knight and H. Ribberink, "European and Canadian non-HVAC Electric and DHW Load Profiles for Use in Simulating the Performance of Residential Cogeneration Systems," tech. rep., Annex 42, IEA, 2007.

[24] I. Knight and I. Ugursal, "Residential Cogeneration Systems : A Review of The Current Technologies," tech. rep., International Energy Agency, 2005.

[25] a. Kirubakaran, S. Jain, and R. Nema, "A review on fuel cell technologies and power electronic interface," Renewable and Sustainable Energy Reviews, vol. 13, pp. 2430-2440, Dec. 2009. 
[26] R. Braun, S. Klein, and D. Reindl, "Evaluation of system configurations for solid oxide fuel cell-based micro-combined heat and power generators in residential applications," Journal of Power Sources, vol. 158, pp. 1290 1305, Aug. 2006.

[27] S. Klein, W. Beckman, J. Mitchell, J. Duffie, and E. al., TRNSYS 17: A Transient System Simulation Program, User Manual. Madison, WI: Solar Energy Laboratory University of Wisconsin-Madison, 2009.

[28] D. Haeseldonckx, L. Peeters, L. Helsen, and W. Dhaeseleer, "The impact of thermal storage on the operational behaviour of residential CHP facilities and the overall CO2 emissions," Renewable and Sustainable Energy Reviews, vol. 11, pp. 1227-1243, Aug. 2007.

[29] K. Alanne, A. Saari, V. I. Ugursal, and J. Good, "The financial viability of an SOFC cogeneration system in single-family dwellings," Journal of Power Sources, vol. 158 , pp. 403416 , July 2006.

[30] I. Beausoleil-Morrison, ed., An Experimental and Simulation-Based Investigation of the Performance of Small-Scale Fuel Cell and Combustion-Based Cogeneration Devices - Final Report of Annex 422 of the International Energy Agency Energy Conservation in Buildings and Community Systems P. 2008.

[31] I. Beausoleil-Morrison and K. Lombardi, "The calibration of a model for simulating the thermal and electrical performance of a $2.8 \mathrm{kWAC}$ solid-oxide fuel cell micro-cogeneration device," Journal of Power Sources, vol. 186, pp. 67--79, Jan. 2009 .

[32] I. Beausoleil-Morrison and H. Ribberink, "The Potential for Reducing Energy Consumption and Greenhouse Gas Emissions in the Ontario (Canada) Housing Sector with Solid-Oxide Fuel-Cell Micro-Cogeneration," in Micro-Cogeneration 2008, no. April, (Ottawa, Canada), 2008.

[33] C. Gähler, M. Gwerder, and R. Lamon, "Optimal Control of CHP Building Energy Systems," tech. rep., Siemens Switzerland Ltd / Building Technologies Group, 2008.

[34] V. Dorer, R. Weber, and a. Weber, "Performance assessment of fuel cell microcogeneration systems for residential buildings," Energy and Buildings, vol. 37, pp. 1132-1146, Nov. 2005.

[35] P. Strachan, G. Kokogiannakis, and I. Macdonald, "History and development of validation with the ESP-r simulation program," Building and Environment, vol. 43, pp. 601-609, Apr. 2008.

[36] J. Clarke, Energy Simulation in Building Design. Oxford: ButterworthHeinemann, 2 ed., 2001.

[37] I. Beausoleil-Morrison, The Adaptive Coupling of Heat and Air Flow Modelling Within Dynamic Whole-Building Simulation. PhD thesis, University of Strathclyde, 2000. 
[38] W. Wang, I. Beausoleil-Morrison, and J. Reardon, "Evaluation of the Alberta air infiltration model using measurements and inter-model comparisons," Building and Environment, vol. 44, pp. 309 318, Feb. 2009.

[39] N. Kelly, Towards a Design Environment for Building-Integrated Energy Systems: The Integration of Electrical Power Flow Modelling with Building Simulation. Ph.d. thesis, University of Strathclyde, Glasgow, UK, 1998.

[40] L. Swan, V. I. Ugursal, and I. Beausoleil-Morrison, "A database of house descriptions representative of the Canadian housing stock for coupling to building energy performance simulation," Journal of Building Performance Simulation, vol. 2 , pp. $75-84$, June 2009.

[41] Environment Canada - Atmospheric Environment Service and National Research Council of Canada, "Canadian Weather Energy and Engineering Data Sets (CWEEDS files) and Canadian Weather for Energy Calculations (CWEC files) - Updated User's Manual," 2010.

[42] N. Saldanha and I. Beausoleil-Morrison, "Measured end-use electric load profiles for 12 Canadian houses at high temporal resolution," Energy and Buildings, vol. 49, pp. 519-530, Mar. 2012.

[43] M. Armstrong, M. C. Swinton, H. Ribberink, I. Beausoleil-Morrison, and J. Millete, "Synthetically derived profiles for representing occupant-driven electric loads in Canadian housing," Journal of Building Performance Simulation, vol. 2, no. 1, pp. 15-30, 2009.

[44] U. Jordan and K. Vajen, "Influence Of The DHW Load Profile On The Fractional Energy Savings: A Case Study Of A Solar Combi-System With TRNSYS Simulations," Solar Energy, vol. 69, pp. 197-208, 2000.

[45] I. Beausoleil-Morrison and N. Kelly, "Specifications for Modelling Fuel Cell and Combustion-Based Residential Cogeneration Devices within Whole-Building Simulation Programs," tech. rep., Annex 42, IEA, 2007.

[46] B. Newton, Modeling of Solar Storage Tanks. Master's thesis, University of Wisconsin-Madison, 1995.

[47] D. Thevenard and K. Haddad, "Development of a Stratified Tank Model with Immersed Heat Exchangers in ESP-r," (Winnipeg), pp. 9-16, 2010.

[48] M. Bell, M. C. Swinton, E. Entchev, J. Gusdorf, F. Szadkowski, W. Kalbfleisch, M. M. Manning, and C. Leban, "Integration of a Residential-Sized Fuel Cell to Supply Electricity \& Heat to a House at the Canadian Centre for Housing Technology," tech. rep., Canadian Centre for Housing Technology, 2005.

[49] GRUNDFOS Pumps Corporation, "Grundfos Product Guide UP Series," 2010.

[50] J. Gusdorf, M. C. Swinton, E. Entchev, C. Simpson, and B. Castellan, "The impact of ECM furnace motors on natural gas use and overall energy use during the heating season of CCHT research facility," tech. rep., Canadian Centre for Housing Technology (CCHT), Ottawa, Canada, 2002. 
[51] K. Lombardi, V. I. Ugursal, and I. Beausoleil-Morrison, "Proposed improvements to a model for characterizing the electrical and thermal energy performance of Stirling engine micro-cogeneration devices based upon experimental observations," Applied Energy, vol. 87, pp. 3271-3282, Oct. 2010.

[52] American Society of Heating Refrigerating and Air-Conditioning Engineers, "ASHRAE Guideline 12-2000 Minimizing the Risk of Legionellosis Associated with Building Water Systems," 2000.

[53] M. Wetter, "Design Optimization with GenOpt," Building Energy Simulation User News, vol. 21, 2000.

[54] M. Wetter and J. Wright, "Comparison of a Generalized Pattern Search and a Genetic Algorithm Optimization Method," in Eighth International IBPSA Conference, (Eindhoven, Netherlands), 2003.

[55] M. Wetter and E. Polak, "A Convergent Optimization Method Using Pattern Search Algorithms with Adaptive Precision Simulation," in Eighth International IBPSA Conference, (Eindhoven, Netherlands), pp. 1393-1400, 2003.

[56] L. Peeters, M. Wetter, A. Ferguson, and W. Dhaeseleer, "The Coupling of ESPr and GenOpt : A Simple Case Study," in SimBuild 2010, Fourth National Conference of IBPSA-USA, (New York City, US), pp. 102-109, 2010.

[57] A. Carlisle and G. Dozier, "An Off-The-Shelf PSO," in Proceedings of the Workshop on Particle Swarm Optimization, (Indianapolis, IN.), 2001.

[58] Ontario Power Authority, "CHP Standard Offer Program Contract, Schedule 1, General Terms and Conditions, Version 1.0.0," 2011.

[59] Hydro One, "Residential Delivery Rates." http://www.hydroone.com/ RegulatoryAffairs/RatesPrices/Pages/ResidentialDeliveryRates . aspx, 2013. Accessed: 26/01/2013. 


\section{Appendix A}

\section{Plant Behaviour}

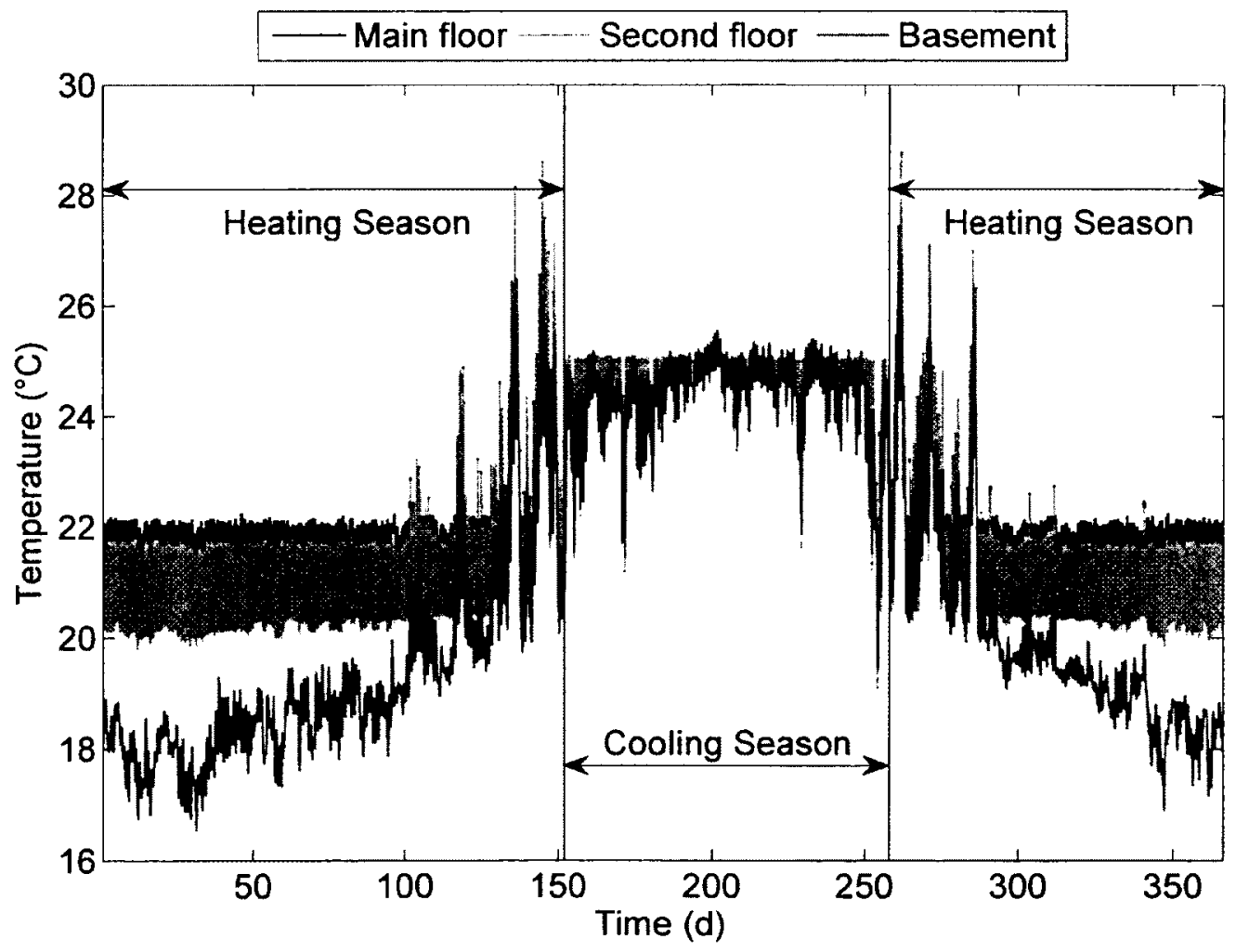

Figure A.1: Annual indoor zone temperatures for the 1-tank plant coupled with building/occupant model B2. Basement temperature varied sinusoidally throughout the year with changing ground temperature. 


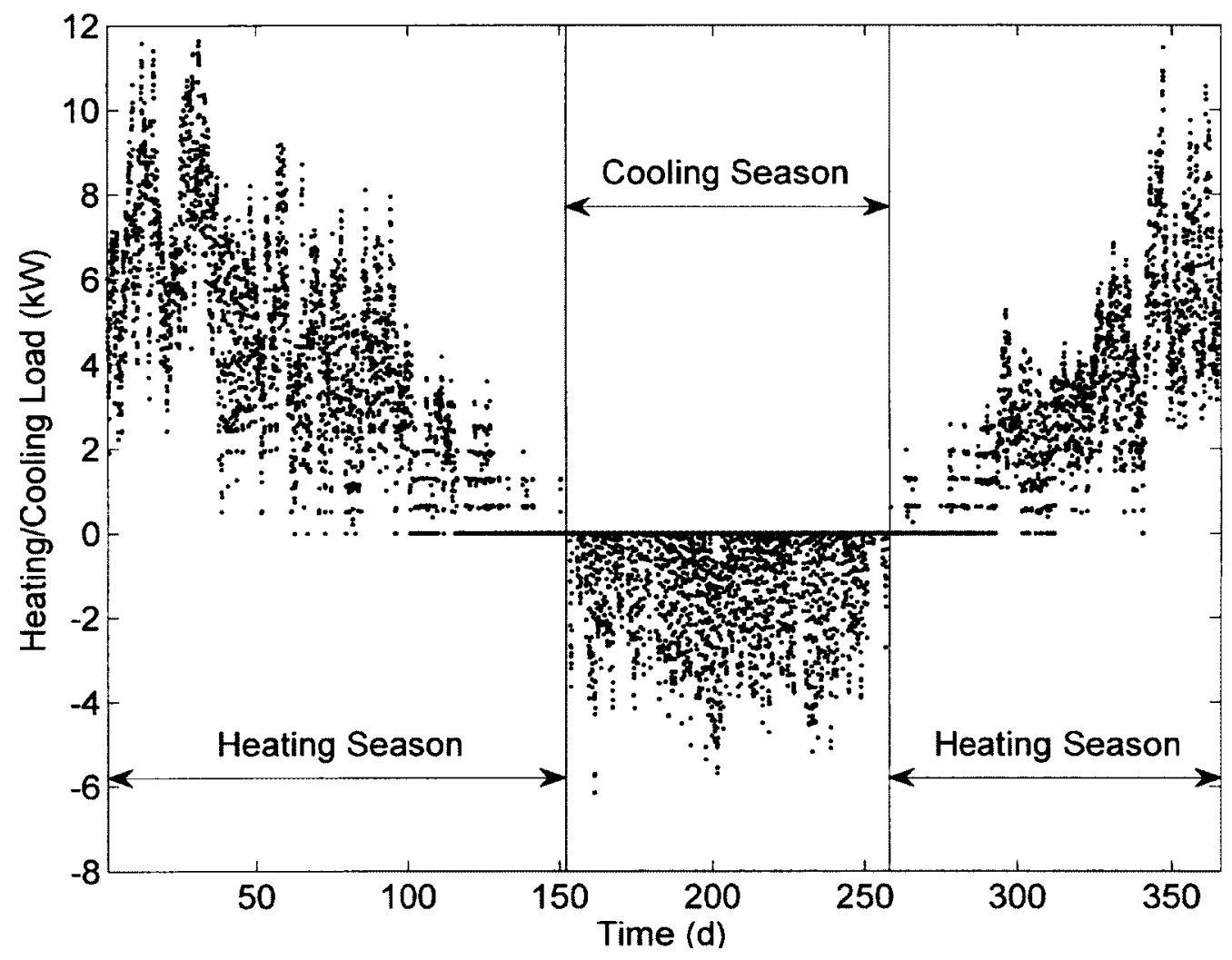

Figure A.2: Modelled heating and cooling loads (averaged hourly) for household B2 coupled with the 1-tank plant. Heating loads were met by an explicitly defined plant model (described in Chapters 3 and 4), while cooling loads were met using ideal heat extraction at the main floor air point. 


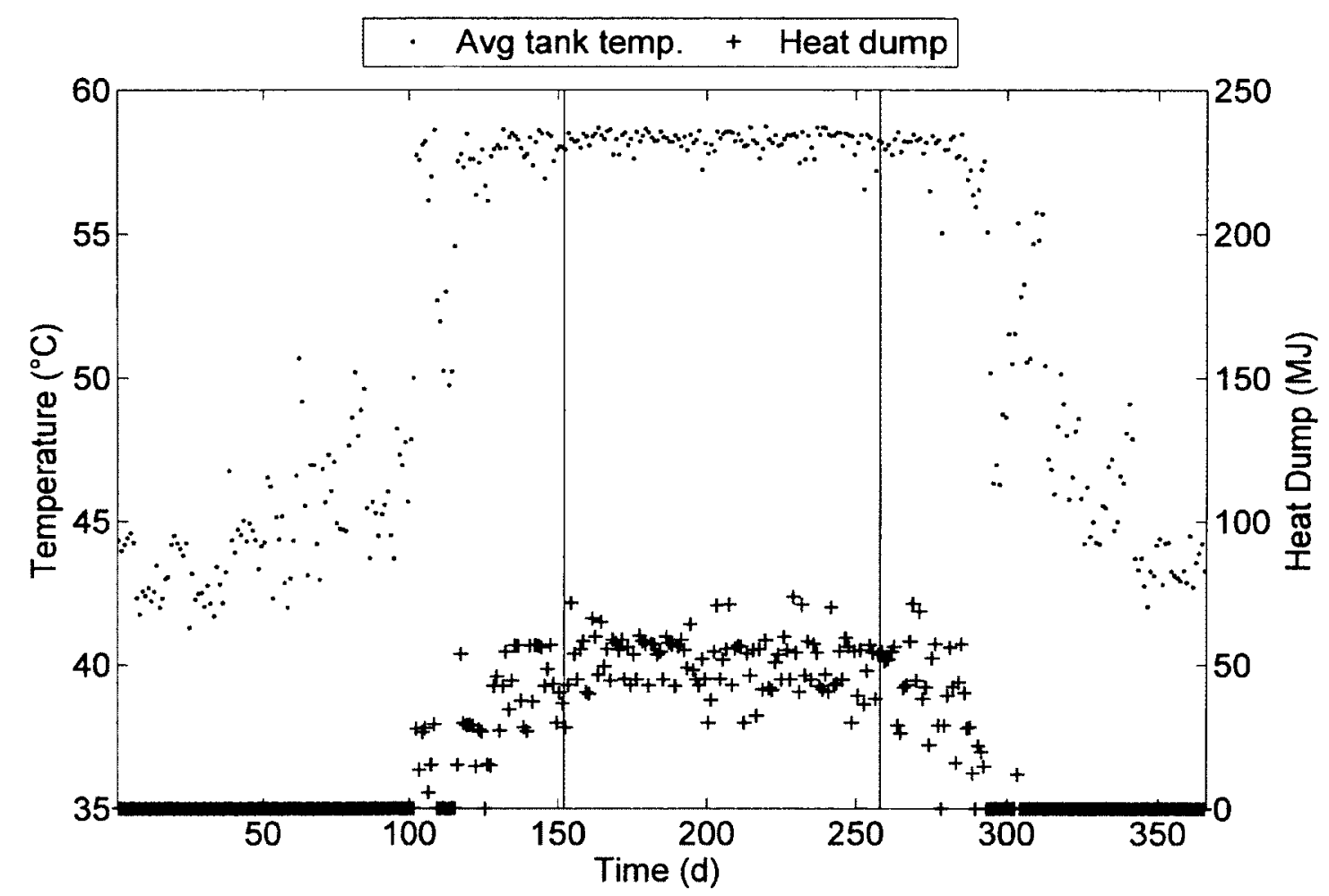

Figure A.3: Heat dump and average tank temperature for the 1-tank plant coupled with household B2 (averaged daily). The heat dump became active when the tank temperature reached $59^{\circ} \mathrm{C}$, as described in Subsection 4.2.2, pg. 43 . 


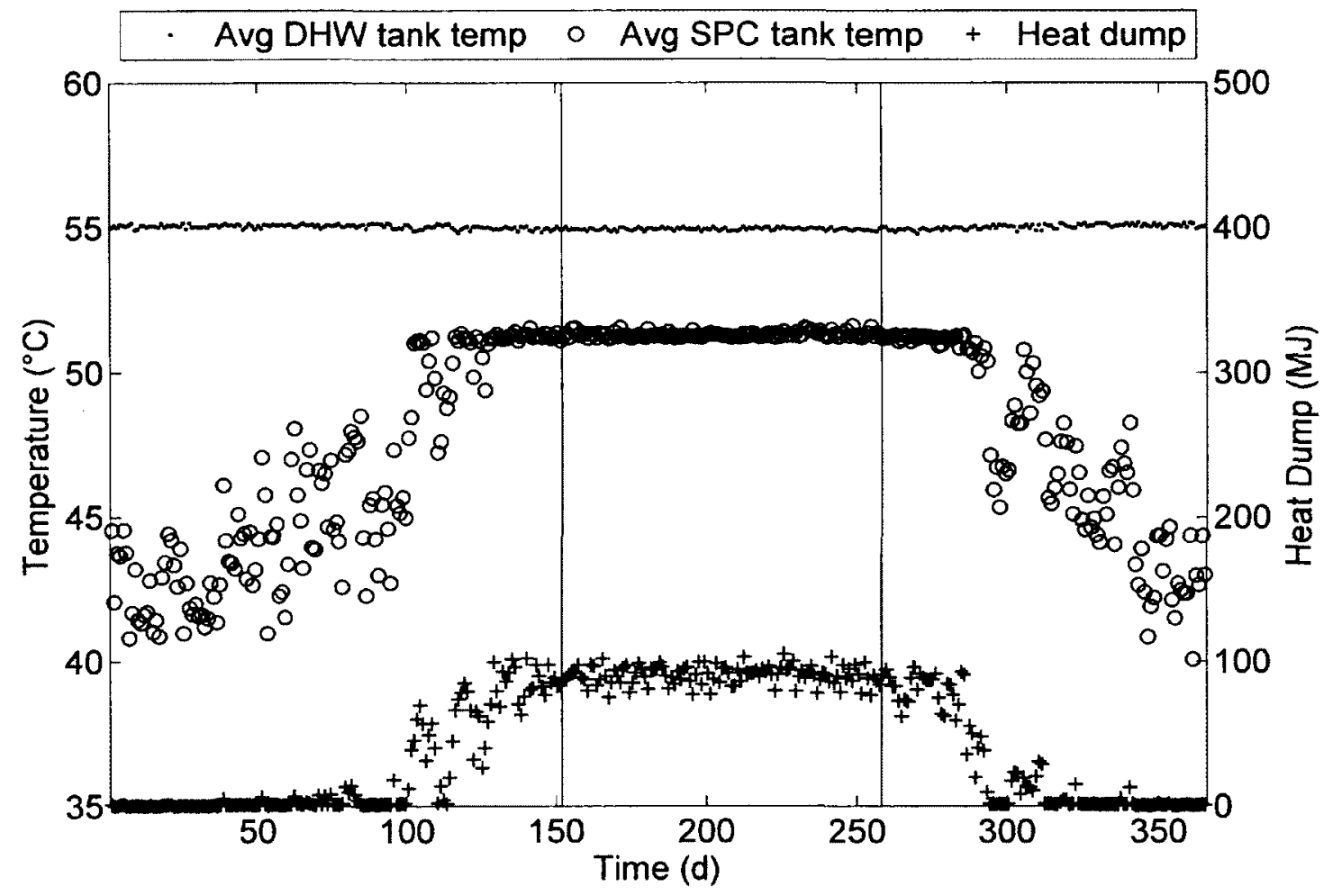

Figure A.4: Heat dump and average tank temperatures for the 2-tank plant coupled with household B2 (averaged daily). The heat dump became active when the tank temperature reached $51^{\circ} \mathrm{C}$, as described in Subsection 4.2.2, pg. 43 . 

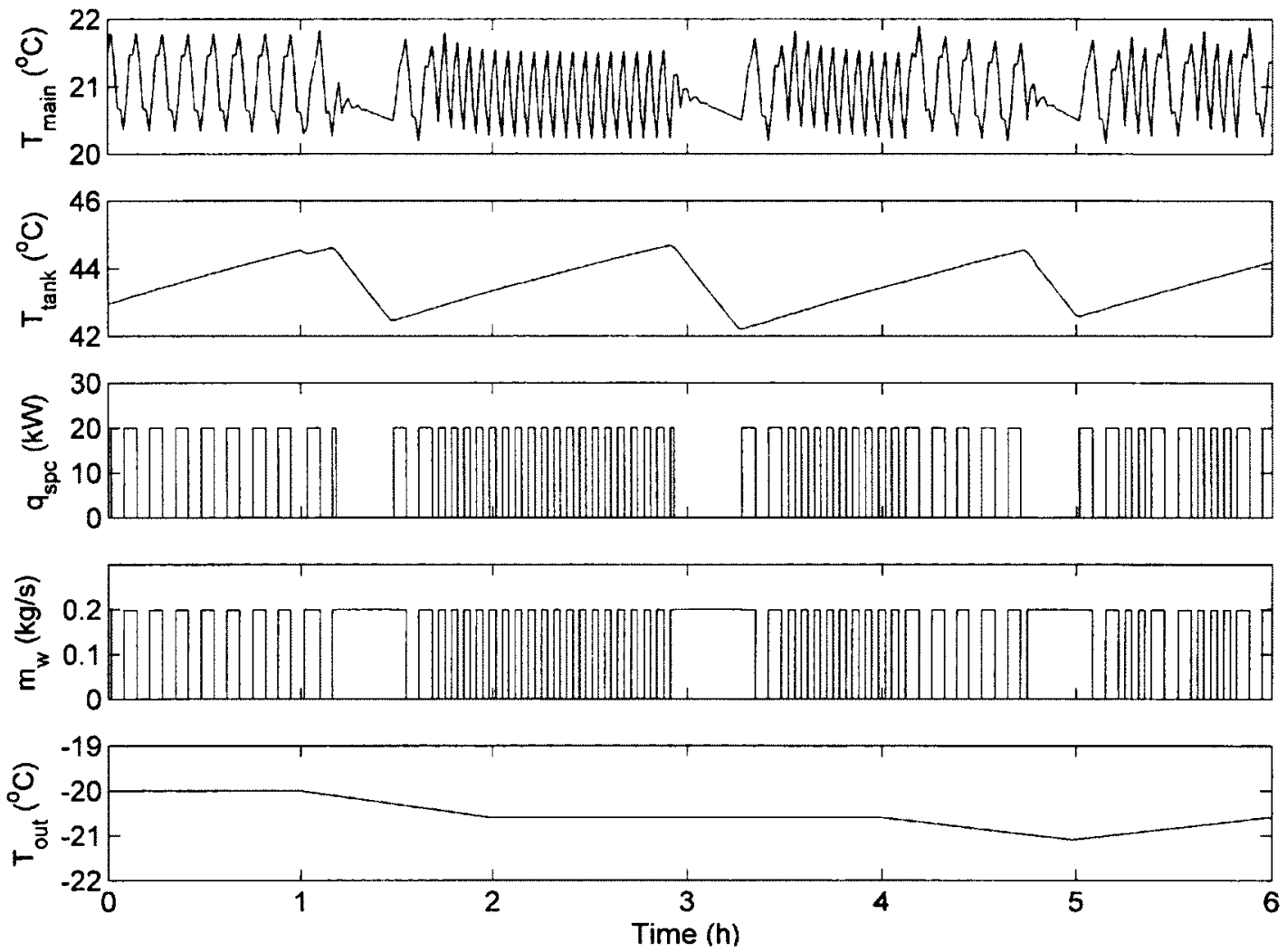

Figure A.5: Space heating performance on January 6 (of CWEC weather data), 12am - 6am. Results for the 1-tank plant coupled with household B2. Instances where the in-line heater and space heating pump operation (plots of $q_{s p c}$ and $m_{w}$ ) did not coincided demonstrate how thermal energy stored in the tank was used to meet space heating loads. 


\title{
Appendix B
}

\section{ESP-r Plant Controller}

\author{
SUBROUTINE controller_01 \\ \#include "plant.h" \\ \#include "building.h" \\ \#include "tdf2.h" \\ C New common bock to hold temperature setpoints for a custom plant controller \\ COMMON/TSETPTS/heat_setpt_low, heat_setpt_high, cogen_setpt, \\ \& dt_cogen, T_inlet_max, tank_t1,t_dhw, boiler_setpt_low, \\ \& boiler_setpt_high, cogen_cons, cogen_elec, cogen_x, heat_dump_1, \\ 2 Qmax_h1,Qmax_h2,pump3_low,pump3_high, heat_dump_true,ct1_flag, \\ \& config_flag,t_elec_avg,pump_ctl_flag, debug_1, debug_2, debug_3 \\ REAL heat_setpt_low, heat_setpt_high, cogen_setpt, \\ \& $d t_{-}$cogen, $T_{-}$inlet_max, tank_t $1, t_{-} d h w$, boiler_setpt_low, \\ \& boiler_setpt_high, cogen_cons, cogen_elec, cogen_x, heat_dump_1, \\ 2 Qmax_h1,Qmax_h2,pump3_low,pump3_high \\ INTEGER heat_dumP_true,ctl_flag,config_flag,t_elec_avg, \\ \& pump_ctl_flag, debug_1, debug_2, debug_3 \\ C Number of components in plant network and control actuation signals. \\ COMMON/C9/NPCOMP, NCI, CDATA \\ INTEGER NPCOMP, NCI (MPCOM) \\ REAL CDATA (MPCOM, MMISCD) \\ C Miscellaneous data for components \\ COMMON/PDBDT/ADATA , BDATA \\ REAL ADATA (MPCOM, MADATA) \\ REAL BDATA (MPCOM, MBDATA) \\ C Plant component pointer. \\ COMMON/C12PS/NPCDAT, IPOFS1, IPOFS2 \\ INTEGER NPCDAT (MPCOM , 9) , IPOFS1 (MCOEFG), IPOFS2 (MCOEFG, MPVAR) \\ C Plant state variables. \\ COMMON/PCVAL/CSVF, CSVP \\ REAL CSVF (MPNODE, MPVAR), CSVP (MPNODE, MPVAR) \\ C Additional res output from plant domain. \\ COMMON/PCRES/QDATA (MPCOM) , PCAOUT (MPCOM, MPCRES), napdat (mpcom) \\ REAL QDATA, PCAOUT
}




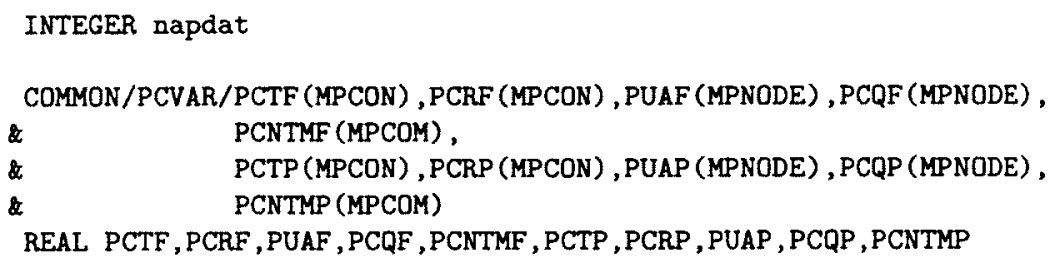

C The following is from climi.F COMMON/FVALA/TFA (MCOM), QFA (MCOM)

REAL TFA, QFA

common/pvala/tpa(mcom), qpa(mcom)

real tpa, qpa

common/trc/itrc

COMMON/PERS/ISD1, ISM1, ISD2, ISm3, ISDS, ISDF , NTSTEP

common/btime/BTIMEP, BTIMEF

REAL BTIMEP, BTIMEF

COMMON/DNORGH/IRTYPE

COMMON/CLIM/IDIF (MT), ITMP (MT), IDNR(MT), IVEL (MT), IDIR(MT),

\& IHUM (MT) , IDIFF, ITMPF, IDNRF, IVELF, IDIRF, IHUMF

integer fidif,fitmp,fidnr,fivel,fidir,fihum

\&

common/fclim/fidif(mt), fitmp(mt), fidnr(mt), fivel (mt), fidir(mt), fihum (mt)

COMMON/CLIMWB/TWBP, TWBF

COMMON/CLIMHG/HEXTP, HEXTF, GEXTP, GEXTF

COMMON/CLIMIP/QFPP, QFFP , TPP, TFP, QDPP, QDFP, VPP , VFP , DPP , DFP , HPP , HFP

COMMON/CLIMIF/QFLWP, QFLWF, TFLWP, TFLWF, QDFLP , QDFLF, VFLP , VFLF,

$\&$ DFLP , DFLF , HFLP, HFLF

COMMON/CLMPHG/HEXTPP , HEXTFP, GEXTPP, GEXTFP, TWBPP, TWBFP

COMMON/WBULBO/IOPT

COMMON/ATPRES/PATMOS

COMMON/PCTSTP/NTSTPP

COMMON/PCTINC/IPTS

COMMON/TS1/NF (MSCH) , IFL (MSCH, MCVT1), FD (MSCH, MCVT1), ITSCF 1 ,

\&

NMAX1 (MSCH)

COMMON/CLMFLG/ICLMFL

C For Debugging

common/pcond/

\& convar(mpcon,mconvr), ! state varibles for connections

* icontp(mpcon), ! type of each connection

* icondx (mpcom, mnodec, mpconc) ! pointer to connections for each component/node real convar

integer icontp, icondx

COMMON/SIMTIM/IHRP , IHRF , IDYP, IDYF , IDWP , IDWF , NS INC , ITS

INTEGER IHRP !-hour of present time-step

INTEGER IHRF !-hour of future time-step

INTEGER IDYP !-year day number of present day

INTEGER IDYF !-year day number of future day

INTEGER IDWP !-day of the week of present day

INTEGER IDWF !-day of the week of future day

INTEGER NSINC !-number of building-side time increments

!-since start of simulation

INTEGER ITS !-current building time-step within

COMMON/PSTCTR/NSINCP, NSNCPR

!-current hour

INTEGER NSINCP

!-current plant timestep within current building timestep 


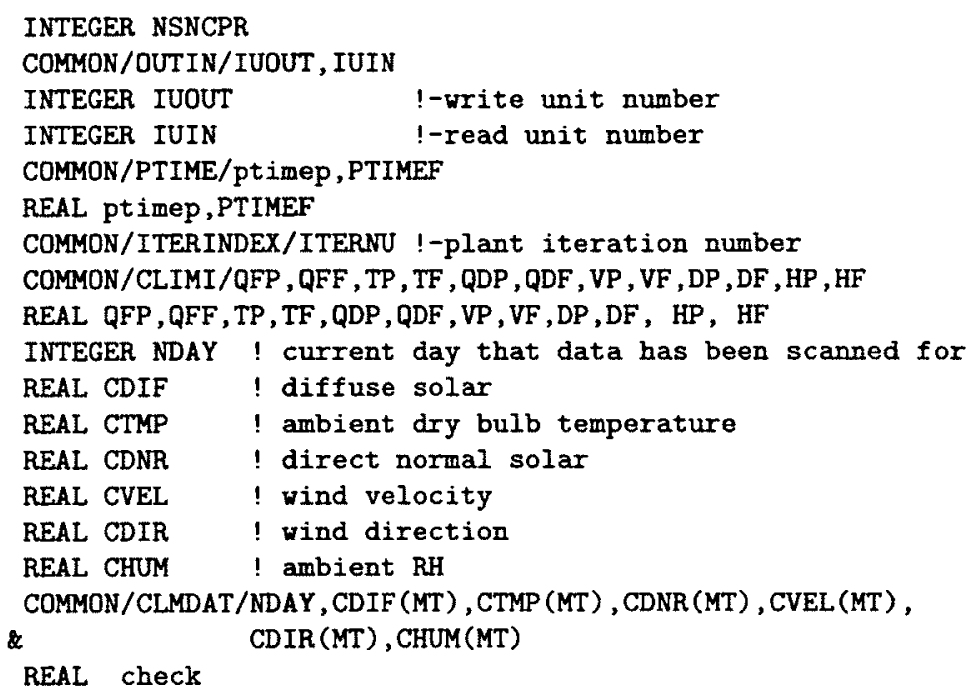

C Type declarations for local variables.

C--

REAL TEMP_TANK1_N1,TEMP_TANK1_N2,TEMP_TANK1_N3

REAL TEMP_TANK2_N1,TEMP_TANK2_N2

REAL FTEMP_TANK1_N1,FTEMP_TANK1_N2,FTEMP_TANK1_N3

REAL FTEMP_TANK2_N1,FTEMP_TANK2_N2

REAL TEMP_cpump, TEMP_sheater,FTEMP_sheater

REAL TEMP_MAIN, TEMP_OUT_PRES

REAL FMDOT_DHW, FMDOT_spump

REAL MDOT_DHW,MDOT_spump, temp_spc_hx

REAL $m 5, b 5, m 6, b 6, m 7, b 7$

! slopes and intercepts

REAL T2_cogen, T1_cogen

REAL sum 1

REAL CP_W ! physical constants

REAL Q_dhw, Q_spc

REAL P_elec, off _peak, mid_peak, on_peak

REAL S_therm, S_elec,S_elec $2, S_{\text {_. cogen, }} S_{-} m i n$

REAL Pel_min,Pel_max

INTEGER i comp_cpump, icomp_spump, icomp_bpump

INTEGER icomp_dhw,icomp_sfan, icomp_coil

INTEGER icomp_tank1, icomp_tank2

INTEGER icomp_cogen,icomp_ht_dump

INTEGER icomp_dheater,icomp_sheater

INTEGER izone_main ! Hardwire zone number of main living space.

INTEGER CV_tank1, CV_cpump, CV_spump, CV_dhw, CV_cogen, CV_sfan

INTEGER CV_coil, CV_dheater, CV_sheater

INTEGER indx, day_of_week

INTEGER clock_hr

INTEGER ht_dump_flag

INTEGER nd

C Determine state of plant components that are used to determine control action.

C Standard variables utilized:

C $\operatorname{NPCDAT}(i, 9)$ row and column number defining location of component ' $i$ ' 


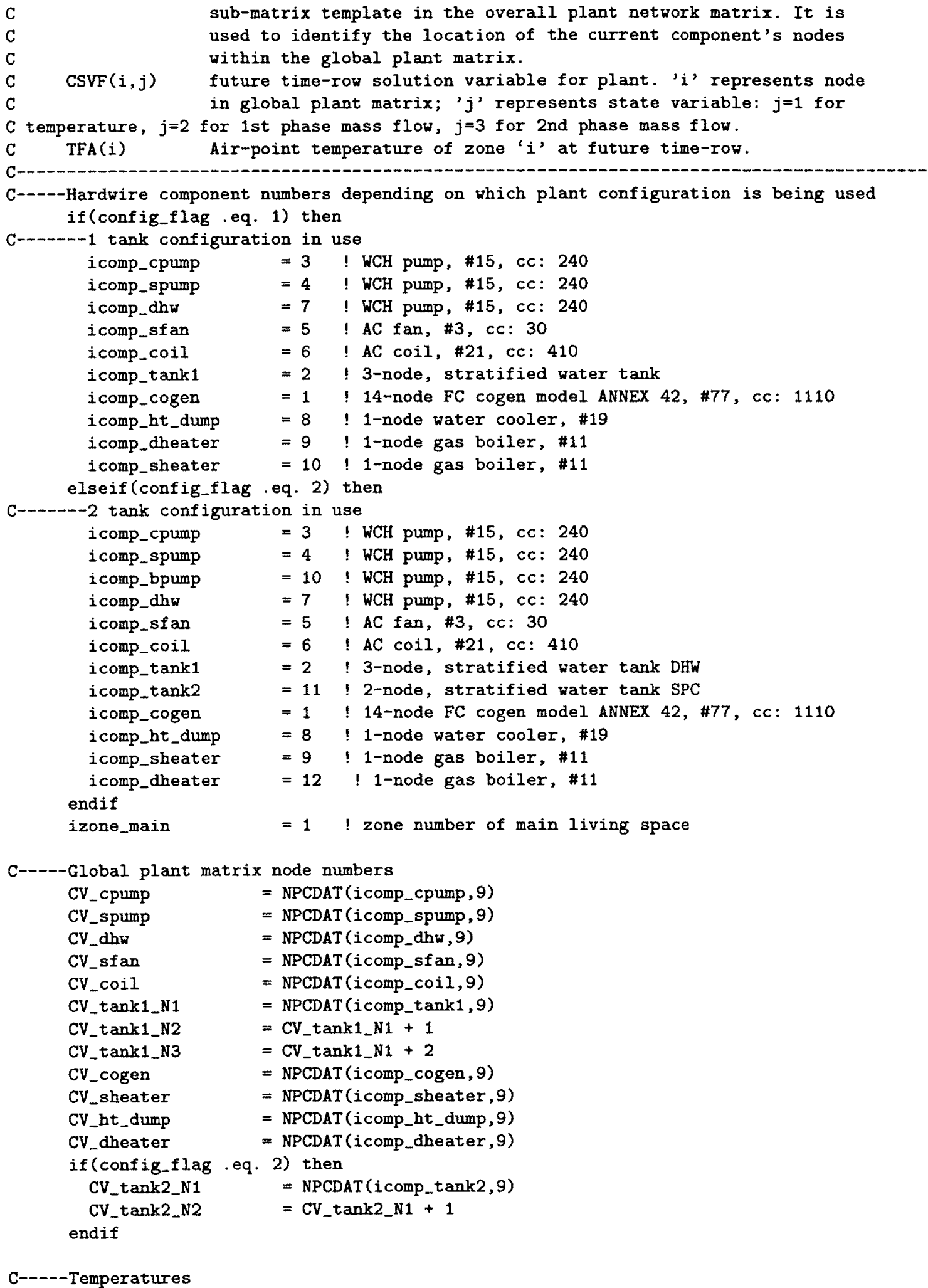




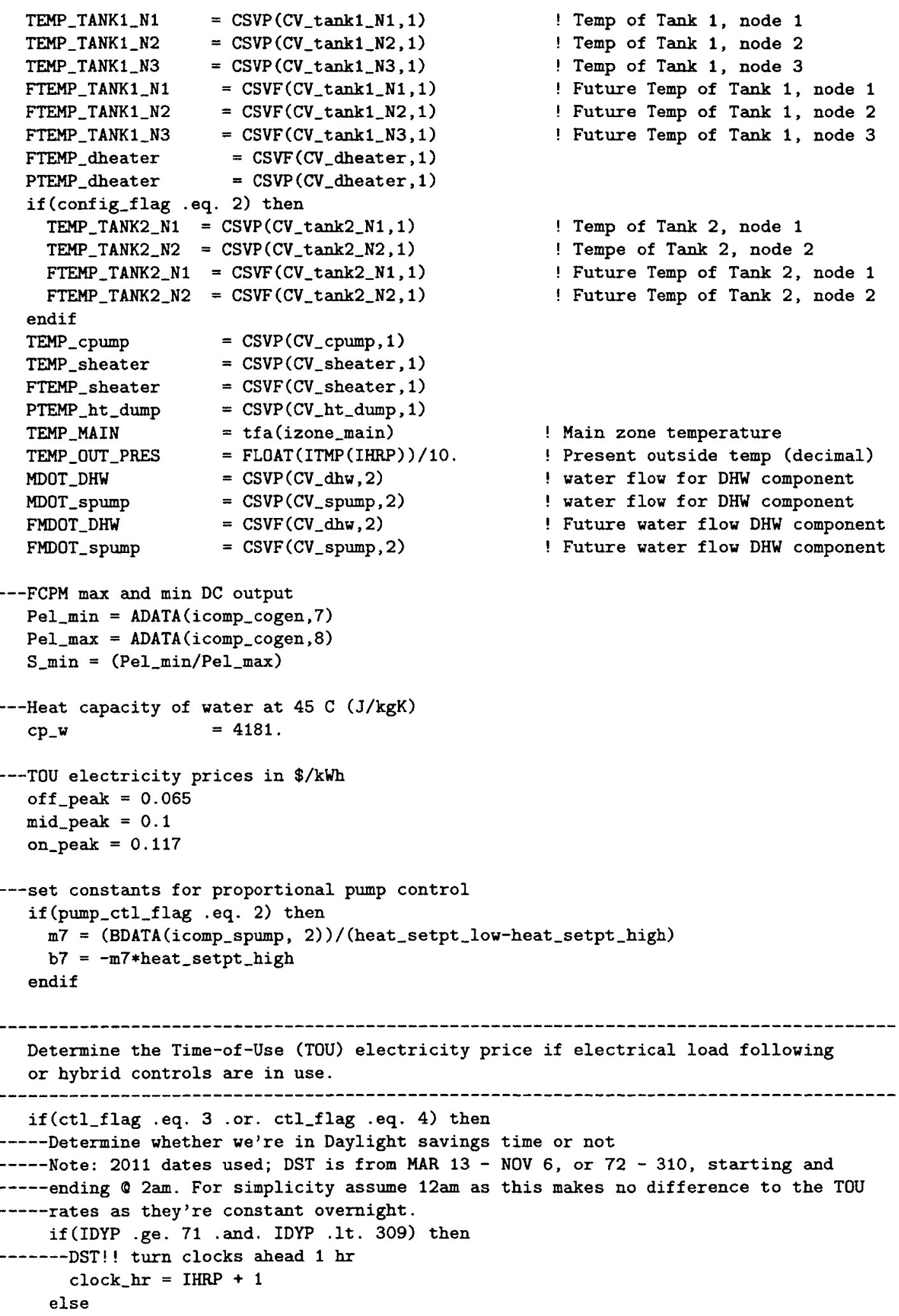




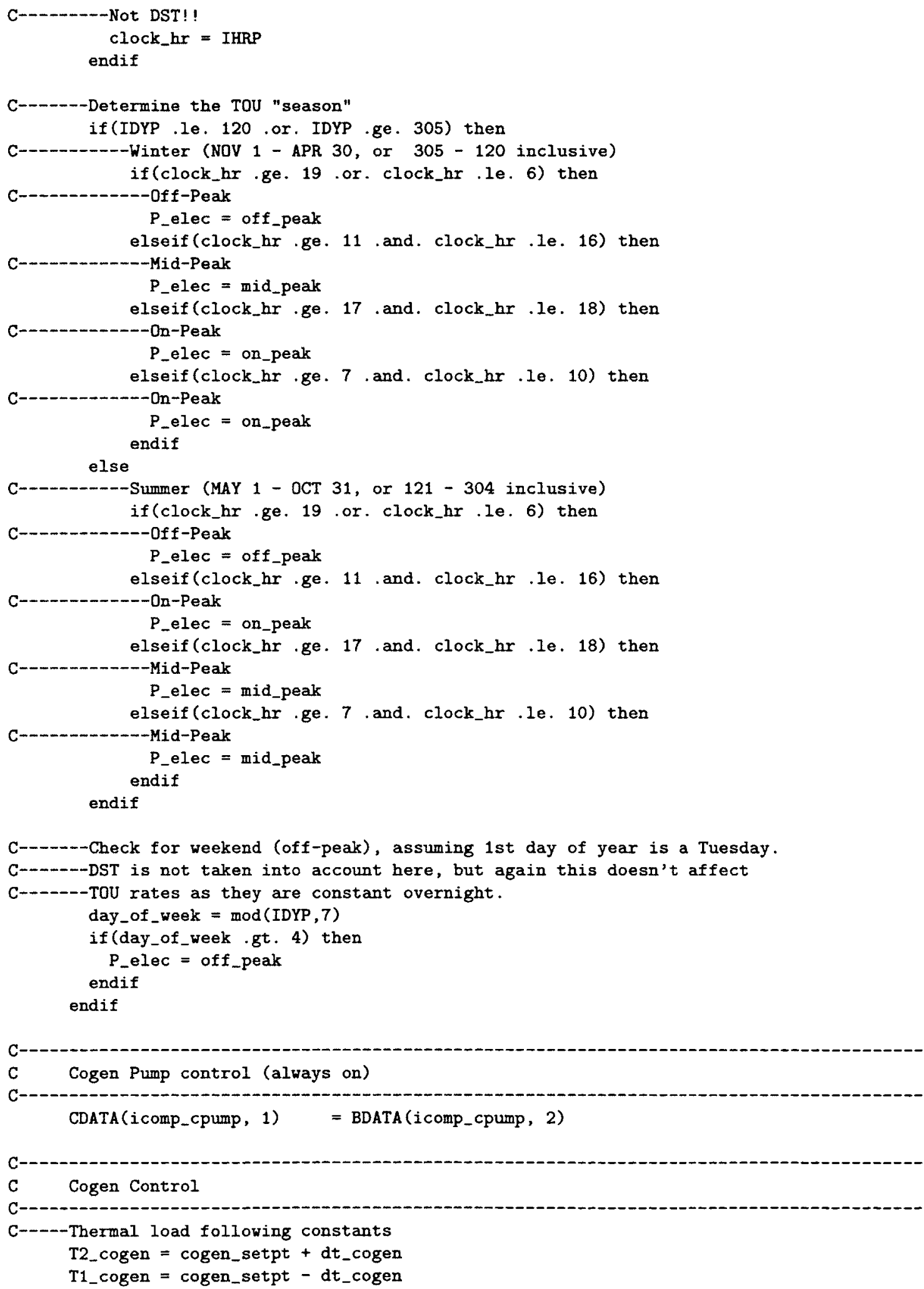




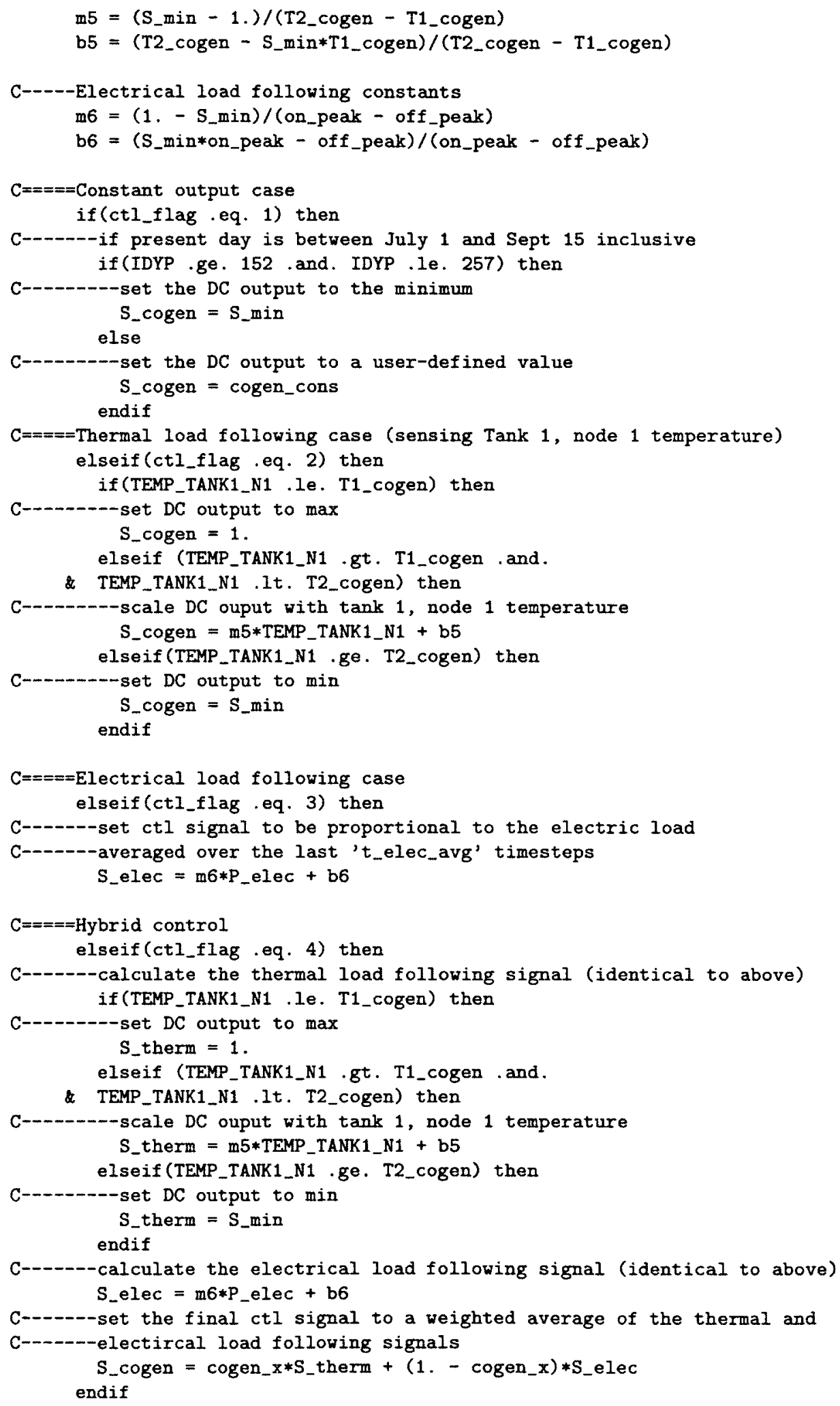


CDATA (icomp_cogen, 1) $=S_{-}$cogen

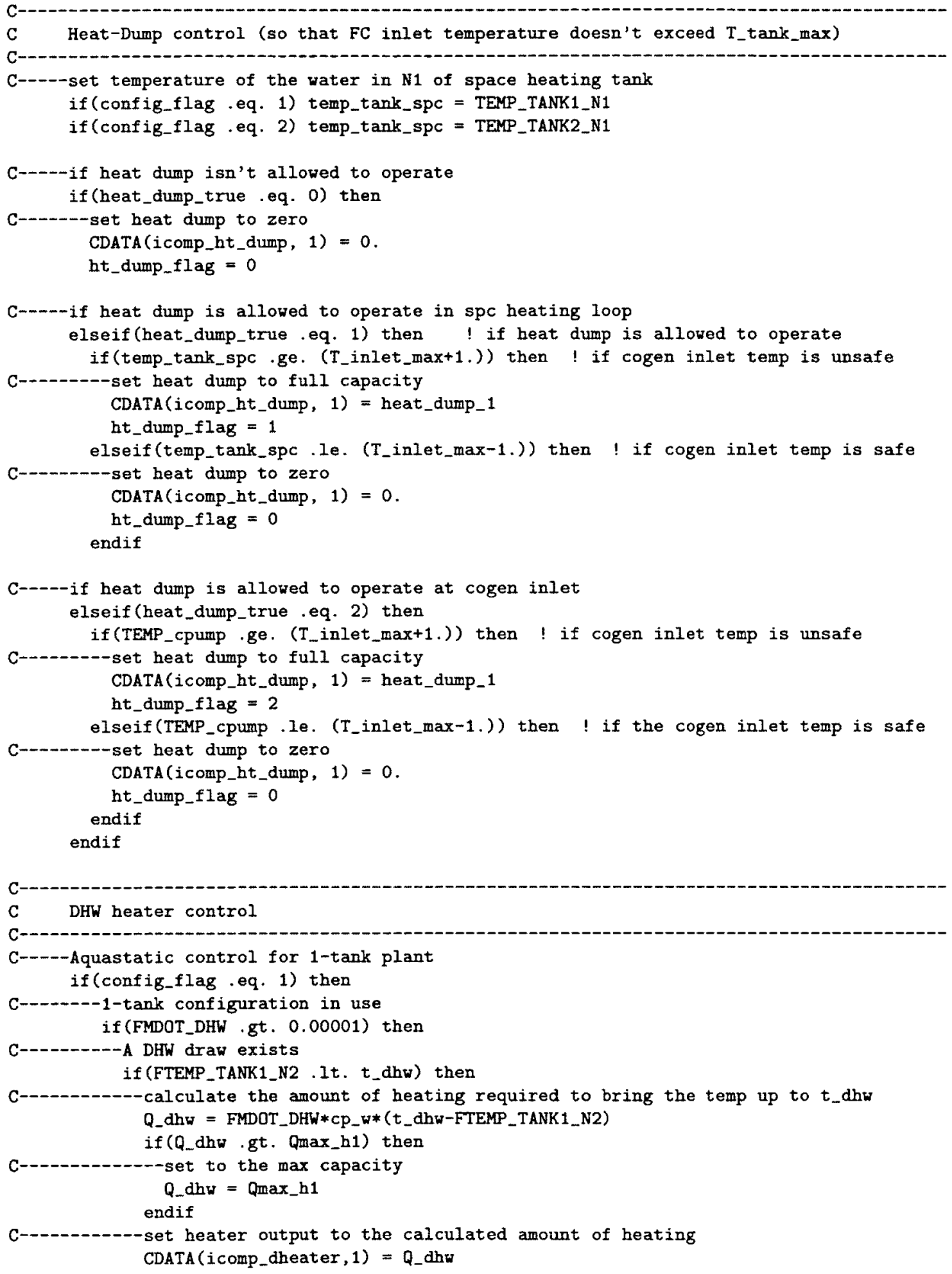




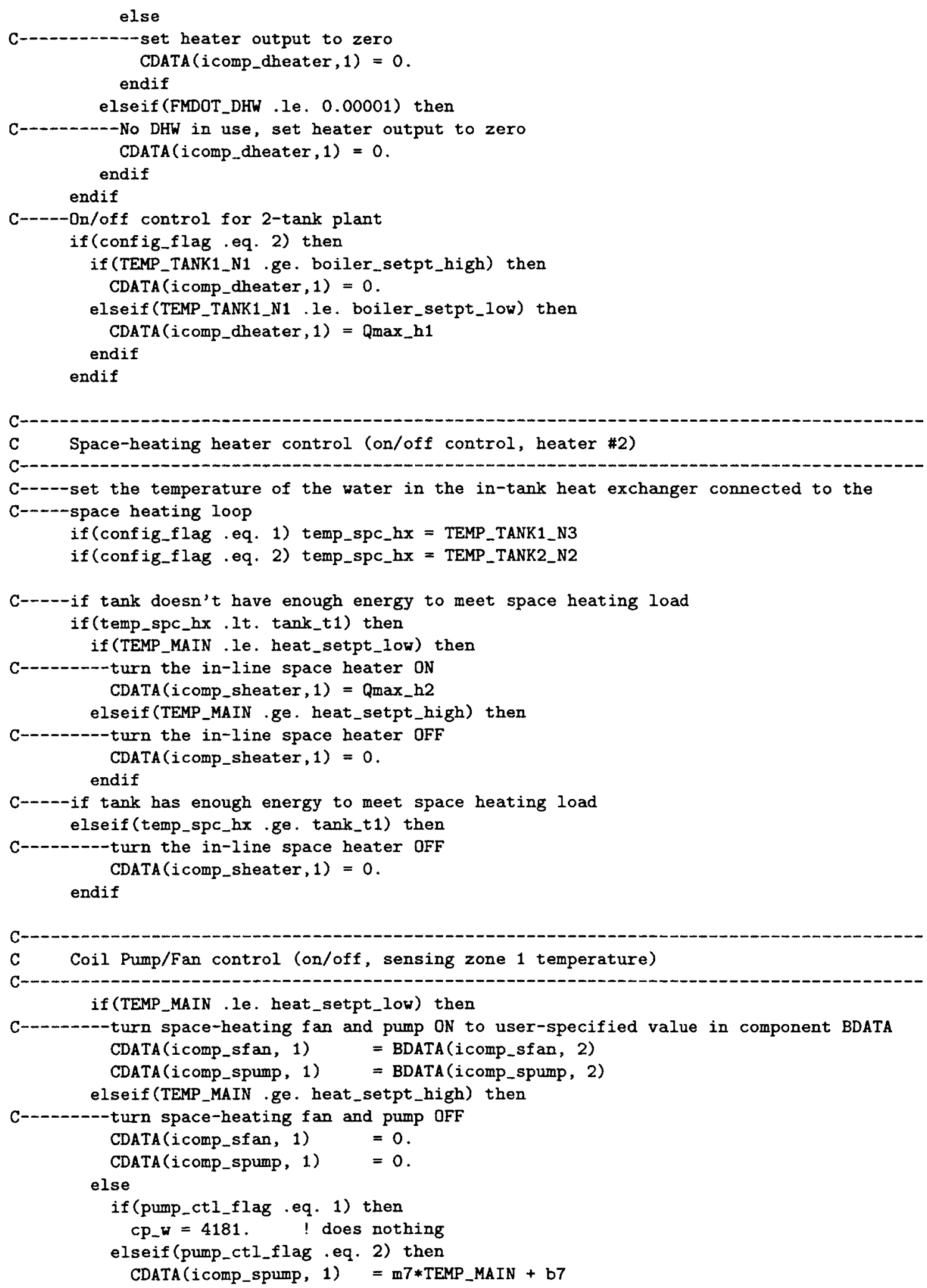




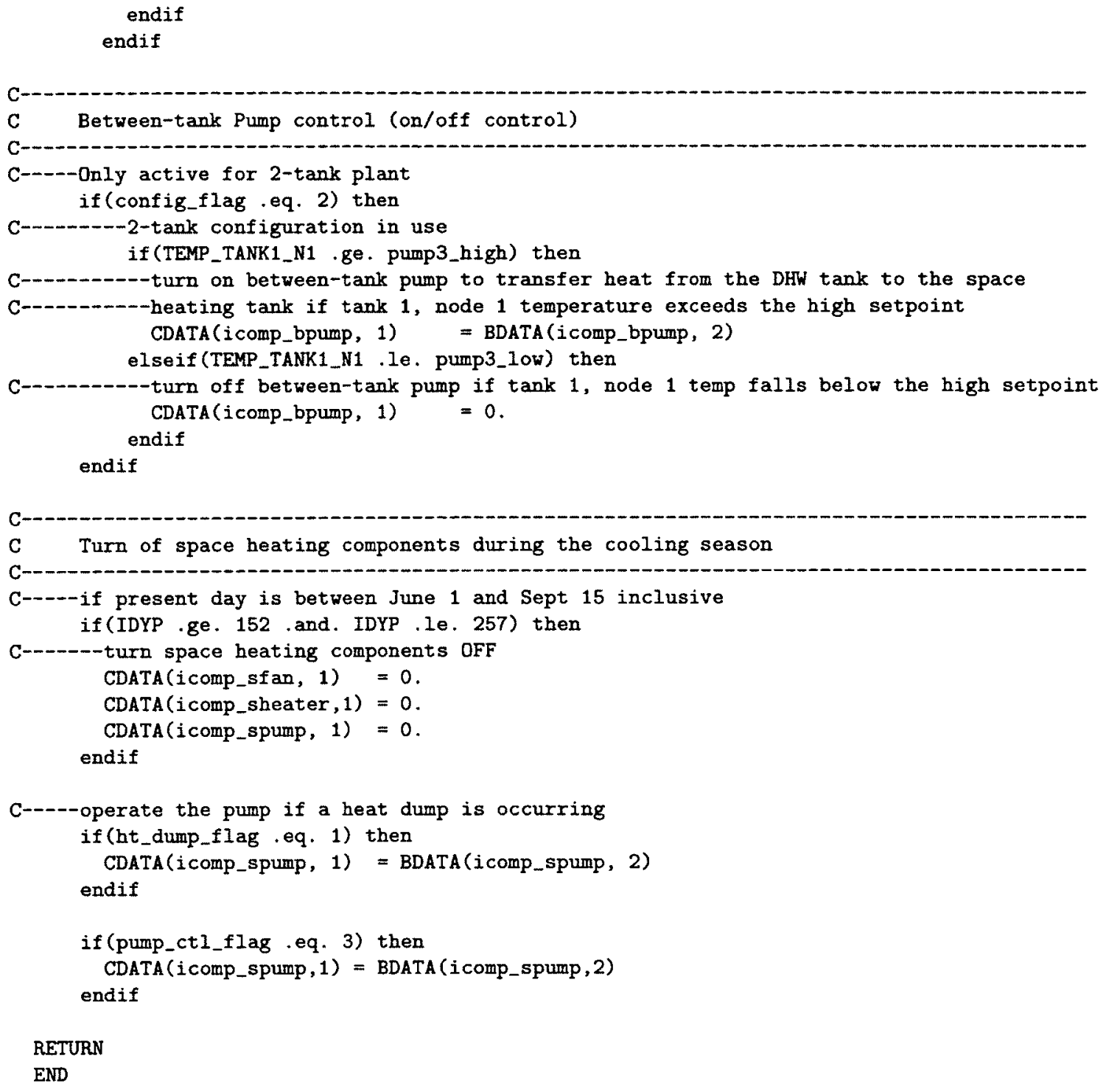




\section{Appendix $\mathrm{C}$}

\section{ESP-r Plant Network Configuration Files}

The following configuration files are specific to household model B2. Files for models B1 and B3 can be found in http://node1.mae.carleton.ca/ibeau students/steph/Models/B1/genopt-cfg/ and http://node1.mae.carleton.ca/ ibeau_students/steph/Models/B3/genopt-cfg/ at revision 958 or later.

\section{C.1 1-tank Plant}

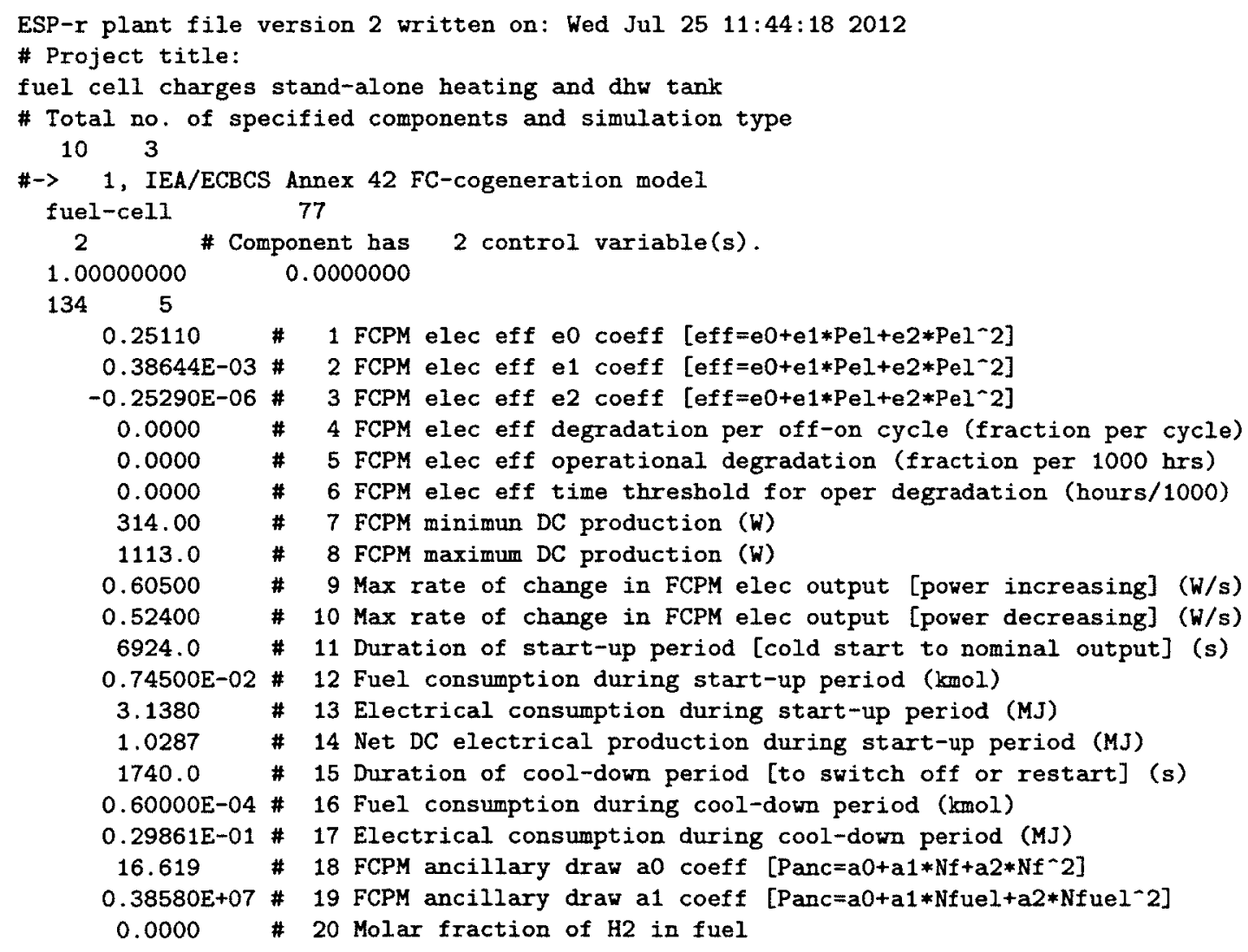




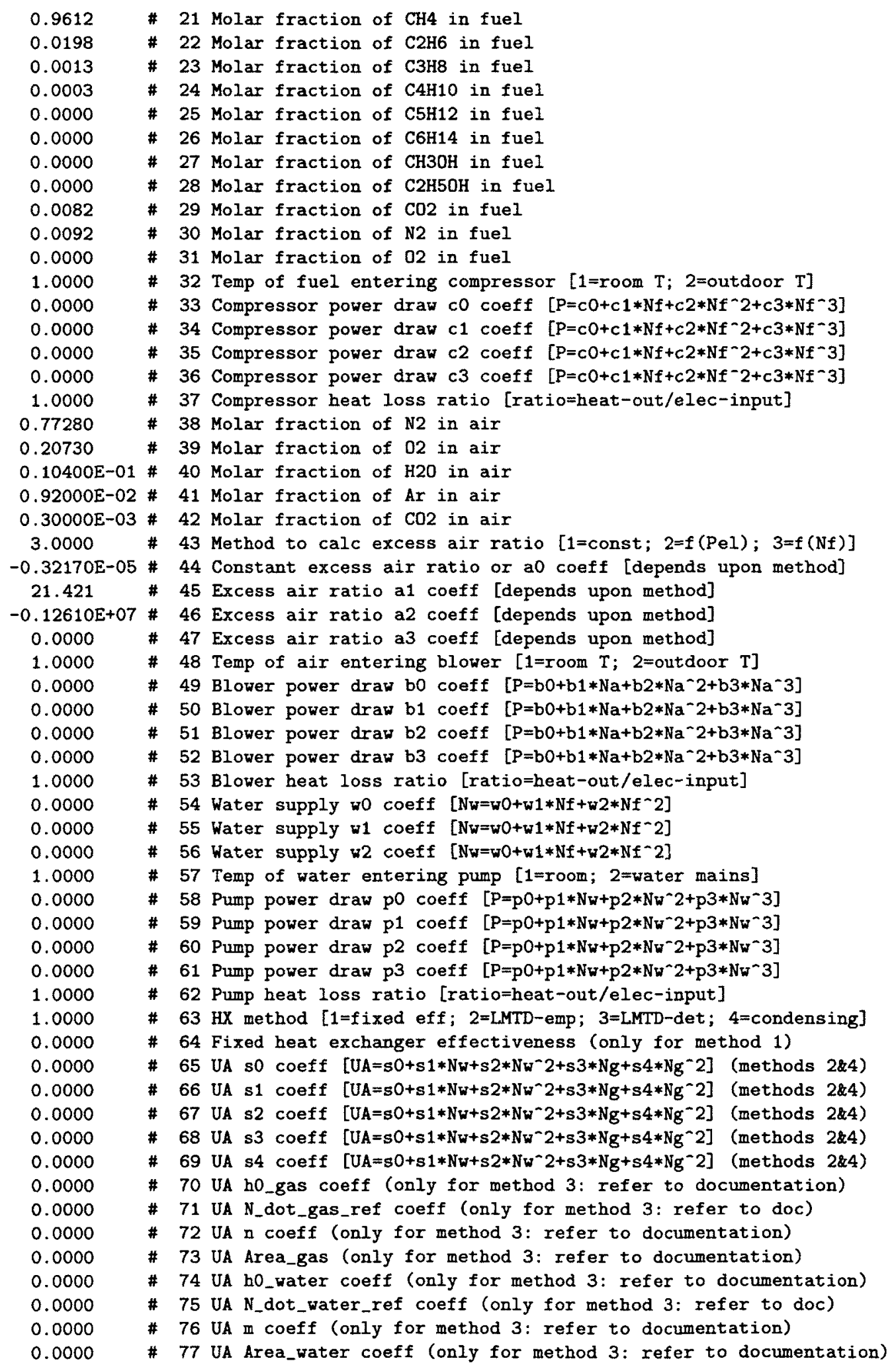




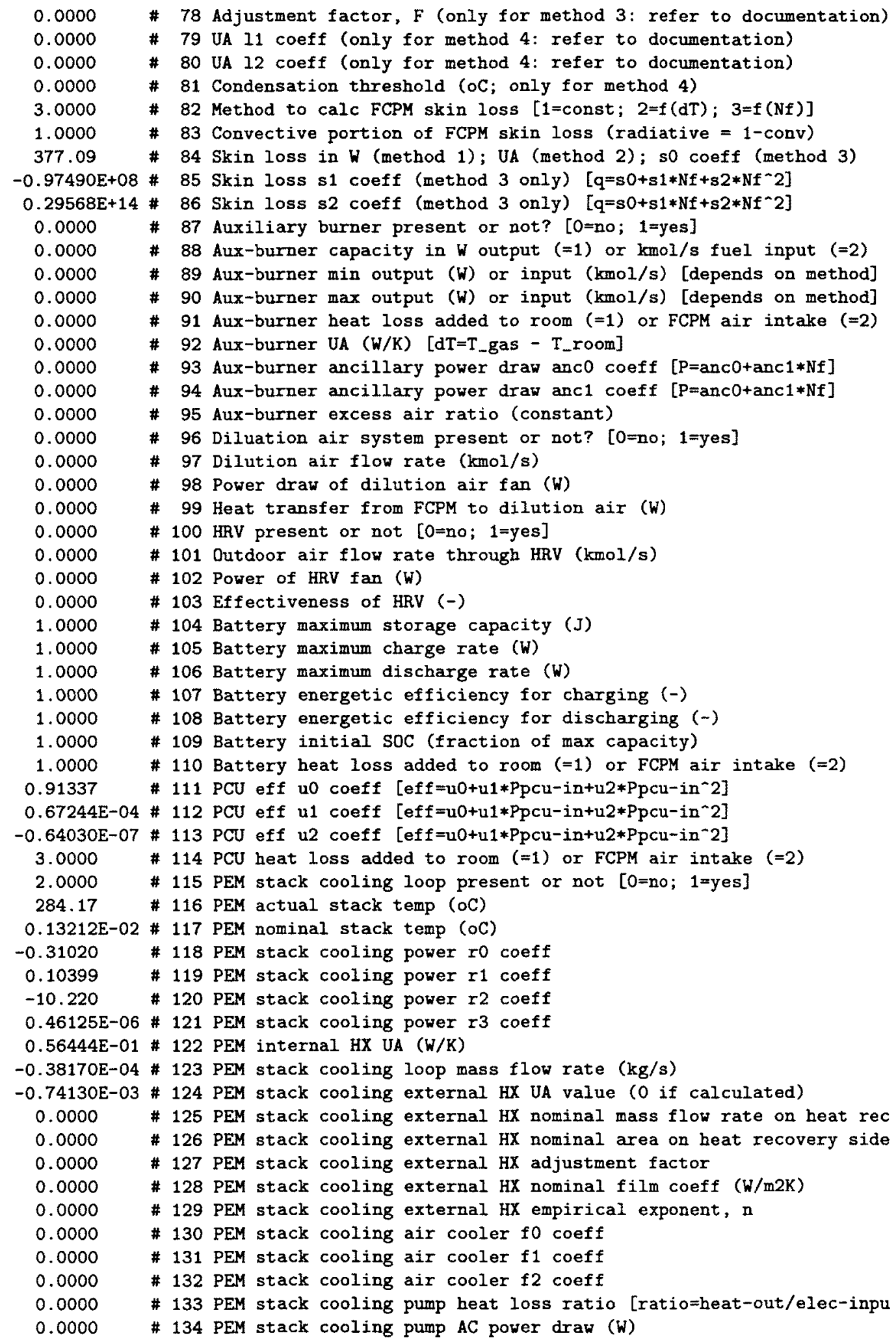


\# Component electrical details.

$$
\begin{array}{llll}
1.000 & -1 & 0.000 & 120.000 \quad 4
\end{array}
$$

\#-> 2, Stratified tank with 2 immersed HXs; 3 node model

hot-water-tank 104

0 \# Component has 0 control variable(s).

25

$\%$ tank_vol\% \# 1 Tank volume (m3)

1.5000 \# 2 Tank height (m)

$-1.0000 \quad \# 3$ Tank perimeter ( $m ;-1$ if cylindrical)

1.5000 \# 4 Height of flow inlet (m)

0.0000 \# 5 Height of flow outlet $(m)$

$0.10000 \quad \# 6$ Tank heat loss coefficient (W/m2-K)

$0.0000 \# 7$ Additional destratification conductivity ( $W / m-K)$

$5.0000 \quad \# 8$ Number of nodes

$1.0000 \quad$ \# 9 Internal time steps per simulation time step

20.000 \# 10 Initial temperature of tank (C)

$100.00 \quad \# 11$ Boiling temperature of fluid (C)

$0.0000 \quad \# 12$ Height of first immersed HX inlet (m)

$1.5000 \quad \# 13$ Height of first immersed HX outlet (m)

$0.25400 \mathrm{E}-01$ \# 14 Inside diameter of first immersed $\mathrm{HX}$ coil (m)

$0.27400 \mathrm{E}-01$ \# 15 Outside diameter of first immersed $\mathrm{HX}$ coil (m)

0.40000 \# 16 Diameter of first immersed $\mathrm{HX}$ coil (m)

$0.57000 \mathrm{E}-01$ \# 17 Pitch of first immersed HX coil (distance from one loop to the $\mathrm{n}$

$300.00 \# 18$ Thermal conductivity of first immersed $\mathrm{HX}$ coil material ( $\mathrm{W} / \mathrm{m} / \mathrm{K})$

0.0000 \# 19 eight of second immersed $\mathrm{HX}$ inlet (m)

1.5000 \#20 Height of second immersed HX outlet (m)

$0.25400 \mathrm{E}-01$ \# 21 Inside diameter of second immersed HX coil (m)

$0.27400 \mathrm{E}-01$ \# 22 Outside diameter of second immersed HX coil (m)

0.40000 \# 23 Diameter of second immersed HX coil (m)

0.57000E-01 \# 24 Pitch of second immersed HX coil (distance from one loop to the

300.00 \# 25 Thermal conductivity of second immersed $\mathrm{HX}$ coil material $(\mathrm{W} / \mathrm{m} / \mathrm{K})$

\#-> 3, variable speed domestic WCH pump; 1 node model fc-pump

1 \# Component has 1 control variable(s).

$1.30000000 \mathrm{E}-04$

65

5.0000 \# 1 Component total mass (kg)

2250.0 \# 2 Mass weighted average specific heat $(\mathrm{J} / \mathrm{kgK}$ )

0.20000 \# 3 UA modulus from wall to environment (W/K)

25.000 \# 4 Rated total absorbed power (W)

$0.07000 \mathrm{E}-03$ \# 5 Rated volume flow rate $\left(\mathrm{m}^{-3} 3 / \mathrm{s}\right)$

$0.70000 \quad \# 6$ Overall efficiency $(-)$

\# Component electrical details.

$\begin{array}{lllll}1.000 & -1 & 0.000 & 120.000 & 4\end{array}$

\#-> 4, variable speed domestic WCH pump; 1 node model

coil-pump

1 \# Component has 1 control variable(s).

9.99999975E-05

65

$5.0000 \quad \# 1$ Component total mass ( $\mathrm{kg}$ )

2250.0 \# 2 Mass weighted average specific heat $(\mathrm{J} / \mathrm{kgK}$ )

0.20000 \# 3 UA modulus from wall to environment ( $W / K$ )

25.000 \# 4 Rated total absorbed power (W)

$0.20000 \mathrm{E}-03$ \# 5 Rated volume flow rate $\left(\mathrm{m}^{-3} / \mathrm{s}\right)$

$0.70000 \quad \# 6$ Overall efficiency $(-)$

\# Component electrical details.
$1.000-1$
0.000
$120.000 \quad 4$ 


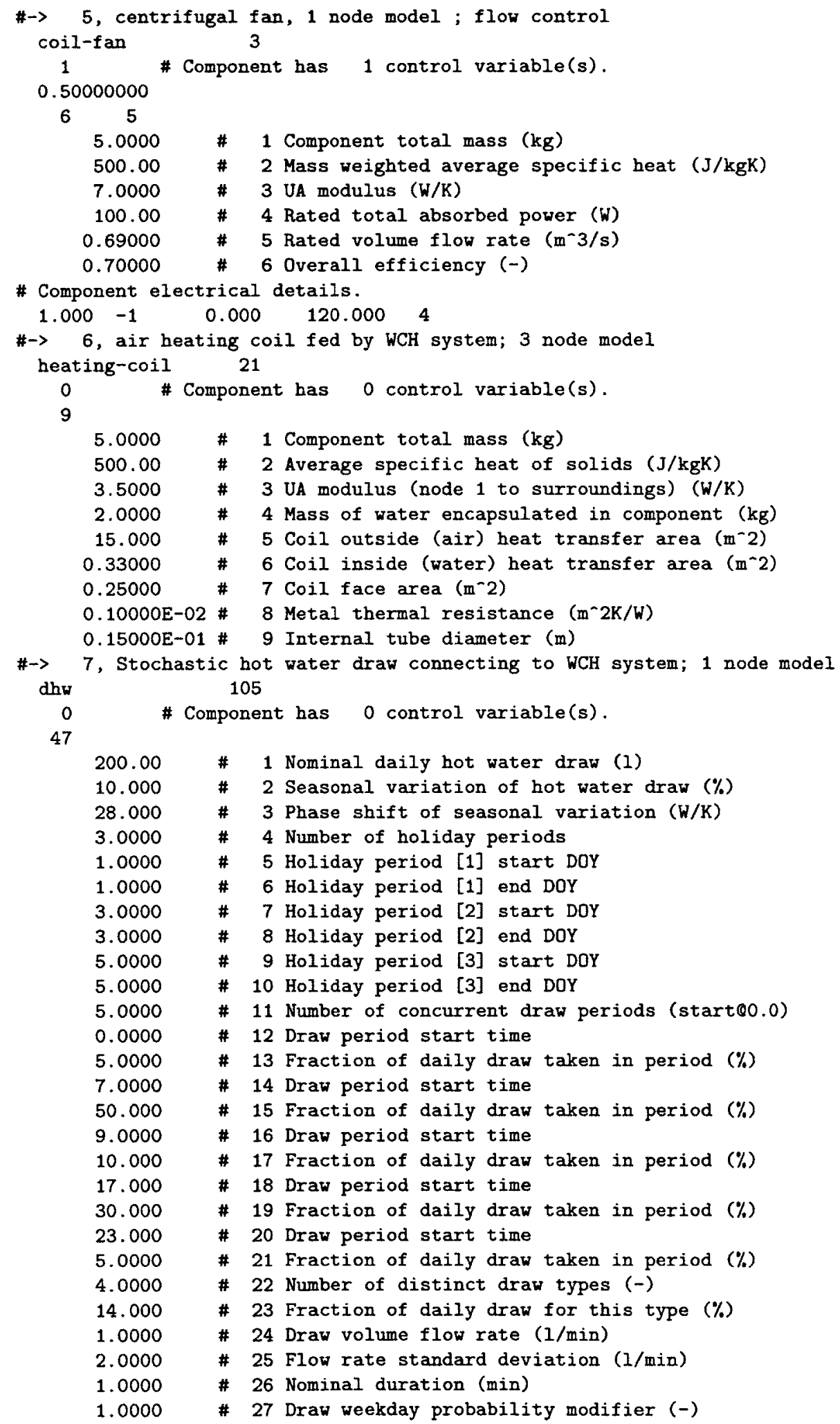




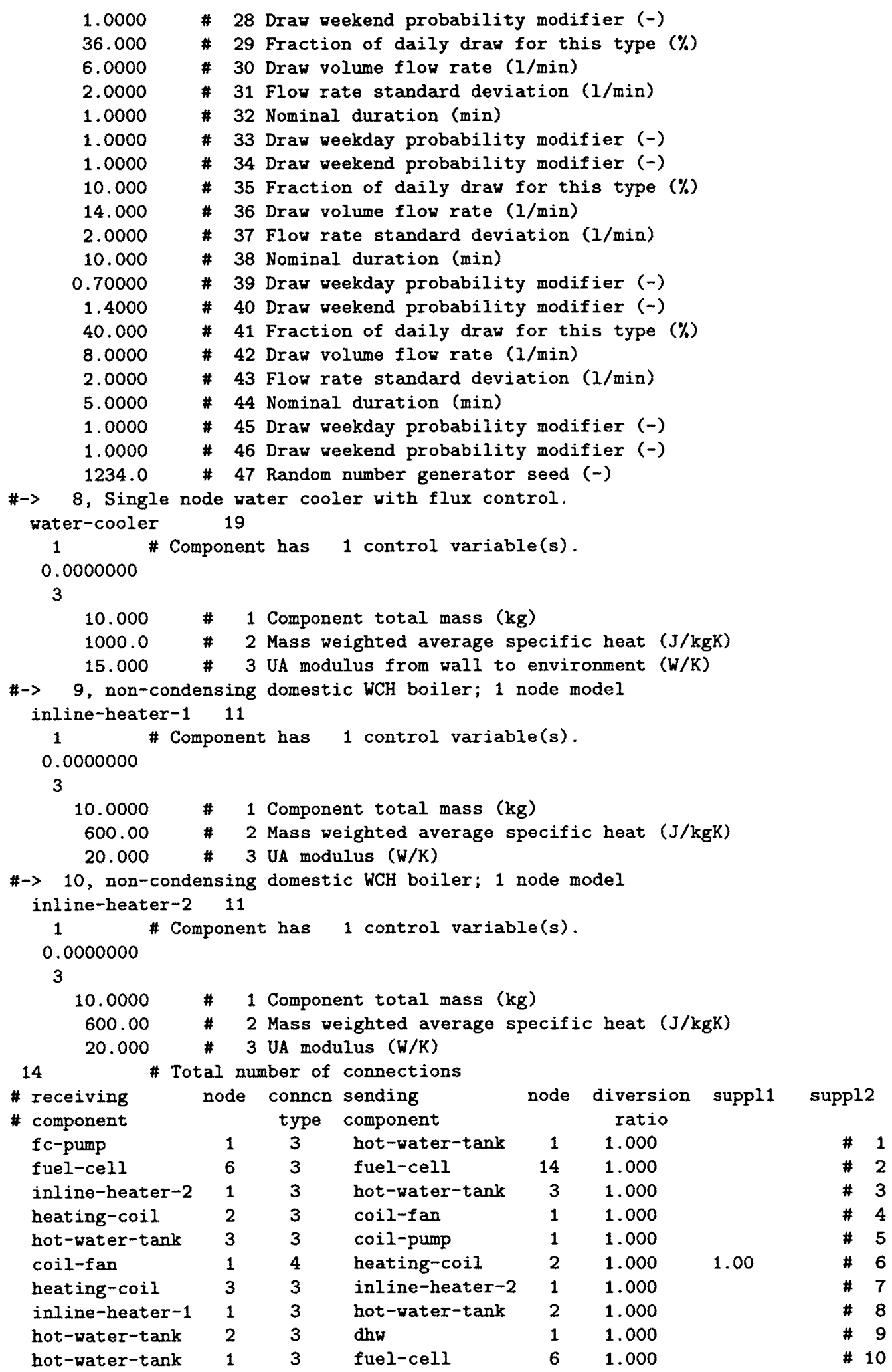




$\begin{array}{lrlllll}\text { dhw } & 1 & 3 & \text { inline-heater-1 } & 1 & 1.000 & \text { \#11 } \\ \text { coil-pump } & 1 & 3 & \text { heating-coil } & 3 & 1.000 & \text { \#12 } \\ \text { water-cooler } & 1 & 3 & \text { fc-pump } & 1 & 1.000 & \text { \# } \\ \text { fuel-cell } & 14 & 3 & \text { water-cooler } & 1 & 1.000 & \text { \# } 14\end{array}$

\# The following is a list of containment temperatures.

2 \# Total number of containments

\# Component cont type suppl1 $\quad$ suppl2 supp13

$\begin{array}{lllll}\text { fuel-cell } & 3 & 3.00000 & 0.00000 & 0.00000\end{array}$

$\begin{array}{lllll}\text { hot-water-tank } & 3 & 3.00000 & 0.00000 & 0.00000\end{array}$

\# No mass flow network defined.

0

\section{C.2 2-tank Plant}

ESP-r plant file version 2 written on: Wed Jun 27 18:34:34 2012

\# Project title:

fuel cell charges stand-alone heating and dhw tank

\# Total no. of specified components and simulation type

123

\#-> 1, IEA/ECBCS Annex 42 FC-cogeneration model

fuel-cell

2 \# Component has 2 control variable(s).

$1.00000000 \quad 0.0000000$

$134 \quad 5$

$0.25111 \# 1$ FCPM elec eff e0 coeff [eff=eo+e1*Pe1+e2*Pe1 2 ]

$0.38642 E-03 \# 2$ FCPM elec eff e1 coeff $\left[\right.$ eff $\left.f=e 0+e 1 * P e l+e 2 * P e P^{\sim} 2\right]$

$-0.25290 \mathrm{E}-06$ \# 3 FCPM elec eff e2 coeff [eff $=e 0+e 1 * \mathrm{Pel}+\mathrm{e} 2 * \mathrm{Pel}{ }^{-2}$ ]

0.0000 \# 4 FCPM elec eff degradation per off-on cycle (fraction per cycle)

$0.0000 \# 5$ FCPM elec eff operational degradation (fraction per 1000 hrs)

0.0000 \# 6 FCPM elec eff time threshold for oper degradation (hours/1000)

$314.00 \quad$ \# 7 FCPM minimun DC production (W)

$1113.0 \quad \# 8$ FCPM maximum DC production (W)

0.60500 \# 9 Max rate of change in FCPM elec output [power increasing] (W/s)

0.52400 \# 10 Max rate of change in FCPM elec output [power decreasing] (W/s)

6924.0 \# 11 Duration of start-up period [cold start to nominal output] (s)

$0.74500 E-02$ \# 12 Fuel consumption during start-up period (kmol)

3.1380 \# 13 Electrical consumption during start-up period (MJ)

1.0287 \# 14 Net DC electrical production during start-up period (MJ)

1740.0 \# 15 Duration of cool-down period [to switch off or restart] ( $s$ )

0.60000 E 04 \# 16 Fuel consumption during cool-down period (kmol)

$0.29861 E-01$ \# 17 Electrical consumption during cool-down period (MJ)

17.248 \# 18 FCPM ancillary draw ao coeff [Panc=a0+a1*Nf+a2*Nf ${ }^{-2}$ ]

$0.31037 E+07$ \# 19 FCPM ancillary draw a1 coeff [Panc=a0+a1*Nfuel+a2*Nfuel-2]

$0.0000 \quad \# 20$ Molar fraction of $\mathrm{H} 2$ in fuel

0.9612 \# 21 Molar fraction of $\mathrm{CH} 4$ in fuel

0.0198 \# 22 Molar fraction of $\mathrm{C} 2 \mathrm{H} 6$ in fuel

0.0013 \# 23 Molar fraction of C3H8 in fuel

0.0003 \# 24 Molar fraction of $\mathrm{C} 4 \mathrm{H} 1 \mathrm{O}$ in fuel

0.0000 \# 25 Molar fraction of $\mathrm{C} 5 \mathrm{H} 12$ in fuel

0.0000 \# 26 Molar fraction of $\mathrm{C} 6 \mathrm{H} 14$ in fuel

0.0000 \# 27 Molar fraction of $\mathrm{CH} 30 \mathrm{H}$ in fuel

0.0000 \# 28 Molar fraction of $\mathrm{C} 2 \mathrm{H} 5 \mathrm{OH}$ in fuel

$0.0082 \quad \# 29$ Molar fraction of $\mathrm{CO} 2$ in fuel

0.0092 \# 30 Molar fraction of $\mathrm{N} 2$ in fuel

0.0000 \# 31 Molar fraction of 02 in fuel

1.0000 \#32 Temp of fuel entering compressor [1=room $T ; 2=0 u t d o o r ~ T]$ 


\begin{tabular}{|c|c|c|}
\hline 0.0000 & 33 & Compressor power draw co coeff $\left[\mathrm{P}=\mathrm{c} 0+\mathrm{c} 1 * \mathrm{Nf}+\mathrm{c} 2 * \mathrm{Nf}-2+\mathrm{c} 3 * \mathrm{Nf}^{-}-3\right]$ \\
\hline 0.0000 & 34 & Compressor power draw $c 1$ coeff $\left[\mathrm{P}=\mathrm{c} 0+\mathrm{c} 1 * \mathrm{Nf}+\mathrm{c} 2 * \mathrm{Nf}{ }^{\wedge} 2+\mathrm{c} 3 * \mathrm{Nf} \mathrm{f}^{-} 3\right]$ \\
\hline 0.0000 & 35 & Compressor power draw $c 2$ coeff $[\mathrm{P}=\mathrm{c} 0+\mathrm{c} 1 * \mathrm{Nf}+\mathrm{c} 2 * \mathrm{Nf}-2+\mathrm{c} 3 * \mathrm{Nf}-3]$ \\
\hline 0.0000 & 36 & Compressor power drau $c 3$ coeff $\left[\mathrm{P}=\mathrm{c} 0+\mathrm{c} 1 * \mathrm{Nf}+\mathrm{c} 2 * \mathrm{Nf}^{\wedge} 2+\mathrm{c} 3 * \mathrm{Nf}^{\wedge} 3\right]$ \\
\hline 1.0000 & 37 & Compressor heat loss ratio [ratio=heat-out/elec-input] \\
\hline 0.77280 & 38 & Molar fraction of $\mathrm{N} 2$ in air \\
\hline 0.20730 & 39 & Molar fraction of 02 in air \\
\hline $0.10400 \mathrm{E}-01$ & 40 & Molar fraction of $\mathrm{H} 20$ in air \\
\hline $0.92000 \mathrm{E}-02$ & 41 & Molar fraction of Ar in air \\
\hline $0.30000 E-03$ & 42 & Molar fraction of $\mathrm{CO} 2$ in air \\
\hline 3.0000 & 43 & Method to calc excess air ratio $[1=$ const; $2=f(P e I) ; 3=f(N f)]$ \\
\hline$-0.32170 E-05$ & 44 & Constant excess air ratio or a 0 coeff [depends upon method] \\
\hline 21.421 & 45 & Excess air ratio a1 coeff [depends upon method] \\
\hline$-0.12610 E+07$ & 46 & Excess air ratio a2 coeff [depends upon method] \\
\hline 0.0000 & 47 & Excess air ratio a 3 coeff [depends upon method] \\
\hline 1.0000 & 48 & Temp of air entering blower $[1=$ room $\mathrm{T} ; 2=$ outdoor $\mathrm{T}]$ \\
\hline 0.0000 & 49 & Blower power draw bO coeff $\left[\mathrm{P}=\mathrm{b} 0+\mathrm{b} 1 * \mathrm{Na}+\mathrm{b} 2 * \mathrm{Na}^{-} 2+\mathrm{b} 3 * \mathrm{Na}^{-}-3\right]$ \\
\hline 0.0000 & 50 & Blower power draw b1 coeff $[\mathrm{P}=\mathrm{b} 0+\mathrm{b} 1 * \mathrm{Na}+\mathrm{b} 2 * \mathrm{Na}-2+\mathrm{b} 3 * \mathrm{Na}-3]$ \\
\hline 0.0000 & 51 & Blower power draw b2 coeff $[\mathrm{P}=\mathrm{b} 0+\mathrm{b} 1 * \mathrm{Na}+\mathrm{b} 2 * \mathrm{Na}-2+\mathrm{b} 3 * \mathrm{Na}-3]$ \\
\hline 0.0000 & 52 & Blower power draw b3 coeff $[\mathrm{P}=\mathrm{b} 0+\mathrm{b} 1 * \mathrm{Na}+\mathrm{b} 2 * \mathrm{Na}-2+\mathrm{b} 3 * \mathrm{Na}-3]$ \\
\hline 1.0000 & 53 & Blower heat loss ratio $[$ ratio=heat-out/elec-input] \\
\hline 0.0000 & 54 & Water supply wo coeff $\left[\mathrm{Nw}=\mathrm{w} 0+\mathrm{w} 1 * \mathrm{Nf}+\mathrm{w} 2 * \mathrm{Nf}^{-}-2\right]$ \\
\hline 0.0000 & 55 & Water supply w1 coeff $[\mathrm{Nw}=\mathrm{w} 0+\mathrm{w} 1 * \mathrm{Nf}+\mathrm{w} 2 * \mathrm{Nf}-2]$ \\
\hline 0.0000 & 56 & Water supply 2 coeff $[\mathrm{Nw}=\mathrm{w} 0+\mathrm{w} 1 * \mathrm{Nf}+\mathrm{w} 2 * \mathrm{Nf}-2]$ \\
\hline 1.0000 & 57 & Temp of water entering pump [1=room; $2=$ water mains $]$ \\
\hline 0.0000 & 58 & Pump power draw po coeff $\left[\mathrm{P}=\mathrm{p} 0+\mathrm{p} 1 * \mathrm{Nw}+\mathrm{p} 2 * \mathrm{Nw}^{\wedge} 2+\mathrm{p} 3 * \mathrm{Nw}^{\wedge} 3\right]$ \\
\hline 0.0000 & 59 & Pump power draw p1 coeff $\left[\mathrm{P}=\mathrm{p} 0+\mathrm{p} 1 * \mathrm{Nw}+\mathrm{p} 2 * \mathrm{Nw}^{-} 2+\mathrm{p} 3 * \mathrm{Nw}^{-}-3\right]$ \\
\hline 0.0000 & 60 & Pump power draw $\mathrm{p} 2$ coeff $\left[\mathrm{P}=\mathrm{p} \mathrm{O}+\mathrm{p} 1 * \mathrm{Nw}+\mathrm{p} 2 * \mathrm{Nw}^{-} 2+\mathrm{p} 3 * \mathrm{Nw}^{-}-3\right]$ \\
\hline 0.0000 & 61 & Pump power draw $\mathrm{p} 3$ coeff $\left[\mathrm{P}=\mathrm{p} 0+\mathrm{p} 1 * \mathrm{Nw}+\mathrm{p} 2 * \mathrm{Nw}^{\wedge} 2+\mathrm{p} 3 * \mathrm{Nw}^{\wedge} 3\right]$ \\
\hline 1.0000 & 62 & Pump heat loss ratio [ratio=heat-out/elec-input] \\
\hline 1.0000 & 63 & HX method [1=fixed eff; $2=$ LMTD-emp; $3=$ LMTD-det; $4=$ condensing $]$ \\
\hline 0.0000 & 64 & Fixed heat exchanger effectiveness (only for method 1) \\
\hline 0.0000 & 65 & UA so coeff $\left[U A=s 0+s 1 * N w+s 2 * \mathrm{Nw}^{-} 2+\mathrm{s} 3 * \mathrm{Ng}+\mathrm{s} 4 * \mathrm{Ng}^{-} 2\right]$ (methods 2\&4) \\
\hline 0.0000 & 66 & UA s1 coeff $\left[\mathrm{UA}_{\mathrm{A}}=\mathrm{s} \mathrm{O}+\mathrm{s} 1 * \mathrm{Nw}+\mathrm{s} 2 * \mathrm{~N}^{-}-2+\mathrm{s} 3 * \mathrm{Ng}+\mathrm{s} 4 * \mathrm{Ng}^{-}-2\right]$ (methods 2\&4) \\
\hline 0.0000 & 67 & UA s2 coeff $\left[U A=s 0+s 1 * N w+s 2 * \mathrm{Nw}^{-} 2+\mathrm{s} 3 * \mathrm{Ng}^{2}+\mathrm{s} 4 * \mathrm{Ng}-2\right]$ (methods 2\&4) \\
\hline 0.0000 & 68 & UA $s 3$ coeff $\left[U A=s 0+s 1 * N w+s 2 * \mathrm{Nw}^{-} 2+\mathrm{s} 3 * \mathrm{Ng}+\mathrm{s} 4 * \mathrm{Ng}^{-2}\right.$ ] (methods 2\&4) \\
\hline 0.0000 & 69 & UA s4 coeff $\left[U A=s 0+s 1 * \mathrm{Nw}^{2}+\mathrm{s} 2 * \mathrm{Nw}^{-} 2+\mathrm{s} 3 * \mathrm{Ng}^{-\mathrm{s}} 4 * \mathrm{Ng}^{-} 2\right]$ (methods 2*4) \\
\hline 0.0000 & 70 & UA ho_gas coeff (only for method 3: refer to documentation) \\
\hline 0.0000 & 71 & UA N_dot_gas_ref coeff (only for method 3: refer to doc) \\
\hline 0.0000 & 72 & UA $n$ coeff (only for method 3: refer to documentation) \\
\hline 0.0000 & 73 & UA Area_gas (only for method 3: refer to documentation) \\
\hline 0.0000 & 74 & UA ho_water coeff (only for method 3: refer to documentation) \\
\hline 0.0000 & 75 & UA N_dot_water_ref coeff (only for method 3: refer to doc) \\
\hline 0.0000 & 76 & UA m coeff (only for method 3: refer to documentation) \\
\hline 0.0000 & 77 & UA Area_water coeff (only for method 3: refer to documentation) \\
\hline 0.0000 & 78 & Adjustment factor, $F$ (only for method 3: refer to documentation) \\
\hline 0.0000 & 79 & UA 11 coeff (only for method 4: refer to documentation) \\
\hline 0.0000 & 80 & UA 12 coeff (only for method 4 : refer to documentation) \\
\hline 0.0000 & 81 & Condensation threshold (oC; only for method 4 ) \\
\hline 3.0000 & 82 & Method to calc FCPM skin loss $[1=$ const; $2=f(d T) ; 3=f(N f)]$ \\
\hline 1.0000 & 83 & Convective portion of FCPM skin loss (radiative $=1$-conv) \\
\hline 377.09 & 84 & Skin loss in $\mathrm{W}$ (method 1); UA (method 2); so coeff (method 3 ) \\
\hline$-0.97490 \mathrm{E}+08$ & 85 & Skin loss s1 coeff (method 3 only) $[\mathrm{q}=\mathrm{s} 0+\mathrm{s} 1 * \mathrm{Nf}+\mathrm{s} 2 * \mathrm{Nf}-2]$ \\
\hline $0.29568 \mathrm{E}+14$ & 86 & Skin loss $s 2$ coeff (method 3 only) $[\mathrm{q}=\mathrm{s} 0+\mathrm{s} 1 * \mathrm{Nf}+\mathrm{s} 2 * \mathrm{Nf}-2]$ \\
\hline 0.0000 & 87 & Auxiliary burner present or not? $[0=$ no; $1=y e s]$ \\
\hline 0.0000 & 88 & Aux-burner capacity in W output $(=1)$ or $\mathrm{kmol} / \mathrm{s}$ fuel input $(=2)$ \\
\hline 0.0000 & 89 & Aux-burner min output $(W)$ or input $(\mathrm{kmol} / \mathrm{s})$ [depends on method] \\
\hline
\end{tabular}




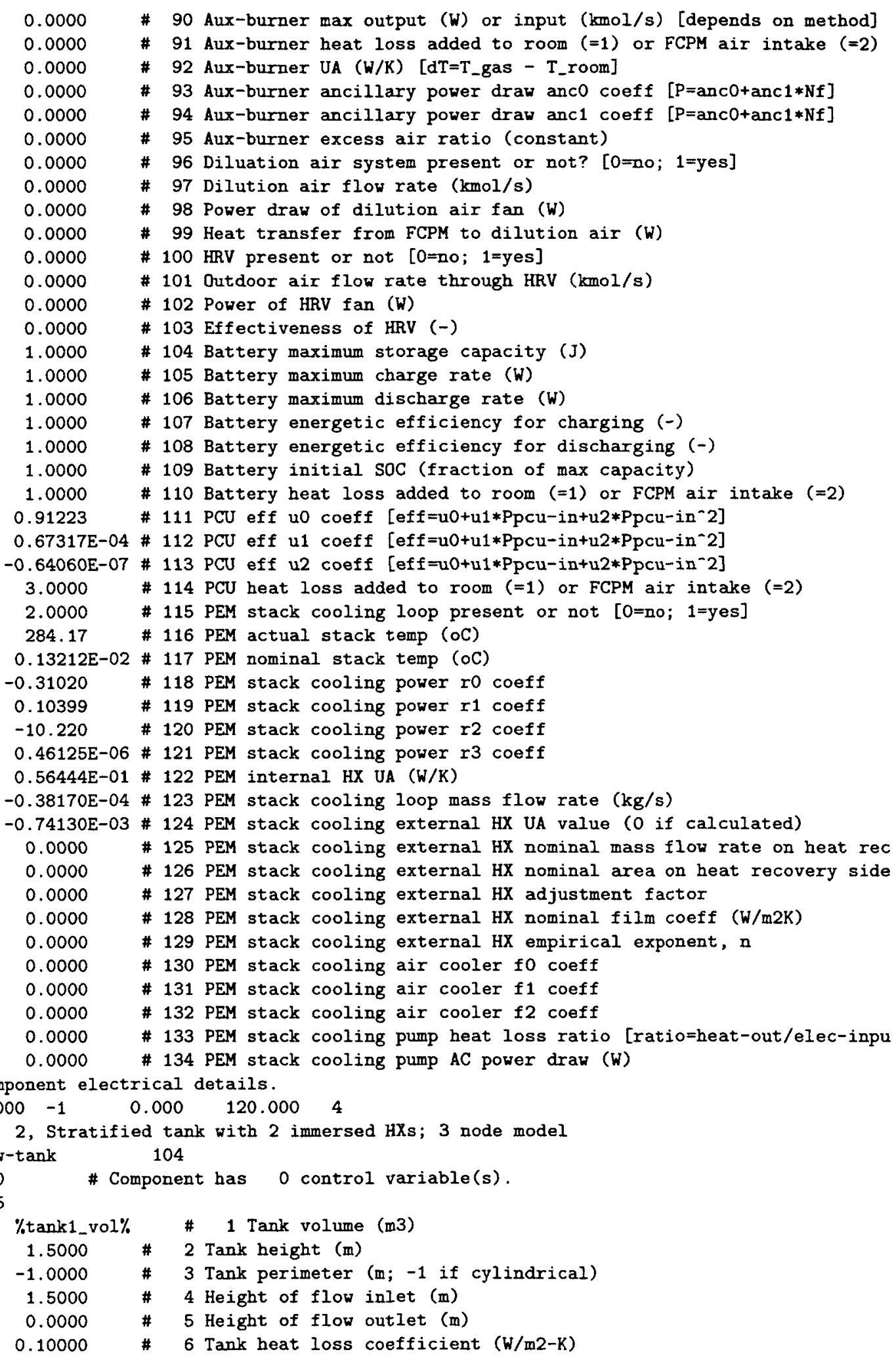




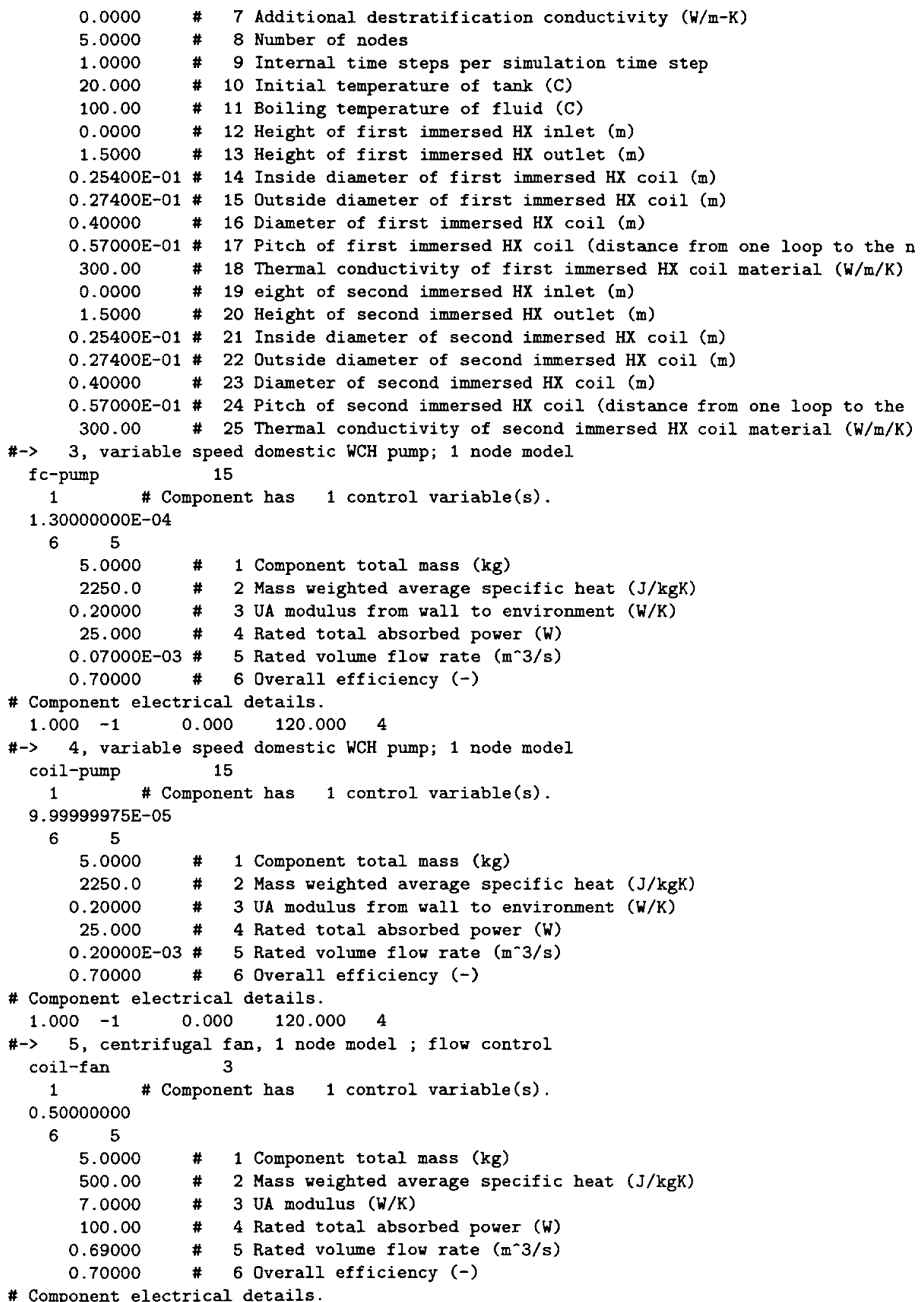




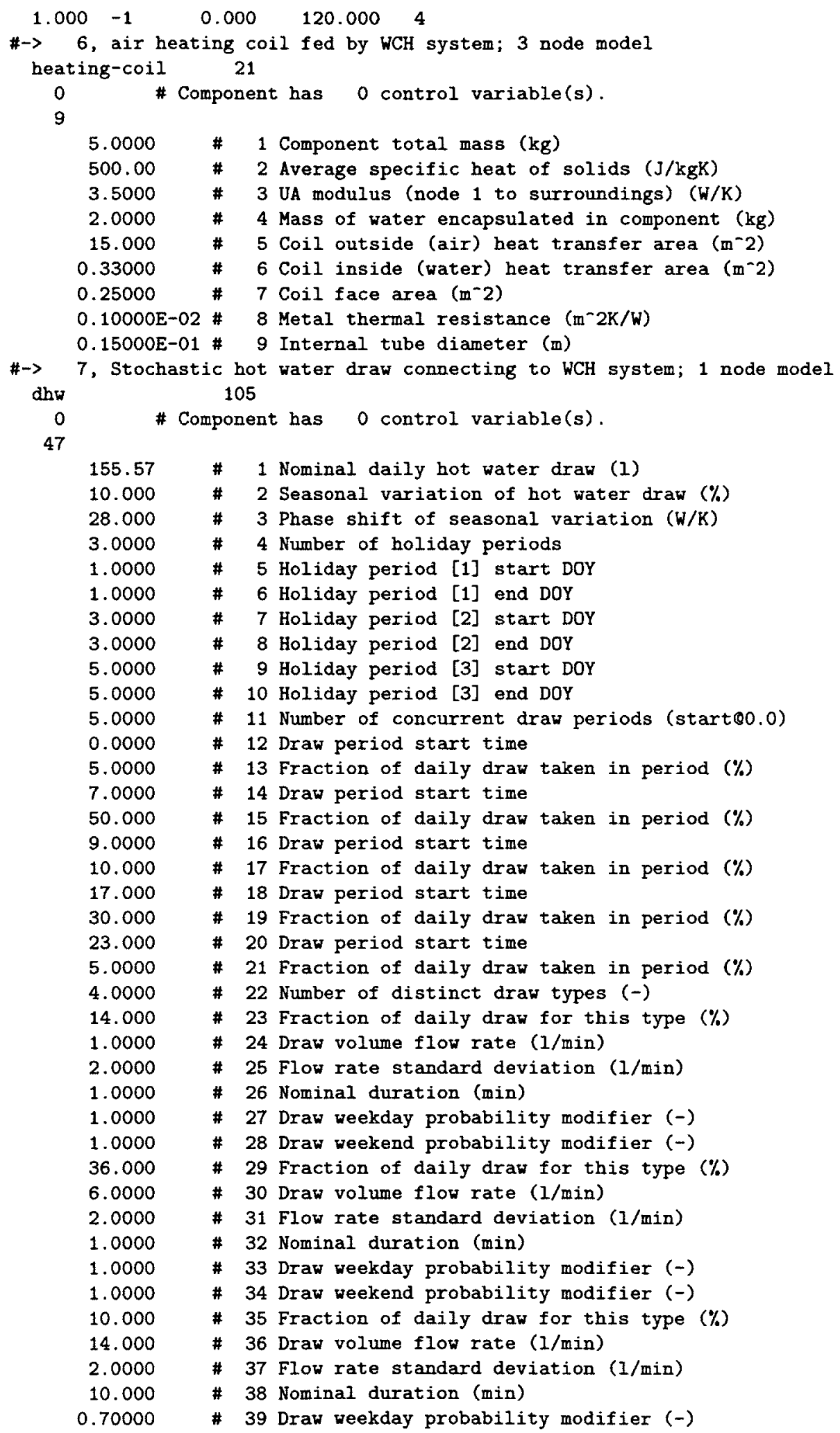




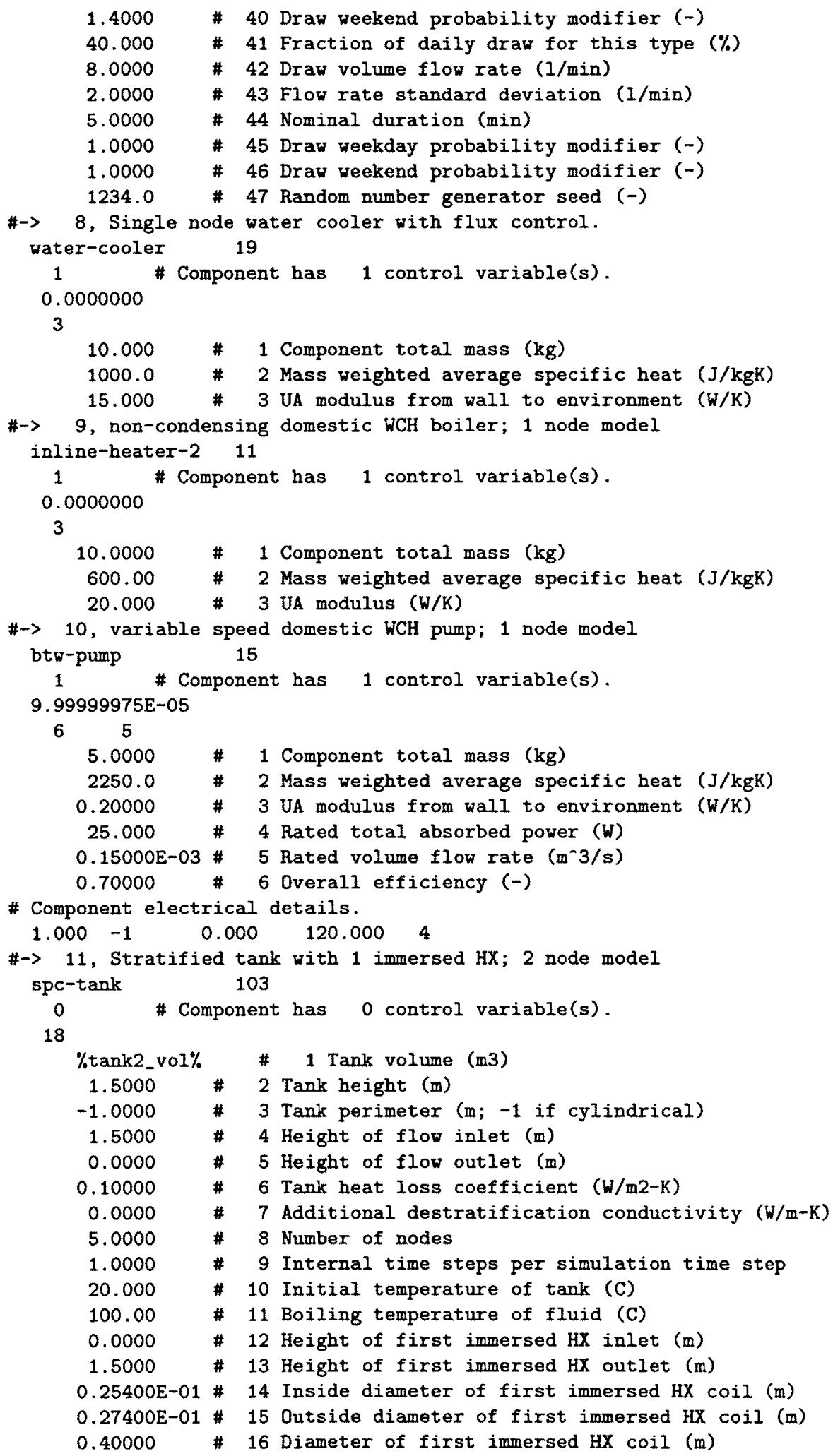




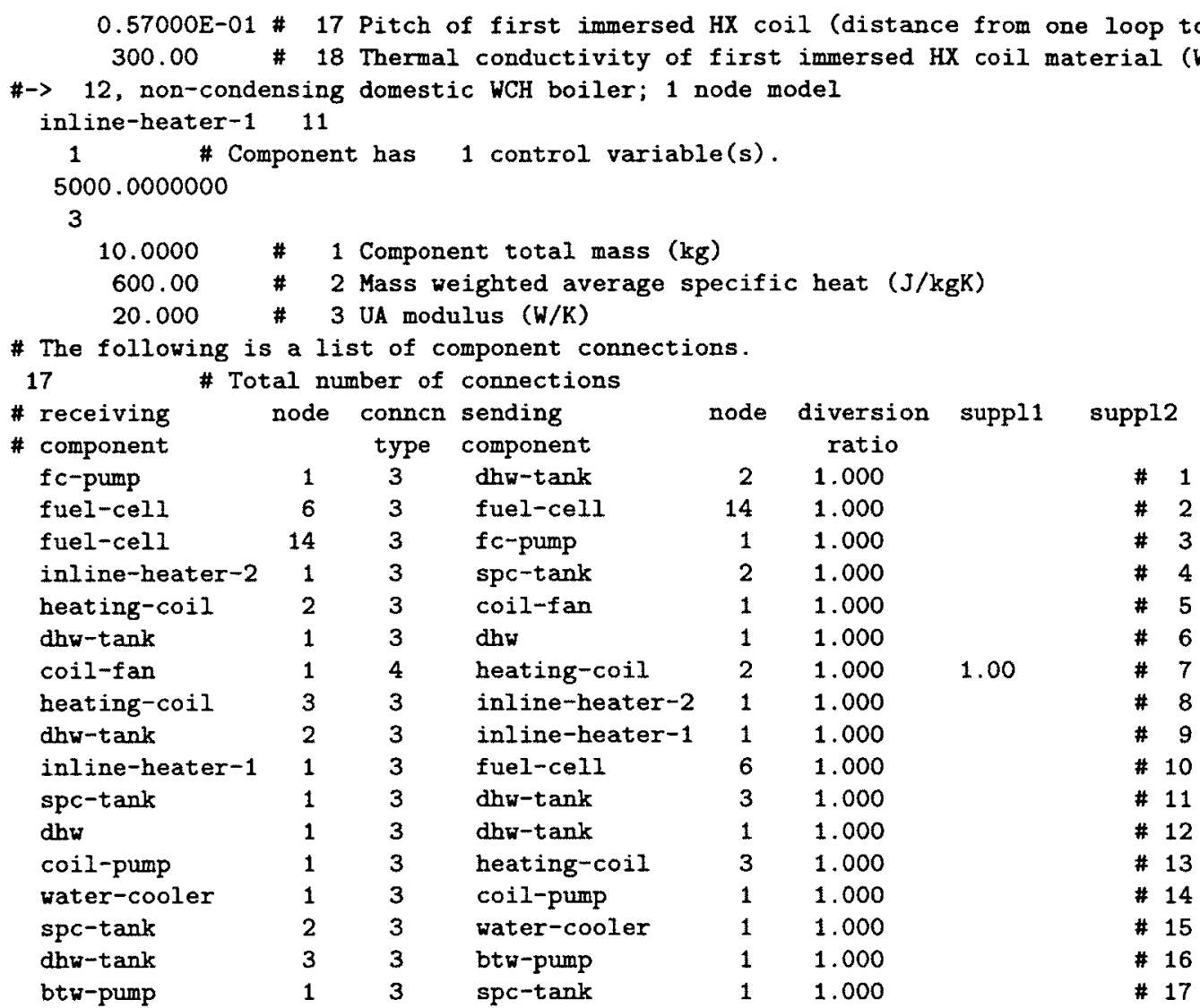

\# The following is a list of containment temperatures. 3

\# Total number of containments

\# Component

cont type

supp11

supp12

supp13

fuel-cell

dhw-tank

$3 \quad 3.00000$

0.00000

0.00000

spc-tank

3.00000

00000

\# No mass flow network defined.

0 


\section{Appendix D}

\section{GenOpt Algorithm Configuration Files}

The following configuration files are specific to the 1-tank plant and 4 particle PSOGPS optimization. Files specific to other particle numbers and the 2-tank plant can be found in http://node1.mae.carleton.ca/ibeau_students/steph/Models/B2/ genopt-cfg/ at revision 958 or later.

\section{D.1 PSO Input File}

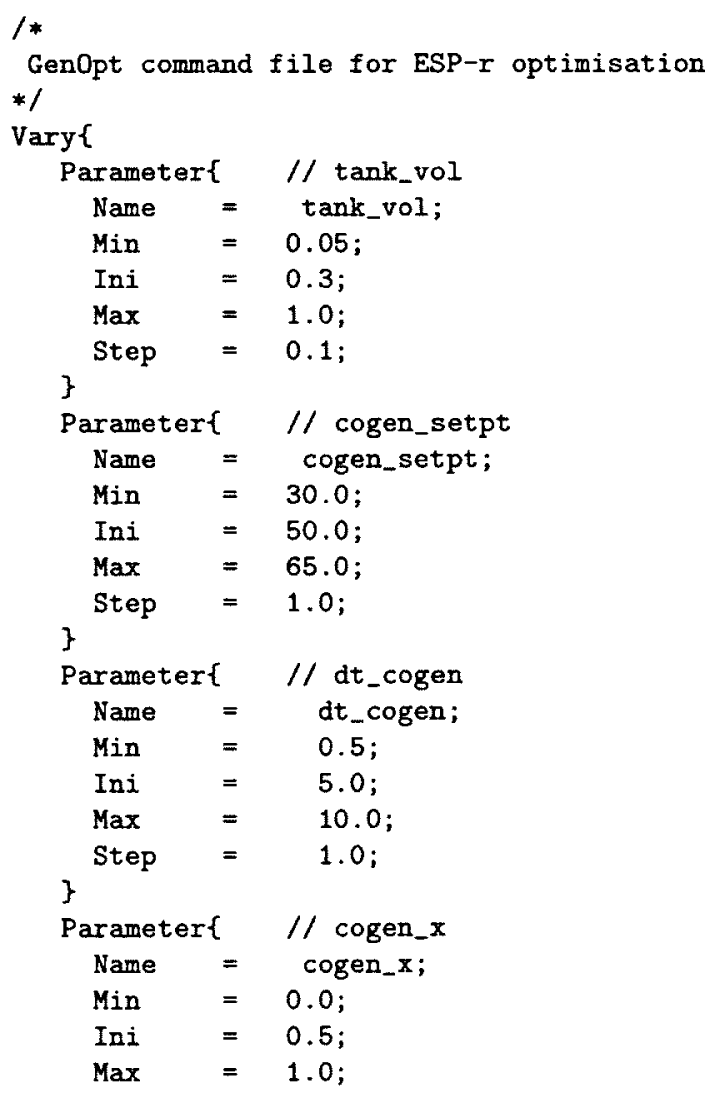




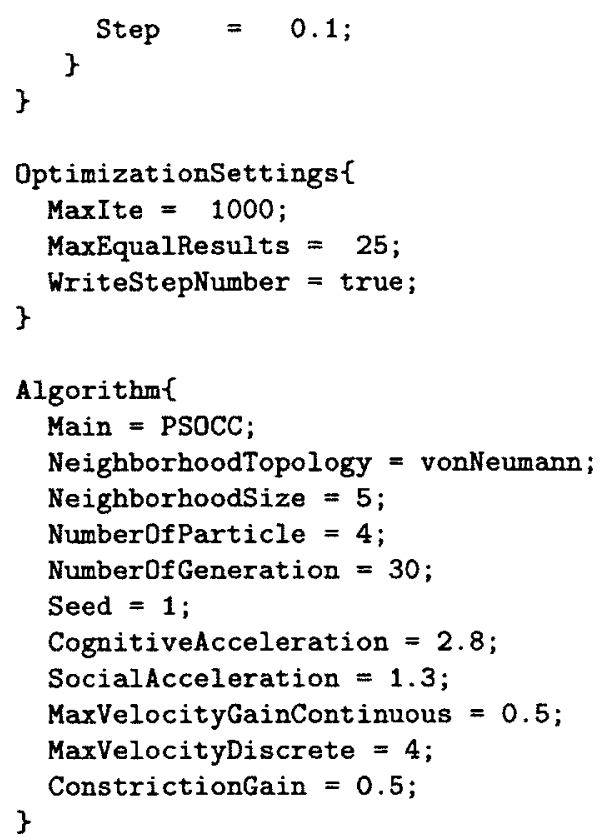

\section{D.2 GPS Input File}

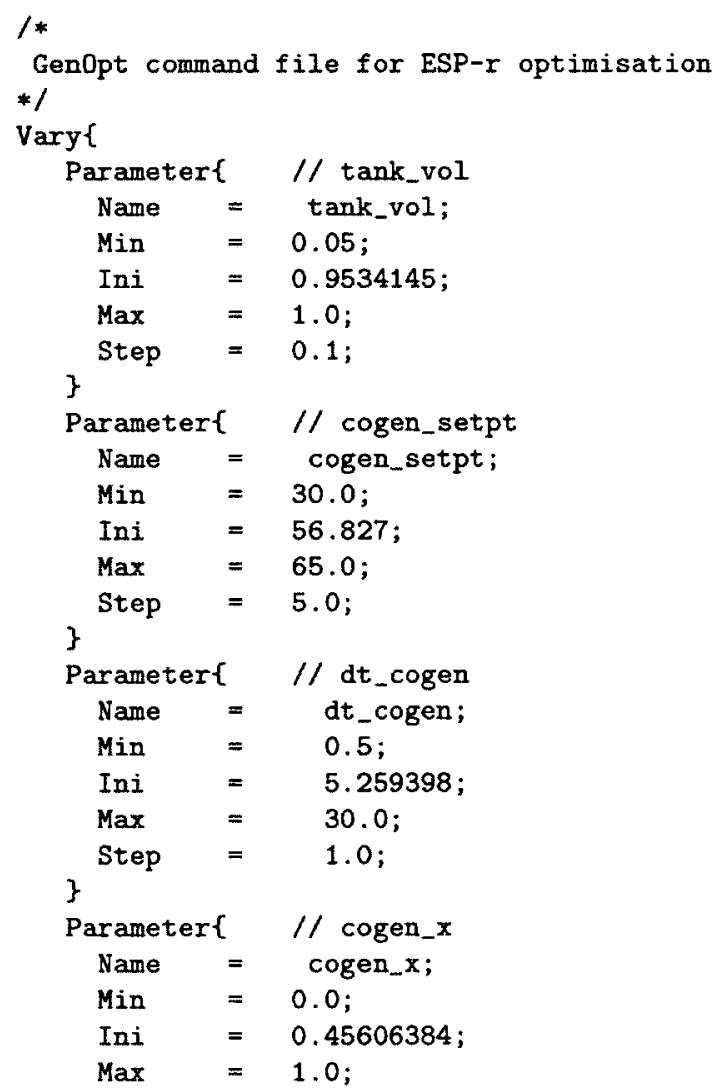




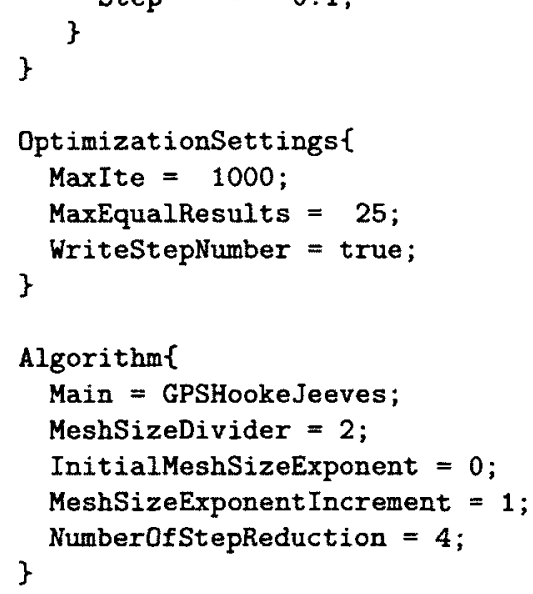




\title{
Appendix E
}

\section{Additional Files}

This appendix contains URLs for the other input files and source code used to obtain the results reported in this thesis. Links, rather than full text files, are provided because of space constraints. All files below should be accessed at revision 958 or later.

\section{E.1 GenOpt-ESP-r Coupling}

\author{
Meta Script \\ URL: http://node1.mae.carleton.ca/ibeau_students/steph/Models/B2/ \\ genopt-cfg/B2-annual-ubuntu.sh \\ Post-processing script \\ URL: http://node1.mae.carleton.ca/ibeau_students/steph/Code/shell_ \\ scripts/post-processor-ubuntu-annual-2.sh
}

Fortran post-processor

URL: http://node1.mae.carleton.ca/ibeau_students/steph/Code/Fortran/ post-processor-res-annual.F

\section{E.2 GenOpt/ESP-r Input Files}

These files are particular to the optimizations run for household model B2. Input files for the other models can be found by replacing B2 in the URL with B1 or B3. 
ESP-r configuration file

URL:

http://node1.mae.carleton.ca/ibeau_students/steph/Models/B2/cfg/B2.cfg

1-tank plant electrical network configuration file

URL: http://node1.mae.carleton.ca/ibeau_students/steph/Models/B2/occ/ config3-B2. enf

2-tank plant electrical network configuration file

URL: http://node1.mae.carleton.ca/ibeau_students/steph/Models/B2/occ/ config5-B2. enf

GenOpt configuration file

URL: http://node1.mae.carleton.ca/ibeau_students/steph/Models/B2/

genopt-cfg/GenOpt_ESP-r_AWS.config

GenOpt initialization file

URL: http://node1.mae.carleton.ca/ibeau_students/steph/Models/B2/

GenOpt_script_AWS.ini 